\title{
The Fifth Wave of the Indonesia Family Life Survey: Overview and Field Report
}

\section{Volume 1}

JOHN STRAUSS, FIRMAN WITOELAR, AND BONDAN SIKOKI

RAND Labor \& Population

WR-1143/1-NIA/NICHD

March 2016

RAND working papers are intended to share researchers' latest findings and to solicit informal peer review. They have been approved for circulation by RAND Labor and Population but have not been formally edited or peer reviewed. Unless otherwise indicated, working papers can be quoted and cited without permission of the author, provided the source is clearly referred to as a working paper. RAND's publications do not necessarily reflect the opinions of its research clients and sponsors. RAND® is a registered trademark. 
For more information on this publication, visit www.rand.org/pubs/working_papers/WR1143z1.html

Published by the RAND Corporation, Santa Monica, Calif.

(C) Copyright 2016 RAND Corporation

RAND $^{\star}$ is a registered trademark

\section{Limited Print and Electronic Distribution Rights}

This document and trademark(s) contained herein are protected by law. This representation of RAND intellectual property is provided for noncommercial use only. Unauthorized posting of this publication online is prohibited. Permission is given to duplicate this document for personal use only, as long as it is unaltered and complete. Permission is required from RAND to reproduce, or reuse in another form, any of its research documents for commercial use. For information on reprint and linking permissions, please visit www.rand.org/pubs/permissions.html.

The RAND Corporation is a research organization that develops solutions to public policy challenges to help make communities throughout the world safer and more secure, healthier and more prosperous. RAND is nonprofit, nonpartisan, and committed to the public interest.

RAND's publications do not necessarily reflect the opinions of its research clients and sponsors.

Support RAND

Make a tax-deductible charitable contribution at

www.rand.org/giving/contribute

www.rand.org 
We recommend the following citations for the IFLS data:

For papers using IFLS1 (1993):

Frankenberg, E. and L. Karoly. "The 1993 Indonesian Family Life Survey: Overview and Field Report." November, 1995. RAND. DRU-1195/1-NICHD/AID

For papers using IFLS2 (1997):

Frankenberg, E. and D. Thomas. "The Indonesia Family Life Survey (IFLS): Study Design and Results from Waves 1 and 2". March, 2000. DRU-2238/1-NIA/NICHD.

For papers using IFLS3 (2000):

Strauss, J., K. Beegle, B. Sikoki, A. Dwiyanto, Y. Herawati and F. Witoelar. "The Third Wave of the Indonesia Family Life Survey (IFLS3): Overview and Field Report". March 2004. WR-144/1NIA/NICHD.

For papers using IFLS4 (2007):

Strauss, J., F. Witoelar, B. Sikoki and A.M. Wattie. "The Fourth Wave of the Indonesia Family Life Survey (IFLS4): Overview and Field Report". April 2009. WR-675/1-NIA/NICHD.

For papers using IFLS5 (2014):

Strauss, J., F. Witoelar, and B. Sikoki. "The Fifth Wave of the Indonesia Family Life Survey (IFLS5): Overview and Field Report". March 2016. WR-1143/1-NIA/NICHD. 


\section{Preface}

This document describes the design and implementation and provides a preview of some key results of the Indonesia Family Life Survey, with an emphasis on wave 5 (IFLS5). It is the first of seven volumes documenting IFLS5.

The Indonesia Family Life Survey is a continuing longitudinal socioeconomic and health survey. It is based on a sample of households representing about $83 \%$ of the Indonesian population living in 13 of the nation's 26 provinces in 1993. The survey collects data on individual respondents, their families, their households, the communities in which they live, and the health and education facilities they use. The first wave (IFLS1) was administered in 1993 to individuals living in 7,224 households. IFLS2 sought to reinterview the same respondents four years later. A follow-up survey (IFLS2+) was conducted in 1998 with $25 \%$ of the sample to measure the immediate impact of the economic and political crisis in Indonesia. The next wave, IFLS3, was fielded on the full sample in 2000. IFLS4 was fielded in late 2007 and early 2008 on the same 1993 households and their splitoffs. IFLS5 was fielded in late 2014 and early 2015 on the same set of IFLS households and splitoffs: 16,204 households and 50,148 individuals were interviewed. Another 2,662 individuals who died since IFLS4 had exit interviews with a proxy who knew them well.

IFLS4 was a collaborative effort of RAND and Survey Meter. Funding for IFLS5 was provided by the National Institute on Aging (NIA), grant 2R01 AG026676-05, the National Institute for Child Health and Human Development (NICHD), grant 2R01 HD050764-05A1 and grants from the World Bank, Indonesia and GRM International, Australia from DFAT, the Department of Foreign Affairs and Trade, Government of Australia.

The IFLS5 public-use file documentation, whose seven volumes are listed below, will be of interest to policymakers concerned about socioeconomic and health trends in nations like Indonesia, to researchers who are considering using or are already using the IFLS data, and to those studying the design and conduct of large-scale panel household and community surveys. Updates regarding the IFLS database subsequent to publication of these volumes will appear at the IFLS Web site, http://www.rand.org/FLS/IFLS.

\section{Documentation for IFLS, Wave 5}

WR-1143/1-NIA/NICHD: The Fifth Wave of the Indonesia Family Life Survey (IFLS5): Overview and Field Report. Purpose, design, fieldwork, and response rates for the survey, with an emphasis on wave 5; comparisons to waves 1, 2, 3 and 4.

WR-1143/2-NIA/NICHD: User's Guide for the Indonesia Family Life Survey, Wave 5. Descriptions of the IFLS file structure and data formats; guidelines for data use, with emphasis on using the wave 5 with the earlier waves 1, 2, 3 and 4 .

WR-1143/3-NIA/NICHD: Household Survey Questionnaire for the Indonesia Family Life Survey, Wave 5. English translation of the questionnaires used for the household and individual interviews.

WR-1143/4-NIA/NICHD: Community-Facility Survey Questionnaire for the Indonesia Family Life Survey, Wave 5. English translation of the questionnaires used for interviews with community leaders and facility representatives.

WR-1143/5-NIA/NICHD: Household Survey Codebook for the Indonesia Family Life Survey, Wave 5. Descriptions of all variables from the IFLS5 Household Survey and their locations in the data files. 
WR-1143/6-NIA/NICHD: Community-Facility Survey Codebook for the Indonesia Family Life Survey, Wave 5. Descriptions of all variables from the IFLS5 Community-Facility Survey and their locations in the data files.

WR-1143/7-NIA/NICHD: Dried Blood Spot User's Guide for the Indonesia Family Life Survey, Wave 5. Descriptions of the dried blood spot field and assay procedures and data quality analysis. 


\section{Contents}

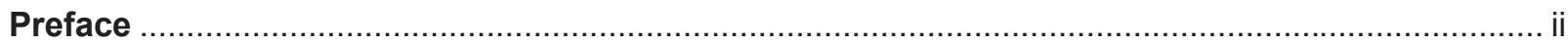

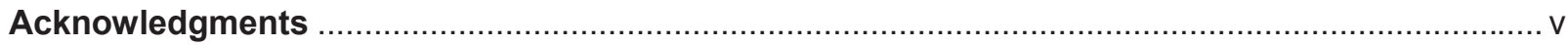

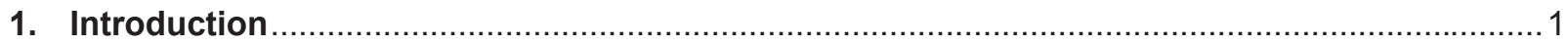

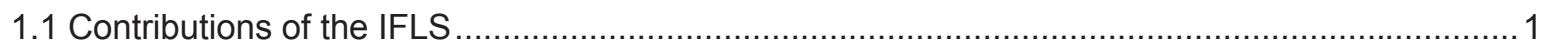

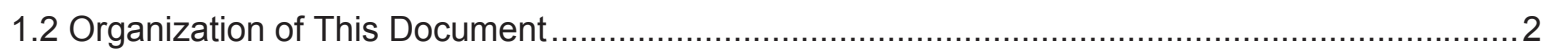

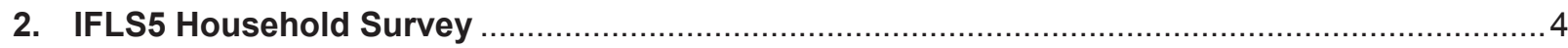

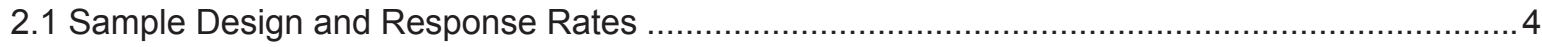

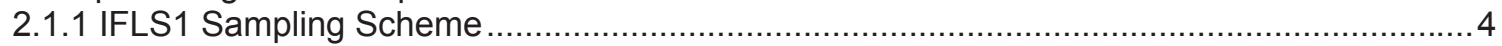

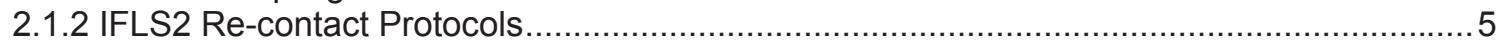

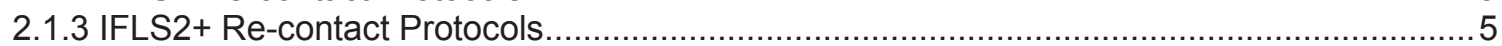

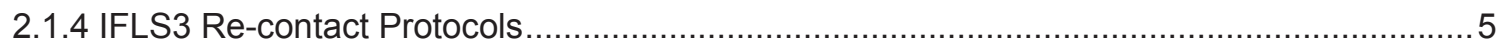

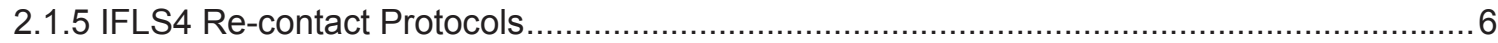

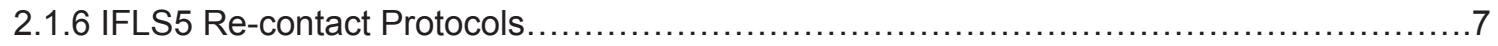

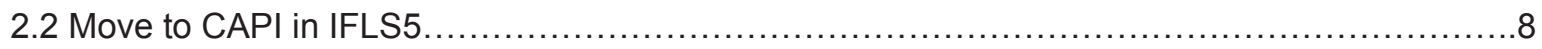

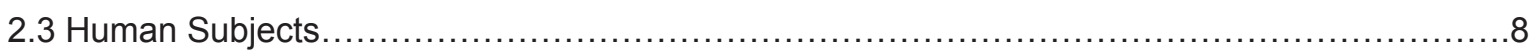

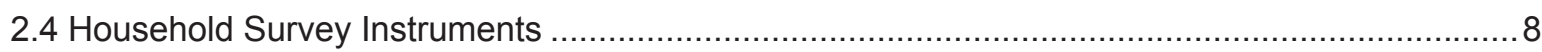

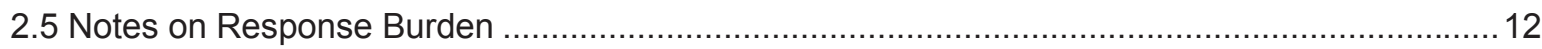

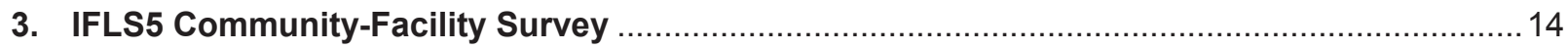

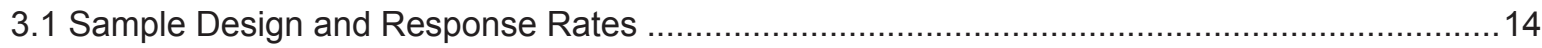

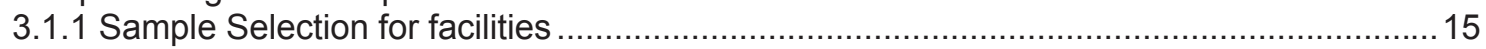

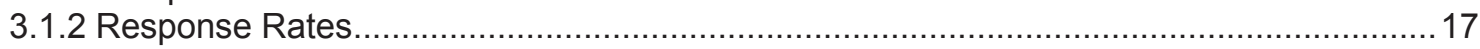

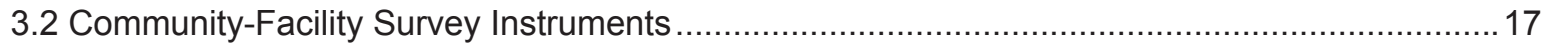

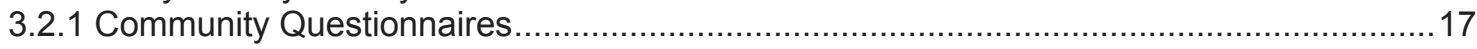

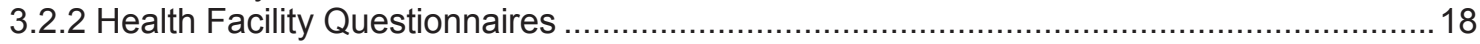

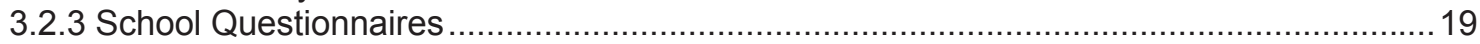

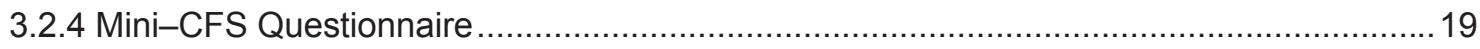

\section{Appendix}

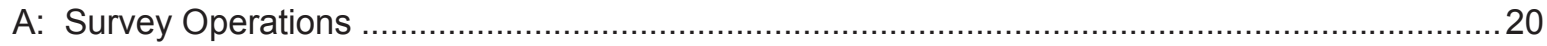

B: Description of the IFLS5 Household Survey Questionnaire …............................................ 30

C: Description of the IFLS5 Community-Facility Survey Questionnaire ....................................40

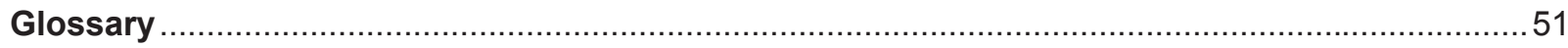

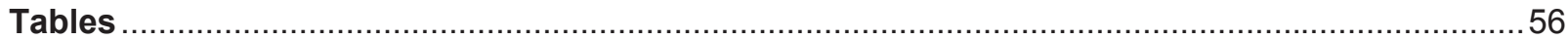




\section{Acknowledgments}

A survey of the magnitude of IFLS is a huge undertaking. It involved a large team of people from both the United States and Indonesia. We are indebted to every member of the team. We are grateful to each of our respondents, who gave up many hours of their time.

IFLS5 was directed by John Strauss (University of Southern California and RAND). Firman Witoelar (Survey Meter) and Bondan Sikoki (Survey Meter) were co-PIs. Sikoki and Witoelar were Field Directors of IFLS5.

Dr. John Giles of World Bank has helped to develop and oversee pretests and training of the community and facility (COMFAS) questionnaire modifications. He also contributed greatly in obtaining a grant from the research arm of World Bank to help fund collection of the community/facility data.

Dr. Peifeng (Perry) Hu of UCLA Medical School directed the laboratory analyses of the dried blood spots (DBS). Dr. Eileen Crimmins of USC provided critical assistance to the DBS part of IFLS and to the quality analysis of the DBS data. Dr. Elizabeth (Henny) Herningtyas of University of Gadah Mada directed the laboratory in Yogyakarta where the assays were done. Validation samples were collected at UCLA under the direction of Heather McCreath and further analyzed at Dr. Alan Potter's laboratory at University of Washington.

Many of our IFLS family colleagues have contributed substantially to the survey. Most of all, however, we are immensely grateful to Dr. Duncan Thomas and Dr. Elizabeth Frankenberg of Duke University and to Dr. James P. Smith of RAND, whose inputs continue to be invaluable and essential; and to Dr. John Phillips of the National Institute on Aging and Dr. Regina Bures of the National Institute of Child Health and Human Development, our project officers, whose continual encouragement and consultation has greatly benefitted this project.

Dr. John McArdle of USC oversaw the creation of the adaptive number series test that is new in IFLS5 (in Section COB of Book 3B). This involved extensive pretests in both Indonesia and Mexico (with the collaboration of MHAS under the direction of Rebeca Wong) and analysis of the pretest data.

Dr. Arthur Stone of USC Center for Economic and Social Research (CESR) and Dr. Jacqui Smith of the University of Michigan provided the hedonic well-being questions (Section PNA of book 3A) from their shorter version that they developed for the Health and Retirement Study (HRS).

Dr. Brent Roberts of University of Illinois and Dr. Angela Duckworth of University of Pennsylvania provided advice on the personality section (PSN in book 3B). Under their guidance we choose the BFI 15 questions as the ones we use.

Dr. Joan Broderick of USC CESR provided advice on the sleep quality and sleep disturbance questions in section TDR in book 3B. These questions were provided from PROMIS (Patient Recorded Outcomes Measurement Information System) staff.

Several people played critical staff roles in the project. Edy Purwanto was the Field Coordinator for the Household Survey, Naisruddin was Field Coordinator for the Community-Facility Survey, lip Umar Rifaii was Field Coordinator for the Computer-Assisted Personal Interview (CAPI) and was responsible for the software development, and Roald Euller of RAND was Chief Project Programmer. Other key Survey Meter programmers were Nursuci Arnashanti and Amalia Rifana Widiastuti. Ika Rini was responsible for managing the dried blood spots when they got to Survey Meter from the field. This included logging in the cards, making sure that all labels were correct and person ids were on the samples, making a judgment and recording data on blood spot quality, and supervising their storage in the freezers and 
monitoring freezer temperatures, Data quality checking at Survey Meter was headed by Dian Hestina, Lazima and Rini Kondesiana.

Strauss and Witoelar oversaw the construction of the sampling weights with the assistance of Yudo Wicaksono. Witoelar also oversaw the work to update geographic location codes using updated BPS location codes; as well as to update the IFLS "commid" community codes for the new areas in which splitoff households were found in 2014. He also did most of the work in obtaining the tables and figures in the Field Report and the User's Guide. Wicaksono worked on the coding of the job-type and sector of work.

The IFLS5 public-use data files were produced with much painstaking work, by our Chief Programmer, Roald Euller. Euller also prepared the information used in the preloaded rosters and other preloaded files and the master household location files that were used in the field work.

The success of the survey is largely a reflection of the diligence, persistence and commitment to quality of the interviewers, supervisors, field coordinators and the support staff at our central headquarters in Yogyakarta. Their names are listed in the Study Design, Appendix A.

Finally, we thank all of our IFLS respondents both in households and communities for graciously agreeing to participate. Without their being willing to share their valuable time this survey could not have been successful. 


\section{Introduction}

By the middle of the 1990s, Indonesia had enjoyed over three decades of remarkable social, economic, and demographic change. Per capita income had risen since the early 1960 s, from around US $\$ 50$ to more than US\$1,100 in 1997. Massive improvements occurred in many dimensions of living standards of the Indonesian population. The poverty headcount measure as measured by the World Bank declined from over $40 \%$ in 1976 to just $18 \%$ in 1996. Infant mortality fell from 118 per thousand live births in 1970 to 46 in1997. Primary school enrollments rose from $75 \%$ in 1970 to universal enrollment in 1995 and secondary schooling rates from $13 \%$ to $55 \%$ over the same period. The total fertility rate fell from 5.6 in 1971 to 2.8 in 1997.

In the late 1990s the economic outlook began to change as Indonesia was gripped by the economic crisis that affected much of Asia. At the beginning of 1998 the rupiah collapsed and gross domestic product contracted by an estimated 13\%. Afterwards, gross domestic product was flat in 1999. Between 2003 and 2014 GDP growth fluctuated between $5 \%$ and $6 \%$ per year and recovery ensued.

Different parts of the economy were affected quite differently by the 1998 crisis, for example the national accounts measure of personal consumption showed little decline, while gross domestic investment declined $35 \%$. Across Indonesia there was considerable variation in the impacts of the crisis, as there had been of the earlier economic success. The different waves of the Indonesia Family Life Survey can be used to document changes before, during and 3,10 and 17 years after the economic crisis for the same communities, households and individuals.

The Indonesia Family Life Survey is designed to provide data for studying behaviors and outcomes. The survey contains a wealth of information collected at the individual and household levels, including multiple indicators of economic and non-economic well-being: consumption, income, assets, education, migration, labor market outcomes, marriage, fertility, contraceptive use, health status, use of health care and health insurance, relationships among co-resident and non- resident family members, processes underlying household decision-making, transfers among family members and participation in community activities.

In addition to individual- and household-level information, IFLS provides detailed information from the communities in which IFLS households are located and from the facilities that serve residents of those communities. These data cover aspects of the physical and social environment, infrastructure, employment opportunities, food prices, access to health and educational facilities, and the quality and prices of services available at those facilities.

By linking data from IFLS households to data from their communities, users can address many important questions regarding the impact of policies on the lives of the respondents, as well as document the effects of social, economic, and environmental change on the population.

IFLS is an ongoing longitudinal survey. The first wave, IFLS1, was conducted in 1993-1994. The survey sample represented about $83 \%$ of the Indonesian population living in 13 of the country's 26 provinces. ${ }^{1}$ IFLS2 followed up with the same sample four years later, in 1997-1998. One year after IFLS2, a 25\% subsample was surveyed to provide information about the impact of Indonesia's economic crisis. IFLS3 was fielded on the full sample in 2000, IFLS4 in 2007-2008 and IFLS5 in 2014-2015.

\subsection{Contributions of the IFLS}

The Indonesia Family Life Survey complements and extends the existing survey data available for Indonesia, and for developing countries in general, in a number of ways.

First, relatively few large-scale population-based longitudinal surveys are available for developing countries and very few are available for an extended period of time; 21 years now for IFLS. IFLS is the only large-scale longitudinal survey available for Indonesia. Because data are available for the same individuals from multiple points in time, IFLS affords an opportunity to understand the dynamics of behavior, at the individual, household and family and community levels.

\footnotetext{
${ }^{1}$ Public-use files from IFLS1 are documented in six volumes under the series title The 1993 Indonesian Family Life Survey, DRU-1195/1-6-NICHD/AID, The RAND Corporation, December 1995. IFLS2 public use files are documented in seven volumes under the series The Indonesia Family Life Survey, DRU-2238/1-7-NIA/NICHD, RAND, 2000. IFLS3 public use files are documented in six volumes under the series The Third Wave of the Indonesia Family Life Survey (IFLS3), WR-144/1-NIA/NICHD. IFLS4 public use files are documented in the series The Fourth Wave of the Indonesia Family Life Survey (IFLS4), WR-675/1-NIA/NICHD.
} 
In IFLS1 7,224 households were interviewed, and detailed individual-level data were collected from over 22,000 individuals. In IFLS2, 94.4\% of IFLS1 households were re-contacted (interviewed or died-see Table 2.1). In IFLS3 the re-contact rate was $95.3 \%$ of IFLS1 dynasty households (any part of the original IFLS1 households). ${ }^{2}$ In IFLS4 the recontact rate of original IFLS1 dynasties was $93.6 \%$ (of course the period between waves was 7 years, not 3 ). In IFLS5 the dynasty recontact rate was $92 \%$. For the individual target households (including splitoff households as separate) the re-contact rate was a little lower, $90.5 \%$. Among IFLS1 dynasties, 87.8\% were either interviewed in all 5 waves, or died (Tables 2.1, 2.2), some 6,341 households, of which 6,275 , or $86.9 \%$ are actually interviewed in all 5 waves. These re-contact rates are as high as or higher than most longitudinal surveys in the United States and Europe. High re-interview rates were obtained in part because we were committed to tracking and interviewing individuals who had moved or split off from the origin IFLS1 households. High re-interview rates contribute significantly to data quality in a longitudinal survey because they lessen the risk of bias due to nonrandom attrition in studies using the data.

Second, the multipurpose nature of IFLS instruments means that the data support analyses of interrelated issues not possible with single-purpose surveys. For example, the availability of data on household consumption together with detailed individual data on labor market outcomes, health outcomes and on health program availability and quality at the community level means that one can examine the impact of income on health outcomes, but also whether health in turn affects incomes.

Third, IFLS collected both current and retrospective information on most topics. With data from multiple points of time on current status and an extensive array of retrospective information about the lives of respondents, analysts can relate dynamics to events that occurred in the past. For example, labor outcomes of young adults can be related to their conditions 21 years earlier as very young children, or in infancy.

Fourth, IFLS collected extensive measures of health status, including self-reported measures of general health status, symptoms, pain, doctor diagnosed chronic conditions, time spent on different physical activities and biomarker measurements (height, weight, leg length, blood pressure, pulse, waist and hip circumference, hemoglobin level, grip strength, lung capacity, and time required to repeatedly rise from a sitting position). In addition dried blood spot data were collected in waves 4 and 5 and assayed for hs C-reactive protein (CRP) in both waves 4 and 5 and for $\mathrm{HbA} 1 \mathrm{c}$ in wave 5 . These data provide a much richer picture of health status than is typically available in household surveys. For example, the data can be used to explore relationships between socioeconomic status and an array of health outcomes.

Fifth, in all waves of the survey, detailed data were collected about respondents' communities and public and private facilities available for their health care and schooling. The facility data can be combined with household and individual data to examine the relationship between, for example, access to health services (or changes in access) and various aspects of health care use and health status. Although the facility data are not designed to be a panel, in fact they are for many facilities.

Sixth, because the waves of IFLS span the period from several years before the 1998 financial crisis hit Indonesia, to just prior to it hitting, to one year, three years, ten years and now 17 years after, extensive research can be carried out regarding the living conditions of Indonesian households during this very tumultuous period and its long-run aftermath.

In sum, the breadth and depth of the longitudinal information over 21 years on individuals, households, communities, and facilities make IFLS data a unique resource for scholars and policymakers interested in the processes of economic development. However, the data are complex. In this and other volumes of the IFLS documentation, we seek to provide scholars and policymakers interested in using the data with the information necessary to do so efficiently.

\subsection{Organization of This Document}

Section 2 documents the IFLS5 Household Survey (HHS), describing the sample and how it changed from IFLS1, providing response rates, and summarizing the questionnaire contents, with comments on respondent burden. A new section describing the IFLS move to computer assisted personal interview (CAPI) is added.

Section 3 documents the IFLS5 Community-Facility Survey (CFS), describing the sample and response rates, summarizing the contents of the questionnaires, and noting links between the household survey and community-facility survey data.

\footnotetext{
${ }^{2}$ Households in which all members died are counted as contacted.
} 
Appendix A describes the process of designing, testing, and fielding IFLS5. Appendixes B and C provide further detail about the household and community-facility survey instruments, respectively. 


\section{IFLS5 Household Survey}

This section describes the IFLS household survey sample, the protocol that was adopted for following movers, and the substance of the survey instruments. Response rates and attrition are discussed.

\subsection{Sample Design and Response Rates}

\subsubsection{IFLS1 Sampling Scheme}

Because it is a longitudinal survey, IFLS5 drew its sample from IFLS1, IFLS2, IFLS2+, IFLS3 and IFLS4. The IFLS1 sampling scheme stratified on provinces and urban/rural location, then randomly sampled within these strata (see Frankenberg and Karoly, 1995, for a detailed description). Provinces were selected to maximize representation of the population, capture the cultural and socioeconomic diversity of Indonesia, and be costeffective to survey given the size and terrain of the country. For mainly cost-effectiveness reasons, 14 of the then existing 27 provinces were excluded. ${ }^{3}$ The resulting sample included 13 of Indonesia's 27 provinces containing $83 \%$ of the population: four provinces on Sumatra (North Sumatra, West Sumatra, South Sumatra, and Lampung), all five of the Javanese provinces (DKI Jakarta, West Java, Central Java, DI Yogyakarta, and East Java), and four provinces covering the remaining major island groups (Bali, West Nusa Tenggara, South Kalimantan, and South Sulawesi).

Within each of the 13 provinces, enumeration areas (EAs) were randomly chosen from a nationally representative sample frame used in the 1993 SUSENAS, a socioeconomic survey of about 60,000 households. ${ }^{4}$ The IFLS randomly selected 321 enumeration areas in the 13 provinces, over-sampling urban EAs and EAs in smaller provinces to facilitate urban-rural and Javanese-non-Javanese comparisons.

Within a selected EA, households were randomly selected based upon 1993 SUSENAS listings obtained from regional BPS office. A household was defined as a group of people whose members reside in the same dwelling and share food from the same cooking pot (the standard BPS definition). Twenty households were selected from each urban EA, and 30 households were selected from each rural EA. This strategy minimized expensive travel between rural EAs while balancing the costs of correlations among households. For IFLS1 a total of 7,730 households were sampled to obtain a final sample size goal of 7,000 completed households. This strategy was based on BPS experience of about $90 \%$ completion rates. In fact, IFLS1 exceeded that target and interviews were conducted with 7,224 households in late 1993 and early 1994.

In IFLS1 it was determined to be too costly to interview all household members, so a sampling scheme was used to randomly select several members within a household to provide detailed individual information. IFLS1 conducted detailed interviews with the following household members:

- the household head and his/her spouse

- two randomly selected children of the head and spouse age 0 to 14

- an individual age 50 or older and his/her spouse, randomly selected from remaining members

- for a randomly selected $25 \%$ of the households, an individual age 15 to 49 and his/her spouse, randomly selected from remaining members.

\footnotetext{
${ }^{3}$ The far eastern provinces of East Nusa Tenggara, East Timor, Maluku and Irian Jaya were excluded due to the high cost of fieldwork in these more remote provinces. East Timor is now an independent state. Aceh, Sumatra's northernmost province, was excluded out of concern for the area's political violence and the potential risk to interviewers. Finally, three provinces were omitted on each of the major islands of Sumatra (Riau, Jambi, and Bengkulu), Kalimantan (West, Central, East), and Sulawesi (North, Central, Southeast). Many of these eastern provinces were covered in IFLS East (see the link on Survey Meter's webpage: www.surveymeter.org).

${ }^{4}$ A similar approach was taken by the Demographic and Health Surveys (DHS) fielded in Indonesia in 1987, 1991, 1994 and 1997. The SUSENAS frame, designed by the Indonesian Central Bureau of Statistics (BPS), was based on the 1990 census. The IFLS was based on the SUSENAS sample because the BPS had recently listed and mapped each of the SUSENAS EAs (saving IFLS time and money) and because supplementary EA-level information from the resulting 1993 SUSENAS sample could be matched to the IFLS sample areas. The SUSENAS EAs each contain some 200 to 300 households, although the BPS listed a smaller area of about 60 to 70 households for its annual survey.
} 
In IFLS2 the goal was to relocate and re-interview the 7,224 households interviewed in 1993 (see Frankenberg and Thomas, 2000, for a detailed description). The total number of households contacted in IFLS2 was $7,698,{ }^{5}$ of which 6,821 were original IFLS1 households and 877 were split-off households. ${ }^{6}$ This represents a completion rate of $94.4 \%$ of the IFLS1 households. One reason for this high rate of retention was the effort to follow households that moved from their original housing structure.

If an entire household, or target respondent(s) moved then they were tracked as long as they still resided in any one of the $13 \mathrm{IFLS}$ provinces, irrespective of whether they moved across those provinces. Target respondents were individuals who split off into new households provided they were a main respondent in 1993 (which means that they were administered one or more individual questionnaires), or they were born before 1968 (that is they were 26 years and older in 1993). Not all individuals were tracked in order to control costs.

Once a household was found, the rules for interviewing household members differed for origin and split-off households. In origin households the goal was to interview all members, unlike in IFLS1. In split-off households only target respondents (IFLS1 main respondents or IFLS1 household members who were born before 1968), their spouses, and any of their biological children living in the household were to be interviewed. The reasoning was to limit the size of the sample so that interviewers were not overwhelmed with large numbers of new respondents who had only a tenuous connection with the IFLS1 household members.

\subsubsection{IFLS2+ Re-contact Protocols}

IFLS2+ was fielded in the second half of 1998 in order to gage the immediate impact of the Asian economic crisis that had hit Indonesia starting in January 1998 (see Frankenberg, Thomas and Beegle, 1999). Since time was short and resources limited, a scaled-down survey was fielded, while retaining the representativeness of IFLS2 as much as possible. A $25 \%$ sub-sample of the IFLS households was taken from 7 of the 13 provinces that IFLS covers. ${ }^{7}$ Within those, 80 EAs were purposively selected in order to match the full IFLS sample. As in IFLS2, all households that moved since the previous interview to any IFLS province were tracked. In addition, new households (split-offs) were added to the sample, using the same criteria as in IFLS2 for tracking individuals who had moved out of the IFLS household. For interviewing individuals within households, the same rules used in IFLS2 were mostly used. In original IFLS1 households, all current members were interviewed individually. One difference was that all current members of split-off households were also interviewed individually, not just a sub-set.

\subsubsection{IFLS3 Re-Contact Protocols}

The sampling approach in IFLS3 was to re-contact all original IFLS1 households having living members the last time they had been contacted, plus split-off households from both IFLS2 and IFLS2+, so-called target households (8,347 households-see Strauss et al., 2004). Main field work for IFLS3 went on from June through November, 2000. A total of 10,574 households were contacted in 2000; meaning that they were interviewed, had all members died since the last time they were contacted, or had joined another IFLS household which had been previously interviewed. Of these, 7,928 were IFLS3 target households and 2,646 were new split-off households. A $95.2 \%$ re-contact rate was thus achieved of all IFLS3 "target" households. The re-contacted households included at least some part of 6,800 of the original 1993 households (dynastic households), or $95.3 \%$ of those. ${ }^{8}$

Of the contacted households, 10,435 households were actually interviewed in $2000 .^{9}$ Of these, 3,774 were split-off households since IFLS1 and 6,661 were IFLS1 households.

\footnotetext{
${ }^{5}$ This includes households all of whose members died by 1997 and a few households that merged into other IFLS households.

${ }^{6}$ Italicized terms and acronyms are defined in the glossary.

${ }^{7}$ The provinces were Central Java, Jakarta, North Sumatra, South Kalimantan, South Sumatra, West Java and West Nusa Tenggara.

${ }^{8}$ The 6,800 includes 32 households all of whose members died between IFLS2 and IFLS3.

${ }^{9}$ The difference between the 10,435 households interviewed and the 10,574 households found are households all of whose members died since the last survey contacted, or who joined other IFLS households.
} 
As in 1997 and 1998, households that moved were followed, provided that they still lived in one the 13

provinces covered by IFLS, or in Riau. ${ }^{10}$ Likewise individuals who moved out of their IFLS households were followed. The rules for following individuals who moved out of an IFLS household were expanded in IFLS3. Target respondents for tracking were:

- 1993 main respondents,

- 1993 household members born before 1968,

- individuals born since 1993 in origin 1993 households,

- individuals born after 1988 if they were resident in an origin household in 1993,

- 1993 household members who were born between 1968 and 1988 if they were interviewed in 1997,

- $20 \%$ random sample of 1993 household members who were born between 1968 and 1988 if they were not interviewed in 1997.

The first two criteria were the same as used in IFLS2. The motivation behind expanding the group of individuals who would be tracked beyond the group followed in 1997 was to be able to follow small children in panel households (children 5 years and under in 1993 and children born subsequently to 1993) and to follow at least a subset of young adults, born between 1968 and 1988. This strategy was designed to keep the sample, once weighted, closely representative of the original 1993 population in the 13 IFLS provinces.

As for individuals, the rules for interviewing individual household members were expanded slightly in IFLS3 from IFLS2. In origin IFLS1 households, everyone who could be was interviewed or had a proxy interview, whether or not they had been household members in IFLS1. In split-off households, all IFLS1 household members, their spouses and biological children, were to be interviewed, but not others (not just the target respondents for tracking, their spouses and children, as in IFLS2). However in many cases all household members were interviewed.

Some 43,649 persons were found currently living in the 10,435 households interviewed. Basic information is available on all persons in the household roster. Of these, 38,823 were to be interviewed with individual books according to the IFLS3 rules laid out above, and of those 37,173 had a direct interview and 1,260 proxy interviews; nearly all of those who should have had either a direct or proxy interview.

\subsubsection{IFLS4 Re-Contact Protocols}

The target households for IFLS4 were the original IFLS1 households, minus those all of whose members had died by 2000, plus all of the splitoff households from 1997, 1998 and 2000 (minus those whose members had died). Main fieldwork went on from late November 2008 through May 2009. In total, we contacted 13,995 households, including those that died between waves, those that relocated into other IFLS households and new splitoff households. Of these, 13,535 households were actually interviewed. Of the 10,994 target households, we re-contacted $90.6 \%$ : 6,596 original IFLS1 households and 3,366 old splitoff households. An additional 4,033 new splitoff households were contacted in IFLS4. Of IFLS1 dynastic households, we contacted 6,761 , or $93.6 \%$. Lower dynasty re-contact rates were achieved in Jakarta $(80.3 \%)$, south Sumatra $(88 \%)$ and north Sumatra (88.6\%). Jakarta is of course the major urban center in Indonesia, and Medan, Indonesia's second largest city is in north Sumatra. It has always been the case for IFLS that in these two metropolitan areas it is hardest to find panel households. On the other hand, in places like west Nusa Tenggara and east Java, our re-contact rates were extremely high $(99.3 \%$ and $98.1 \%$ respectively of dynastic households).

IFLS4 used the almost the same re-contact protocols as IFLS3. In particular, the rules for tracking individuals who had moved were:

- 1993 main respondents,

- 1993 household members born before 1968,

- individuals born since 1993 in origin 1993 households, also in splitoff households if they are children of 1993 IFLS household members

- individuals born after 1988 if they were resident in an origin household in 1993,

- 1993 household members who were born between 1968 and 1988 if they were interviewed in 2000,

\footnotetext{
${ }^{10}$ There were also a small number of households who were followed in Southeast Sulawesi and Central and East Kalimantan because their locations were assessed to be near the borders of IFLS provinces and thus within cost-effective reach of enumerators.
} 
- $\quad 20 \%$ random sample of 1993 household members who were born between 1968 and 1988 if they

were not interviewed in 2000.

One small change in IFLS4 was that whereas in IFLS3 new babies born since IFLS2 were to be tracked if they were considered household members in 2000, now they were to be tracked even if they were not considered household members in 2007, that is they had moved out in earlier years, but were still alive. Interviewing rules were also kept the same as 2000. In particular, in origin IFLS1 households, everyone who could be was interviewed or had a proxy interview, whether or not they had been household members in IFLS1. In split-off households, all IFLS1 household members, their spouses and children, were to be interviewed, but not others. However as in previous waves, basic information was collected on everyone living in the household in Book K, section AR.

There were 50,580 individuals in the interviewed households. We have at least some information on all of those persons in the household books. In addition, we have information in the individual books on 44,103 persons, whom we interviewed directly or by proxy (only 1,532 were by proxy interview).

\subsubsection{IFLS5 Re-contact protocols}

The re-contact protocols for IFLS5 were unchanged from IFLS4. The rules for following moved individuals were:

- 1993 main respondents,

- 1993 household members born before 1968,

- individuals born since 1993 in origin 1993 households, also in splitoff households if they are children of 1993 IFLS household members

- individuals born after 1988 if they were resident in an origin household in 1993,

- 1993 household members who were born between 1968 and 1988 if they were interviewed in 2007,

- $20 \%$ random sample of 1993 household members who were born between 1968 and 1988 if they were not interviewed in 2007.

Household fieldwork took place between September 2014 and March 2015. Tracking activities were performed starting in March 2015 through August 2015, with a short break for Idul Fitri. The more recent the wave, the more work is involved with long distance tracking because households that already split off in earlier waves have to be tracked outside of their original IFLS1 EAs, plus new splitoff households need to be tracked as well. Moreover, when an individual or household moves, usually it is not moving with other households, so the network of households and individuals to track expands rapidly. This resulted in IFLS5 in taking longer to conduct the tracking activities.

In Tables 2.3a and $\mathrm{b}$ it is apparent that tracking is quite important if we want to keep households in the survey. Since IFLS4, only $53.6 \%$ of households did not move, and only $64.6 \%$ stayed within the village/urban community. Most of the movers are people who start new splitoff households, over $80 \%$ of original IFLS1 households stayed in the same village since IFLS4, but only just over $50 \%$ of splitoffs. Since IFLS1, over $80 \%$ of original IFLS1 households have stayed within the same village, but only $37 \%$ of splitoff households. So, tracking is important. Had we not tracked mover households and splitoffs outside of the village where they were last found, we would have lost a full $1 / 3$ of the households we interviewed in IFLS5.

To demonstrate the importance of splitoff households in IFLS, we can compare the number of persons found in original IFLS1 households to those found in households that were splitoffs since 1997 (wave 2). They are now approximately equal, 22,090 persons found in IFLS5 in original IFLS1 households and 28,058 in splitoff households (Tables 2.4b and 2.4c).

Among the original 33,081 IFLS1 household members, about one-third, 11,040 were found in their original IFLS households during IFLS5 (Table 2.5). Another 8,667 were found elsewhere and another 4,538 had died by IFLS4. Of these, 2,662 had exit interviews with knowledgeable proxy respondents in IFLS5. The recontact rate (including deaths) in IFLS5 among IFLS1 individuals is thus 76\%. Of IFLS1 main respondents, the recontact rate is higher, $82 \%$. Among age groups, the lowest recontact rates of IFLS1 household members are for persons who were teenagers (15-19) in 1993, while the highest recontact rates are for persons who were mid-aged and older in 1993. Over the course of IFLS, 17,295 individual respondents are found alive in all 5 waves (52.3\% of IFLS1 household members), of which 11,889 (54\% of IFLS1 "main respondents") have interviews in all five waves (Tables $2.6 \mathrm{a}, 2.6 \mathrm{~b}) .^{11}$

\footnotetext{
${ }^{11}$ The difference is because not all IFLS1 members were given individual books.
} 
For IFLS5 we moved from paper and pencil questionnaires that were input electronically in the field after the interview, to a computer-assisted personal interview system (CAPI). After consideration of several potential CAPI programs, including MMIC, we chose to use CSPro. Our programmers were very familiar and skilled in CSPro and there were certain advantages to using CSPro for our purposes. In particular in CSPro it is very easy for an interviewer to go back in the program to correct any errors, something which is more involved in MMIC, for example. Also we had been using CSPro to program our older data entry system, which facilitated the re-programming for CAPI. lip Umar Rifaii and the other programmers, Nursuci Arnashanti and Amalia Rifana Widiastuti did an outstanding job in doing the programming. This task took nearly 18 months, starting in March 2013. The bulk of the programming was finished by October 2013 after 7 months, at which point we conducted extensive pretests of the CAPI system. Further refinements and changes in the questionnaire were made through the period of the household questionnaire training of trainers in May 2014 and the first main training in August 2014, which is why the 18 months in total.

The move to CAPI has many, well-known advantages. For example, skip patterns are now programmed into the data entry program so interviewers won't make errors with respect to skips. It is now straightforward to use randomization in the program, for example, in choosing which level to start with when we are using unfolding brackets to bound answers with respect to income or wealth sources, or which list of words to use in the immediate and delayed word recall. There is a major savings in logistics costs and planning because it is not necessary to mail boxes of questionnaires to various points on the travel plan of each field team. And a related cost savings because of saved printing costs. For a large-scale survey like IFLS, these savings are truly enormous and a really major advantage of CAPI. There are offsetting larger costs, notably that each interviewer now needs a laptop or tablet (we used small Dell laptops), but there exist net cost savings for IFLS.

Showcards were also introduced in IFLS5 to accompany the CAPI. For some questions it was useful to have showcards to help the respondents understand the question. Showcards were translated into several key languages in addition to Bahasa Indonesia (the CAPI was however only in Bahasa- if translation was required, this was done on the spot by the interviewer or a helper).

One potential disadvantage is that it is more involved to undertake data quality checks in the field. In our past system we had data entry persons in the field with the interviewing teams. They entered data into electronic form from paper in the base camps and in the process made many checks and sent interviewers back to households to re-check answers in real time. Replacing this system took much thought, experimentation and pretesting. Some of the experience of the China Health and Retirement Study (CHARLS) was very helpful and was borrowed. The details are described in the field operating procedures, but highlights included programming checks for inadmissible values of data and other out of range data checks that were implemented immediately, and then corrected. We separately recorded all interviews with a sound system built into the laptops. These recordings were uploaded right away to our data uploading website or mailed back to our central headquarters in Yogyakarta (which took a maximum of 2 days). We had a team of people in Yogya who listened to random parts of these recordings for random interviews (the details are provided below in the field procedure section), and then compared answers to the electronic data. When discrepancies were found they got back to the teams, generally within 1 week of the original interview for interviewers to recheck questionable answers. This was a short enough time period that the teams could still get back to households to re-check answers.

\subsection{Human Subjects}

IFLS goes through IRB review both at RAND and in Indonesia. For IFLS5 the IRB in Indonesia was associated with Survey Meter. AT RAND IRB review has taken place since IFLS1.

\subsection{Household Survey Instruments}

IFLS is a comprehensive multipurpose survey that collects data at the community, household and individual levels. The household survey includes household- and individual-level information. One or two household members were asked to provide information at the household level. The interviewers then attempted to conduct an interview with every individual age 11 and over. For children less than 11, interviewers attempted to interview a parent or caretaker. The strategy used after IFLS1 of interviewing all household members, was more expansive than the IFLS1 strategy of interviewing a sample of household members. Because obtaining interviews with all household members is difficult, IFLS5, like earlier waves, included a proxy book that was used for collecting more limited information (from other household members) about individuals who could not be interviewed in-person. 
The household questionnaire in IFLS5 was organized like its earlier counterparts and repeated many of the 9 same questions to allow comparisons across waves. The IFLS1 questionnaire contained many retrospective questions covering past events. IFLS5 followed IFLS2, 3 and 4 in asking full retrospectives of new respondents. Respondents in IFLS5 were considered to be panel respondents if they had answered individual books in IFLS4. Panel respondents were usually only asked to update the information, from the information they provided in IFLS4, although in some cases they were asked to recount histories since 2007. Enumerators had pre-printed information loaded on CAPI for every panel individual they interviewed, containing the answers from which the information was to be updated. For example, in module $\mathrm{CH}$ in book 4, women are asked questions about their biological children. Children who were born before 2007 and listed in the relevant sections ( $\mathrm{CH}$ and BA) of IFLS3 would be listed in the preloaded information and the enumerator would prompt the respondent with the children born to-date then and then update the information in $\mathrm{CH}$. Table 2.7 outlines the questionnaire structure and contents, which are described in more detail below.

The household survey questionnaire was divided into books (usually addressed to different respondents) and subdivided into topical modules or sections. Four books collected information at the household level, generally from the household head or spouse ${ }^{12}$ : books $\mathrm{T}, \mathrm{K}, 1$, and 2. The next four books collected individual-level data from adult respondents (books $3 \mathrm{~A}$ and $3 \mathrm{~B}$ ), ever-married female respondents (book 4), and children younger than 15 (book 5). Some modules appear in more than one book to facilitate collecting the data efficiently (for example, ever-married women under 50 answer questions about marriage in book 4 , whereas other respondents answer marriage questions in book $3 \mathrm{~A}$ ). Some modules appear in both a household book and an individual book (for example HR), because we wanted to make sure that we collected data for the household as a whole, in addition to collecting data from individuals. Individual measures of health status were recorded for each household member (book US). Household members older than age 7 were asked to participate in cognitive assessments of their general intellect, as well as their skills in mathematics (book EK). More detail on the contents of the individual books is provided below and in Appendix B of this volume and in Volume 2.

Book T: Tracking Book. Book T is a contact book for households, all target households: all original IFLS1 households plus split-off households from IFLS2, 2+, 3 and 4 have at least one book T. A book T was filled out at every location where a household was searched. In the public release only one book $T$ is provided for each household, from when a household was actually contacted, or from the last place where it was searched. For the purpose of users, the key variables are TB1 and TB2, which record whether the household was found and interviewed or not, had all members die, moved or moved into another IFLS household, in which case TB2 lists the household id of the destination household. Book T also has location and other tracking information, which will generally not be important for users and is not in the public release.

Book K: Control Book and Household Roster. Book K records the location of the household, for households that were found and interviewed. Information on the composition of the household and on basic socio-demographic and some economic characteristics of all household members were collected, as were information on key characteristics of the housing structure that the interviewer could observe and about the household's plans to move in the future (helpful in planning for subsequent rounds of data collection and in tracking respondents who moved).

Exit Interview Form. We added this form in IFLS5. This is for respondents alive in 2007 who died by IFLS5. We had limited information in Book $\mathrm{K}$ about respondents who died, notably their date of death, but not much other information about their lives in the period before death. We designed this form in part from the Health and Retirement Study (HRS) exit form. In it we obtained information on the respondent's health and life conditions in the period immediately before death. Date of death was recorded along with some limited cause of death data. We also collected information on where the respondent died, whether the respondent was employed before death and if so at what, their health a year before death and a list of chronic health conditions and whether the respondent had been diagnosed with each of these, and when. Medical expenses just before death and funeral expenses were also collected.

Book 1: Household Expenditures and Knowledge of Health Facilities. This book was typically answered by a female respondent, either the spouse of the household head or another person most knowledgeable

\footnotetext{
${ }^{12}$ In every IFLS wave, one member of the household was designated the household head by the person who provided information on the composition of the household. The head of the household is defined as a person who is responsible for keeping up the daily need of the household or a person whom the members of the household considered to be the head. Where a married couple headed the household, the husband was generally designated the head and the wife, the spouse of the head. The head of the household in IFLS1 was not always the head of the household in subsequent waves, even when still present.
} 
about household affairs. The first module recorded information about household expenditures ${ }^{13}$ and about 10 quantities and purchase prices of several staples. The second module obtained details about transfers from key government programs, including food aid programs, unconditional and conditional cash transfer programs. This module was updated for IFLS5. We dropped the crime module in IFLS5 because there was very little that was reported in IFLS4. In the community survey we retained a module on conflict, but not on crime. Finally the last section probed the respondent's knowledge of various types of public and private outpatient health care providers. This information was used in drawing the sample of facilities for interviews in the Community-Facility Survey.

Book 2: Household Economy. This book was usually answered by the household head or the head's spouse. Sections asked about housing characteristics, household businesses (farm and nonfarm), nonbusiness assets, and nonlabor income. Combined with individual-level data on labor and nonlabor income collected in book $3 \mathrm{~A}$, this information can be used to provide a picture of current household income from market-wage income, family businesses and nonlabor income. In addition, a section asked about conditions related to the many natural disasters that have plagued Indonesia in recent years. A final section asked about borrowing and repayment of loans taken out in the last year. A module used in IFLS4 on avian flu was dropped because this was not an issue in 2014-15.

Book 3A: Adult Information (part 1). This book asked all household members 15 years and older about their educational, marital, work, and long-run migration histories. In addition, the book included questions on asset ownership and non-labor income, household decision-making, fertility preferences, (for women 50 and older) cumulative pregnancies, subjective views of their happiness and living standards. Sections were also asked about retirement and pensions, attitudes about risk and time-preferences, the degree of trust of their neighbors, individual religiosity and attitudes of religious tolerance. In the risk and time-preference attitude section there are two sets of questions which have different levels of payoffs. In IFLS5 we randomized the order of these, unlike IFLS4.

A new section in IFLS5, PNA, asked about hedonic well-being yesterday and was taken from the Health and Retirement Study (HRS). Dr. Arthur Stone and Dr. Jacqui Smith were heavily consulted on this section, that they designed for the HRS. A list of 12 words, both negative and positive feelings, were given and the respondent recorded on a 5 point ordinal scale whether they felt this feeling yesterday. The ordering of the first 11 words was randomized in CAPI, but the final word was always pain. After this more detailed questions about pain were included, including regarding the severity of any pain and on which body part the pain was felt. This section was heavily pretested to make sure the words translated easily into Indonesian.

The amount of retrospective information collected varied by section and by whether the respondent had answered book III in IFLS4. Respondents who did not complete book III in IFLS4 were typically asked for lengthy histories that mirrored the data obtained in IFLS1. Respondents who had answered book III in IFLS4 were generally asked only to update the information for the period since 2007 . The specific rules varied by module (see User's Guide (WR-675/2-NIA/NICHD), Table 2.2.).

Book 3B: Adult Information (part 2). Book 3B emphasized current rather than retrospective information and was heavily devoted to health. Separate modules addressed smoking habits, insurance coverage, detailed health conditions including physical function limitations, activities of daily living (ADL's) and instrumental activities of daily living (IADL's), food intake frequencies, use of inpatient and outpatient care, and participation in community development activities. We also had questions about doctor diagnoses of the respondent's chronic health conditions and mental health (depressive symptoms). Two other sections (BA and TF) asked in detail about the existence and characteristics of non- resident family members (parents, siblings, and children) and about whether money, goods, or services were transferred between these family members during the year before the interview. Another section asked about parental expectations of their children's schooling, health and living standards. The sections on ADL's, IADL's and physical functioning were changed slightly to be better harmonized with the HRS.

There were several new sections to Book 3B added in IFLS5. The biggest set of changes were in the cognitive capacity sections $\mathrm{CO}$ and $\mathrm{COB}$. We added serial subtraction of 7 's from 100 , naming of as many animals as possible within 60 seconds, and a timed counting backwards from 20 as fast as possible (the latter two sets of questions for respondents aged 50 and above). These additions helped to further harmonize IFLS

\footnotetext{
${ }^{13}$ All IFLS waves included essentially the same items and reference periods for food expenditures. For non-food expenditures IFLS1 is differently constructed. For each non-food item, IFLS1 asked whether the reported expenditure pertained only to the individual answering the question or the household as a whole. This way of asking about expenditures is not standard in budget surveys and was dropped in IFLS2, with the cost that 1993 expenditures are not directly comparable with expenditures in later waves. IFLS2, 2+,3, 4 and 5 expenditures, however, are directly comparable. The IFLS expenditure module is a shortened version (about 30 minutes) of the three-hour module included in every third year of the SUSENAS. It is very similar to the SUSENAS short-form consumption module.
} 
with HRS. For the immediate and delayed word recall we made sure in pretests that the average time between the two sets of recall was 4 minutes, again to better harmonize with HRS.

Perhaps the most important addition to the cognition section is module COB, which includes an adaptive number series test that was adopted from HRS, with changes, under the direction of Dr. John McArdle. We were worried about the degree of difficulty of the HRS test in a low numeracy country like Indonesia. To adjust for this, we added some easier questions, keeping a number of the HRS questions so that the answers could be later scaled to be comparable. This adjusted set of number series questions was pretested extensively in Indonesia, in two different provinces and both in rural and urban areas. These questions were also pretested by the Mexican Health and Aging Study (MHAS). A report analyzing these pretest data, written by McArdle, is available on the IFLS website. More details about the pretest are included in Appendix B.

A second new module was added about personality (section PSN). We use the Big Five Index 15 (BFI 15), which is a set of 15 adjectives representing all 5 of the big five personality groups, 3 words for each of the 5 . It is a subset of BFI 44. A five point ordinal scale was used to represent how well the respondent believed that attribute represented them. This scale is used in many population surveys, such as the German socioeconomic panel (GSOEP). We experimented in pretests with the 26 item scale used by HRS, which is the same as that used in MIDAS, but several of the words in that scale did not translate easily into Indonesian. We did not have that problem with the BFI 15 scale. Four lists of the same 15 words were constructed and which list was used was determined randomly in CAPI. Dr. Brent Roberts provided significant advice for this module and Dr. Angela Duckworth provided advice as well.

Another new module for IFLS5 (TDR) regards sleep quality and sleep-related impairment. Five questions for each, quality and impairment, over the last 7 days, were used with a 5 point ordinal scale. These questions are a small subset of questions used by PROMIS. The adjectives were translated and re-translated following PROMIS guidelines. Survey Meter staff did the initial translation into Indonesian. Then two independent outside translators were hired and re-translated back into English. The English re-translation agreed with the Promis English. Dr. Joan Broderick was instrumental in advising us with this section and in obtaining permission for IFLS to use these questions.

Two more sections were added into IFLS5, early health (EH) and childhood SES (SA). IFLS has always included a substantial amount of retrospective questions, on marriage history, birth history, migration history, work history and so forth. For respondents who came into IFLS at mid-or older ages, we do not have information about health during childhood, nor about many family socio-economic circumstances during childhood. We have tried to fill these gaps with these two sections. We include a general health question about health before age 16 (on an excellent, very good, good, fair, poor scale). This question has been successfully used in several other studies including HRS and CHARLS. We ask about certain health conditions during childhood, including whether the respondent had certain childhood diseases and had to be hospitalized for over 1 month. For the socio-economic environment we ask about age 12, which is an age we have other background questions already in IFLS. We ask about the number of rooms in the dwelling, how many people lived there, how many older and younger brothers and sisters lived in the household then, the marital status of their parents at that time, whether either parent smoked, drank heavily or had mental problems, the number of books in the household (on an ordinal scale) and the occupation of the main household breadwinner. These questions are a subset of questions from the life history modules of ELSA and SHARE, used by CHARLS for example.

Book Proxy: Adult Information by Proxy. The proxy book was designed to facilitate collecting data by proxy about individual adults who could not be interviewed directly. The proxy book contains shortened versions of most of the sections included in books 3A, 3B, and 4. Some additional questions were added in IFLS5 reflecting some of the new modules and changed questions in the main questionnaire.

Book 4: Ever-Married Woman Information. This book was administered to all ever-married women age 15-49 and to women who completed book 4 in IFLS4, irrespective of age. Book 4 collects retrospective life histories on marriage, children ever born, pregnancy outcomes and health-related behavior during pregnancy and childbirth, infant feeding practice, and contraceptive use. The marriage and pregnancy summary modules replicated those included in books $3 A$ and $B$ so that women who answered book 4 skipped these modules in books $3 A$ and B. Similarly, women who answered questions about non- resident family in book 4 skipped that module in book 3B. A separate module asked married women about their use of contraceptive methods. No new modules were added to Book 4 in IFLS5.

Book 5: Child Information. This book collected information about children younger than 15 . For children younger than 11, the child's mother, guardian, or caretaker answered the questions. Children between the ages of 11 and 14 were allowed to respond for themselves if they felt comfortable doing so. The six modules focused on the child's educational history, morbidities, self-treatment, inpatient and outpatient visits and nonresident parents. Each paralleled a module in the adult questionnaire (books $3 \mathrm{~A}$ and $\mathrm{B}$ ), with some age- 

younger children. No new modules were added to Book 5 in IFLS5.

Book US: Physical Health Assessments. In addition to the respondent-assessed health status information recorded in books 3B and 5, IFLS5 continued the practice of earlier waves in seeking to collect physical health assessments on every respondent. In IFLS5 measurements were taken by the regular interviewers, who received special training during their regular training. Some new measurements were added in IFLS5: lower leg length and upper arm length replaced leg length for respondents aged 40 and over. These limb lengths do not shrink with age and so can be a better measure of maximum height for older respondents. Also added were a balance test for respondents 45 and above and a timed walk for respondents 60 and above. These were added to help further harmonize IFLS with the HRS surveys. More details are discussed in Appendix B.

We also collected dried blood spots (dbs) in IFLS5, as we did in IFLS4. The target sample in IFLS5 were the subset of respondents who had dbs taken in IFLS4. We are assaying for hs C-reactive protein (hs CRP) as in IFLS4, plus we are adding an assay for HbA1c in IFLS5. These data will become available, with a special User Guide, later, after the laboratory analyses are completed and the data checked and validated. Validation samples were collected on persons in the United States and analyzed in a laboratory at the University of Washington and at our laboratory in Indonesia.

Books EK: Cognitive Assessments. In IFLS3 and 4 respondents aged 7-24 were administered cognitive tests to assess their general cognitive level, as well as skills in mathematics. We continued this in IFLS5, but we expanded the age range for the tests to include all respondents older than 24 . The tests include an abridged version of the Ravens test, which is a test of fluid intelligence and some simple arithmetic questions. The age range was expanded in IFLS5 because the fluid intelligence test used for younger respondents in IFLS3 and 4 has proven to be so useful to users. As in IFLS3 and 4, two levels of tests were given, an easier version to all respondents (including those who never attended or were not currently enrolled in school) aged 7-14 and a more difficult version to all older respondents. The easier test, EK1, was re-administered to those who had taken it in IFLS4, and the harder test, EK2, also given as these children were now older than 14. The arithmetic questions were given to respondents aged 59 and under. Those over age 60 were not given those questions, only the fluid intelligence part.

\subsection{Notes on Response Burden}

The household survey instrument is complicated and takes time to complete. In IFLS we attempt to organize and format the instrument so as to minimize response burden. As Table 2.8 shows, the lion share of questionnaire books were completed in one visit. The median time to complete a book varied across the books, with the longest times observed for the household expenditure book and the individual-level books addressed to adults, about 40 minutes each.

Because of the move to CAPI response times have decreased, mostly because complicated skip patterns are programmed into CAPI so the interviewer does not have to think about what question to ask next. For books such as Book 4 this resulted in a fairly large time decrease. Even for Books 3A and 3B for which we added new sections, the median interview time did not rise compared to IFLS4. On the other hand these CAPI median times are not exactly comparable to those reported in prior user guides because with CAPI the times are actual times asking and answering questions, whereas in the past the times referred to times spent in the household for a particular book. These can be different because the respondent may need a break for taking care of a child for example. That time would be included in median times reported in past waves, but not in these new CAPI times.

Some respondents answered more than one book because they provided information not only about themselves but also about their household and potentially about their children, spouse, or parents. Table 2.9 shows median completion times for respondents of different types. Ever-married women age 15-49 generally spent more time being interviewed than others, the median time being about 2.5 hours, including all books that they were administered. They were asked to answer three individual-level books for themselves and were likely to answer book 1 (household expenditures and knowledge of health services) as well as book 5 if they had young children. The median time for women 50 and older, regardless of marital status, was 140 minutes, and it was the same for married men. Never-married women age 15-49 spent only 100 minutes total answering questions, and a little less for unmarried men. For children aged 11-14, the only children who might have answered questions, the median response time was only 25 minutes. 


\section{IFLS5 Community-Facility Survey}

IFLS collected very detailed information on the characteristics of communities that might affect individual behavior. For each IFLS community in which we interviewed households, extensive information was collected from community leaders and from staff at schools and health facilities available to community residents. In past waves, these data had been collected only in the original 312 IFLS1 communities ( 9 of which were socalled "twin" enumeration areas that resided in the same larger community, thus making up 321 communities in total). Starting in IFLS3, a reduced, basic set of data for new communities to which IFLS households moved was also collected and this was continued in IFLS4 and 5.

In IFLS5 the fieldwork for the community/facility (COMFAS) questionnaires started in March 2015. This was a somewhat longer lag behind the household survey than in prior waves. Starting later enabled us to have completed household questionnaires from the main field work (before tracking) from all 321 original EAs. This in turn allowed construction of the facility sampling frames for each EA and to inspect them for duplicate facilities, which were then removed from the frames before the sampling was done (see below for more details on sampling).

This section describes the community-facility survey sample for IFLS5, summarizes the contents of the survey instruments, and notes the links between community-facility and household survey data.

\subsection{Sample Design}

The community-facility survey sought information about the communities of household respondents. We followed the procedures of prior waves of IFLS to obtain most of our information, and added some new modules and updated questions regarding social safety net and other programs. Note that one of the 312 original IFLS ea's, EA156, COMMID 3249, in west Java, had no households in it in 2014/15. It had become a commercial area.

- The official village/township leader ${ }^{14}$ and a group of his/her staff were interviewed about aspects of community life. Data were extracted from community records, reported in Book 2. Supplementary information was obtained by interviewing the head of the community women's group, ${ }^{15}$ who was asked about the availability of health facilities and schools in the area, as well as more general questions about family health, Book PKK.

- In visits to local health facilities and schools, staff representatives were interviewed about the staffing, operation, and usage of their facilities, prices and the availability of appropriate equipment and supplies. For health facilities, measures of process quality were taken. Books regarding health services for the elderly and one for traditional practitioners were also asked.

- Data on prices were collected from three complementary sources: from a large local market, two stores or street stalls and one interview with a group of up to three knowledgeable local informants.

- We interviewed up to two local informants from different backgrounds about various aspects of village life, including social safety nets, decentralization and local governance.

- We dropped the ADAT book, which collects information about local traditions, because it was asked in IFLS4 and 7 years was considered too short to get new information.

- Another new addition of IFLS3 continued in IFLS5 was to interview the official village/township leader of the communities to which IFLS respondents had moved (different from the 312 original IFLS1 communities) to obtain a minimal amount of information on communities to which households had re-located. We collected information on factors such as total population, conditions of the village, access to the village, electricity availability, water, schools and health services in the village, existence of social safety net programs and some prices. This book was expanded some in IFLS5 to include better coverage of safety net programs, and other matters.

\footnotetext{
14 In Indonesia, village leaders are typically elected whereas municipality leaders are appointed. We use the terms "village" and "municipality" interchangeably.

${ }^{15}$ Besides having a village leader, Indonesian villages have a Family Welfare Group (PKK), usually headed by the wife of the village leader. The PKK is responsible for implementing a 10-point program mostly relating to family health. Although the village leader is nominally responsible for family health, activities related to family health are almost always sponsored by the PKK.
} 
To cover the major sources of public and private outpatient health care and school types, we defined six strata of facilities to survey:

- Government health centers and subcenters (puskesmas, puskesmas pembantu)

- Private clinics and practitioners including doctors, midwives, nurses, and paramedics (klinik, praktek umum, perawat, bidan, paramedis, mantri) ${ }^{16}$

- Community health posts (posyandu)

- Community health posts for the elderly (posyandu lancia)

- Traditional health practitioners

- Elementary schools $(S D)$

- Junior high schools $(S M P)$

- Senior high schools $(S M U)$ / Senior vocational high schools (SMK)

IFLS5 used the same protocol for selecting facilities as in earlier waves. We wanted the specific schools and health providers for detailed interviews to reflect facilities available to the communities from which household respondents were drawn. Rather than selecting facilities based solely on information from the village leader or on proximity to the community center, we sampled schools and health care providers from information provided by household respondents. We followed the strategy first used in IFLS3, to track households that moved to or near the EA (in the same village/ kecamatan) during the main field work period, rather than after main fieldwork was over. This enabled us to add facilities to the sample frame from locally- tracked households. This strategy was adopted since it was felt that the tracked household information would cover facilities in the EA.

Health Facility Sampling Frame. For each EA, we compiled a list of facilities in each health facility stratum from household responses about the names and locations of facilities the respondent knew about. Specifically, we drew on responses from book 1, module PP of the household survey, which asked (typically) the female household head if she knew of health facilities of various types, such as government health centers. The names and locations provided were added to the sampling frame.

Household respondents did not need to have actually used a health facility for it to be relevant to the facility sample. Though someone in the household may well have used a facility that was mentioned, any facility known to the respondent was relevant. Requiring actual use of a facility was rejected because it was judged that that approach would yield a more limited picture of community health care options (since use of health care is sporadic) and possibly be biased because the sample would then be choice-based.

School Sampling Frame. Names of candidate schools were obtained from household responses to book K, module AR, in which (typically) the household head verified the name and location of all schools currently attended by household members under age 25 . Therefore, unlike the health facility sampling frame, each school in the candidate list had at least one member of an IFLS household attending.

Final Samples. Not all identified health facilities and schools were eligible for interview. A facility was excluded if it had already been interviewed in another EA, if it was more than 45 minutes away by motorcycle. The facilities that were located in another area were eligible for interview so long it was in our reachable area (about 45 minutes away by motorcycle). We set a quota of facilities to be interviewed in each stratum in each EA. The goal was to obtain, for each stratum, data on multiple facilities per community. The quotas were different for different strata. For example, a larger quota was set for private practitioners than for health centers because Indonesian communities tend to have more private practitioners than health centers.

\footnotetext{
${ }^{16}$ Because of time and money constraints, IFLS2 and IFLS3 did not interview traditional practitioners, as did IFLS1. In IFLS4 and 5 we added them back in part because there were indications that they had become more important in recent years. And whereas IFLS1 grouped doctors and clinics in a different stratum from midwives, nurses, and paramedics, those strata were combined in IFLS2 and IFLS3 because of the difficulty of categorizing practitioners correctly. An advantage of grouping all private practitioners in one stratum is that the mix of provider types interviewed within the stratum better reflects what is available in the community. For example, in communities where paramedics were more plentiful than doctors, the mix of interviewed providers reflects that fact.
} 
Stratum

Government Health centers and subcenters

Private clinics and practitioners

Community health posts

Community health posts for the elderly

Traditional practitioners

Community informants

Elementary schools

Junior high schools

Senior high schools
Quota per EA

3

5

2

2

2

2

3

3

2

Two forms were used in developing the facility sample for each stratum. Sample Listing Form I (SDI) provided space to tally household responses and ascertain which facilities met the criteria for interview and were not duplicates of each other. Those facilities constituted the sampling frame and were listed on the second form, Sample Listing Form II (SDII), in order of frequency of mention. The final sample consisted of the facility most frequently mentioned plus enough others, randomly selected in CAPI, to fill the quota for the stratum. ${ }^{17}$ Note that because we sampled randomly from sample frames constructed by householder knowledge of facilities in 2014, we may not necessarily have re-sampled facilities that were sampled in prior waves; however many facilities will be the same. The variable FCODE can be used to match facilities from wave to wave.

\footnotetext{
17 In some EAs the pooled household responses did not generate enough facilities to fill the quota. Then, information from the village/township leader or women's group head was used to supplement the sample frame. The list of facilities from the household data was cleaned in central Survey Meter headquarters to eliminate duplicate facilities. The cleaned list was then sent to the community/facility teams and put onto their laptops, after which the CAPI program took the random samples.
} 
Community Informant Sampling Frame. Sampling was also used to identify the informants to be interviewed for the community informant book. The informants came from six categories of types of community leaders: elementary school principal, health professional, religious leader, youth activist, political party activist and business leader. For each category the kepala desa or kelurahan suggested two names, one of whom was considered the more knowledgeable person. Then 2 of the categories were chosen randomly in CAPI and a third was also randomly chosen as a backup. For the two chosen categories the name of the person considered most knowledgeable was chosen. If that person was not available the second name within that category was chosen. If none of the suggested names for that category were available, the backup category was chosen.

\subsubsection{Response Rates}

Table 3.1 shows the number of community-facility respondents and facilities covered in all waves of IFLS. In all waves we met our interviewing quotas. In IFLS5 960 public health clinics and sub-clinics; 1,600 private health facilities; over 630 community health posts and 490 health posts for the elderly and over 2,500 schools were interviewed. Table 3.2 shows the number of facilities interviewed in each province, by stratum. Also 320 markets were visited to collect prices, plus 320 price informants and 640 stalls or stores. A further 4,054 communities where mover households live were administered our abridged mini-Comfas questionnaire.

Despite not being intended, a number of the same facilities interviewed in IFLS5 were also interviewed in one or more prior waves. This was especially true for public health centers and sub-centers and for schools. For these groups the turnover rate is small and the number available to be sampled per community is also small. The lowest re-interview rate was in private health facilities. This is not surprising since there are numerous private facilities, so the sampling rates are smaller, plus the yearly turnover is larger. The re-interview rate could have been increased by deciding a priori to go back to the same facilities that we visited in the previous waves. However, we judged it important to refresh the sample to allow for new facilities, since the communityfacility survey was intended to portray the current nature of the communities and the facilities in which IFLS households resided. Table 3.3 shows the number of facilities interviewed in IFLS5 for which IFLS1, 2, 3 or 4 data also exist, and the number of new facilities interviewed only in IFLS5. The exception is community health posts (posyandu). No community health post interviewed in IFLS5 has the same ID as its previous IFLS counterparts. That is because both the locations and volunteer staff change over time, so determining whether an IFLS5 post was the same as a post in IFLS1, 2, 3 or 4 is effectively impossible. It is perhaps more appropriate to regard a community health post as an activity rather than a facility. As one can see, many IFLS5 facilities were interviewed in at least one earlier wave, especially for government health clinics (71\%), primary and junior high schools ( $40 \%$ and $47 \%$ respectively).

\subsection{Survey Instruments}

As with the household survey, the community-facility questionnaires were divided in books (addressed to different respondents) and subdivided into topical modules. Community-level information was collected in six books: book 1, book 2, book PKK, book SAR, book informant, and the prices books. Health facility information was collected in books Puskesmas, Private Practice, Posyandu and Posyandu Lancia and Traditional Practitioner. Each level of school was covered in a single book, because the contents were nearly identical: book School. In IFLS5 the puskesmas book was divided into two, and the school book was divided into four parts. Table 3.4 briefly summarizes the structure and contents of each book, which are described below and in Appendix $\mathrm{C}$ in more detail.

\subsubsection{Community Questionnaires}

Book 1: Community History and Characteristics. This book collected a wide range of information about the community. It was addressed to the head of the community in a group interview. Ideally the group included the village or township leader, one or two of his staff members, and one or two members of the Village Elders Advisory Board, but the composition varied across villages, reflecting who was available and whom the village leader wanted to participate. Respondents were asked about available means of transportation, communications, sanitation infrastructure, agriculture and industry, history of the community, credit opportunities, community development activities, the availability of schools and health facilities, community welfare and economic changes. No new sections were added in IFLS5, but several questions in several parts of the book were revised and updated, especially in section PAP, which covers social safety net programs.

Book 2: Community Statistics. This book provided a place to record statistical data about the community. Generally the data were extracted from the community's Statistical Monograph or from a copy of its PODES questionnaire. In IFLS5, like IFLS3 and 4, information on local budgets and revenues were gotten. The village or township leader or their staff showed the interviewers information from the APPK (Kelurahan 
Budget Management) or APPKD (Village Revenue and Expenditure Budget). If neither source was available, the village head was asked to estimate the answer, which was recorded as an estimate. Separate modules asked the interviewer to make direct observations about community conditions.

Book PKK: Village Women's Organization. This book was administered to the head of the village women's group, the PKK. Respondents were asked about the availability of health services and schools in the community; including outreach activities, changes in the community over time, and different dimensions of community welfare.

Book SAR: Service Availability Roster. The Service Availability Roster (SAR) was intended to gather in one place cumulative information across all waves, on all the schools and health facilities available to residents of IFLS communities. It included

- Facilities cumulatively identified in the previous waves, IFLS4- SAR (which included facilities listed in IFLS1, 2, 3 and 4)

- New facilities identified by respondents in IFLS5 household modules PP and AR but not mentioned in IFLS4-SAR

- Any other facilities mentioned by the head of the village/township or the women's group head in Modules I and J in IFLS5 Community-Facility Survey books 1 or PKK.

For each facility mentioned, we collect data on the date it opened, if it was still open at the time of the survey and if not, the date of closing. By collecting this information we have a retrospective history on service availability to the community, covering the period of IFLS. The head of the village/township or the women's group head was asked to estimate the distance, travel time, and travel cost to the facility.

Book Informant: Community Informant. This book collected information from two informants on poverty alleviation programs in the community, perceptions on community infrastructure, local governance and decentralization and community social interactions. Special attention was paid to assessment of the quality of services available to the community and to the quality of local government.

\subsubsection{Health Facility Questionnaires}

Separate books were designed for each health facility stratum:

- Book Puskesmas for government health centers and sub-centers

- Book Private Practice for private doctors, clinics, midwives/village midwives, nurses, and paramedics

- Book Posyandu for community health posts

- Book Posyandu Lancia for community health posts for the elderly

- Book Traditional practice for traditional health practitioners

The contents of books Puskesmas and Private Practice were very similar to those in earlier waves to maximize comparability. Both books were designed to indicate the facility's functional capacity: adequacy of the laboratory, pharmacy, equipment, staff, the physical environment; and the adequacy of specific services for outpatient care, care for pregnant women, well-baby care, and family planning.

Both Puskesmas and Private practice books collected data on the availability and prices of services, lab tests, and drugs; and on the availability of equipment and supplies. Both allowed the interviewer to record direct observations about the drugs stocks, laboratory, and vaccine storage rooms. A module in both books was concerned with the availability and prices of services for "poor" patients, covered by new health social safety net programs. Special modules in book Puskesmas focused on decentralization, decision making, and finance, repeating baseline modules from IFLS3 and from IFLS4. Also health vignettes that were reintroduced in IFLS4, were conducted again in IFLS5. These set out 4 kinds of health cases, about which the health practitioners were asked a series of questions. The health cases included prenatal care, child care for a child with diarrhea, adult care for someone with upper respiratory problems, and adult health care for someone wanting their blood sugar checked. The answers can be scored against so-called "correct" answers to get at the quality of health practitioners. As mentioned, the puskesmas book was divided into two parts in 
IFLS5. The second part focused on staff information. These questions were separated because the entire 18 book took a long time to complete; we decided to break up the interview.

The contents of books Posyandu and Posyandu Lancia reflected the different roles these facilities play in providing health services to mothers and children and to old people. They asked about the characteristics of the volunteer staff (including general education and health training) and their frequency of contact with outreach workers from the government health center (puskesmas). In addition to questions about services offered at the posts, there were general questions about health problems in the village. Modules, first added in IFLS3, were continued about the posyandu revitalization program and resources.

\subsubsection{School Questionnaire}

The questionnaires for schools, combines the three levels of schools, elementary, junior high school, and senior high school. In most of the modules, the principal or designee answered questions about the staff, school characteristics, and student population. Questions were asked about scholarship programs; social safety net assistance for schools, like the DBO (Operational Funds Assistance) and Operational and Maintenance Funds; and decision-making at the schools, specifically the level at which decisions are made for specific tasks (school, district school ministry or central government education ministry). Another module, investigating teacher characteristics, was focused on home room teachers and asked about their background, classes and certification, whether they had it or had applied for it. Direct observations by interviewers were collected regarding the quality of the classroom infrastructure. The final modules recorded student expenditures, math and language scores on the UAN tests (the replacement for EBTANAS) for a random sample of 25 students for each test, ${ }^{18}$ and counts of teachers and students for the school year 2014/2015.

\subsubsection{Price Books}

Price information was collected in three books, identical to prior waves. The market price book was collected by interviewers in each of the 320 original EA's. Interviewers had their own small scales and purchased and weighted foods of different kinds to get prices. The stall/market price book was similar, but administered at local stalls or markets, 2 per original EA. Finally, an informant was interviewed to obtain a different set of prices.

\subsubsection{Mini-CFS questionnaire}

This book was new in IFLS3 and continued in IFLS4 and 5. It applied to community leaders from villages that were not original IFLS villages, where the IFLS households/members had moved. This book contained a shortened combination of questions of books I and II. It collected basic data of the village's infrastructure such as total population, main sources of income, number of health facilities by type, and price and wage data. The information collected in this abbreviated book was expanded in IFLS4 and again in IFLS5.

\footnotetext{
${ }^{18}$ UAN and EBTANAS tests are national achievement tests administered at the end of each school level (e.g., after grade 6 , for students completing elementary school). The scores can be used to judge student achievement levels in a school.
} 


\section{Appendix A: Survey Operations}

This appendix describes the process of developing and fielding IFLS4. The survey was designed between October 2012 and April 2014.Training of trainers began in May to June 2014 while interviewer training began in early August 2014 (after Ramadan and Idul Fitri), and field work took place largely between late October 2014 and the end of April 2015, with long distance tracking extending through the end of August 2015. Table A. 1 shows a timeline of IFLS4 activities.

\section{Development of Questionnaire and Field Procedures}

The household and community-facility questionnaires fielded in IFLS1, plus the improvements made in IFLS2, $2+, 3$ and 4 provided the base for the IFLS5 questionnaires. The goal was to keep the instruments as similar as possible across the four full waves in substantive content and questionnaire wording so as to maximize comparability to enable longitudinal analyses by users. Changes were made to correct mistakes considered large and important and to collect new data on topics of particular interest: new cognition tests, measures of personality, new subjective well-being measures and measures of sleep quality were some of the major innovations in IFLS5. Coverage and workings of public social safety net programs was updated. A few questions and modules from earlier waves were deleted, skip patterns were occasionally changed to improve the interview flow and new modules and questions were added.

Piloting of new or heavily changed modules was done in Magelang ,Yogyakarta and West Nusa Tenggara between October 2012 and April 2013. During this pilot new modules were tested mainly using paper questionnaires. The second pilot was focused on testing the CAPI program and was conducted in Yogyakarta between June and September 2013.

The instruments, software used for CAPI (CSPro), and field procedures were extensively tested before the fieldwork began. Protocols for locating and re-interviewing IFLS respondents were revised, based on IFLS4 protocols, and were tested and further revised during pilot tests and full-scale pretests for IFLS5. New questions and modules were developed and tested using focus groups and pilot tests. The household questionnaire and biomarker questionnaires were tested in their entirety during a full-scale pretest. The community-facility questionnaire had a separate pretest. Pretests allowed us to evaluate questionnaire changes in a field setting.

\section{Pretest of Household Questionnaire}

The pretest of the household questionnaire was conducted in Solo (urban) and nearby Sukaharjo (rural), Central Java from October to November 2013. The pretest focused on questionnaire content, field editing protocols, use of CAPI and general field procedures. Its primary objectives were to:

- Fully test the revised household questionnaire under field settings, separately for an urban and a rural area

- Evaluate the length of the questionnaire, the length of each module, and the burden imposed on different types of respondents.

- Evaluate the content of new questionnaire modules or those with major changes.

- Testing the use of preloaded materials for panel respondents

- Testing the use of CAPI program for data collection

We used 15 staff for the pretest, many of whom who had been senior field staff in earlier waves of IFLS and who were targeted to be senior field staff for IFLS5. The PI and co-PIs also participated. The three weeks were spent in thoroughly training the staff in the use of the revised questionnaires by using CAPI and further developing teaching materials that would be later used in training. This training was very participatory and as a consequence many questionnaire revisions were made as a result of discussions. Live respondents were brought into the meeting rooms during the period for practice. At the end, a formal full field test was conducted on 50 households ( 25 each, rural and urban) over a six day period. Based on debriefings from the pretest and on statistical analysis of the data, further changes were made to the questionnaires.

Considering that we had not used CAPI system before IFLS5 we also designed a new system of training whereby we emphasize that the interviewers should possess not only the knowledge on the questionnaire 
but also skills of operating the computer. For this purpose we conducted pre-test of training on March 24 to 20 April 17, 2014 in Yogyakarta to test an effective way to train interviewers using CAPI system. We recruited eight interviewers who did not have any interviewing experience.

CAPI Procedures. In previous rounds of IFLS we used paper and pencil questionnaires that were input electronically in the field after the interview for the household survey and for the community-facility survey. For IFLS5 we moved completely from paper and pencil to a computer- assisted personal interview system (CAPI).We chose to use CSPro after several consideration of other potential CAPI program, including MIMIC. One of the consideratons is that our programmers were very familiar and skilled in CSPro, In addition CSPro have certain advantages that suit our purpose. For example it is user friendly, it is easier for interviewers to navigate between questions and it is easy for them to go back in the program to correct any errors, something which is more involved in MIMIC, for example. Application in CSPRO is not server-based, it is portable and much easier to be combined with other software (such GPS, audio, photo). Furthermore we have been using CSPro to program our data entry in the past which make the transition to CAPI system easier. The development of data entry program took nearly 18 month starting in March 2013. Although the bulk of the program were completed in October 2013, further refinement of the program were made alongside the changes that were made in the questionnaire up to the main training in August 2014.

The CAPI data entry program was designed to accommodate not only entry data but also other functions such as the use of GPS measurement, audio recording, picture taking and other features to assist interviewer not to spend much time of respondent at the same time getting good quality data such as calculator functions and notes as well as checks for missing data and data consistency.

At the onset of the field work it is the enumerator's responsibility to install the right data entry program at the beginning of the data collection or whenever there is updated DE program. The interviewer has to make sure that the laptop is well charged before he /she can do the interview. When interviewers complete their interview they first edit it themselves by checking if there are calculation or notes that need to be entered. Then they check for missing data and run a program for consistency checks. All errors have to be examined and corrected before the data can be submitted to the data editor. The data editor will combine all the data files submitted by the interviewers and again errors will be checked. Data editor will copy the error log if any and given it back to the interviewers to make corrections. The completed data file will then be uploaded via a website specially provided for it. Uploading of the data was done daily. The data editor also has responsibility to listen to the audio recording as part of the quality control procedure. These recordings were either uploaded onto the website or (because of large file sizes) mailed back to our central headquarters in Yogyakarta (which took a maximum of 2 days).

Showcards were also introduced in IFLS5 to accompany the CAPI. For some questions it was useful to have showcards to help the respondents understand the question. Showcards were translated into five key languages in addition to Bahasa Indonesia (the CAPI was however only in Bahasa- if translation was required, this was done on the spot by the interviewer or a helper).

\section{Quality Control in CAPI}

Unlike in the paper-based interview, with CAPI system we do not have backup paper questionnaires which can be checked back later when necessary. It is therefore necessary to design quality control procedure that is suitable for CAPI system to maintain good quality data. Quality control was done in the field as well as in the headquarter in Yogya. In the field it was the responsibility of the supervisor and data editor to listen to the recording interview for selected random interviews. In the first two enumeration areas they had to listen to up to two interviews of each interviewer and thereafter randomly selected interviews. Supervisors also had the responsibility to do observation and verification of $10 \%$ of interviews. Verification was done by listening to parts of interview recordings. We also had a team of people in Yogya who listened to random parts of these recordings for random interviews and then compared answers to the electronic data. When discrepancies were found they got back to the teams, generally within 1 week of the original interview for interviewers to recheck questionable answers. This was a short enough time period that the teams could still get back to households to re-check answers. The details of our quality control procedures are listed in the table below.

\begin{tabular}{|l|l|l|}
\hline Quality Control In the Field & & \\
\hline First two EAs & & \\
\hline Task & Who & What to look for/listen for \\
\hline Observe first interview of each interviewer. & $\begin{array}{l}\text { Supervisor, } \\
\text { Data Editor }\end{array}$ & $\begin{array}{l}\circ \quad \text { Reading skills, delivery of questions } \\
0 \quad \text { Entry skills/accuracy (compared against data) }\end{array}$ \\
\hline
\end{tabular}




\begin{tabular}{|c|c|c|}
\hline $\begin{array}{l}\text { Listen to recordings of the first } 2 \text { interviews of } \\
\text { each interviewer (K roster, BA roster, and key } \\
\text { questions in } \mathrm{UT}, \mathrm{NT}, \mathrm{DL}, \mathrm{TK}, \mathrm{MG})\end{array}$ & $\begin{array}{l}\text { Supervisor, } \\
\text { Data Editor }\end{array}$ & $\begin{array}{ll} & \text { Adherence to protocols } \\
\circ & \text { Probing techniques } \\
\circ & \begin{array}{l}\text { Interview settings (background noises, presence of } \\
\text { other household members) }\end{array} \\
\circ & \text { Rapport with respondents }\end{array}$ \\
\hline \multicolumn{3}{|l|}{ All EAs } \\
\hline Task & Who & What to look for/listen for \\
\hline Observation of interview & $\begin{array}{l}\text { Supervisor, } \\
\text { Data Editor }\end{array}$ & $\begin{array}{l}\text { Each interviewer observed at least once, } 10 \% \text { random } \\
\text { sample of interviews after first }\end{array}$ \\
\hline Random audio checking & Data Editor & $\begin{array}{l}\text { One interview of each interviewer: } \\
\text { specific sections (K roster, BA roster, and key } \\
\text { questions in UT, NT, DL,TK, MG) }\end{array}$ \\
\hline Random verification & Data Editor & $\begin{array}{l}\text { One interview of each interviewer: house sticker, AR } \\
\text { who are HH members, who were interviewed. Verify } \\
\text { broadly TK, MG, RJ, RN. Whether US were } \\
\text { measured, EK tests were administered. }\end{array}$ \\
\hline HH completion rates & Supervisor & rates $<100 \%$ \\
\hline Book completion rates & Supervisor & rates $<100 \%$ \\
\hline US Completion rates & Supervisor & rates $<100 \%$ \\
\hline Proxy rates & Supervisor & Rates $>3 \%$ \\
\hline \multicolumn{3}{|l|}{ Quality Control In PIP/HQ } \\
\hline Audio checking & $\begin{array}{l}\text { Quality control } \\
\text { team }\end{array}$ & $\begin{array}{l}\text { Randomly selected interviews and problem teams and } \\
\text { problem interviews as evidenced by error logs } \\
\text { produced in the field: K roster, BA roster, and key } \\
\text { questions in UT, NT, DL,TK, MG. }\end{array}$ \\
\hline Random verification & $\begin{array}{l}\text { Quality control } \\
\text { team }\end{array}$ & rates $<100 \%$ \\
\hline $\begin{array}{l}\text { HH completion rates (including HH/T1 } \\
\text { tracking) }\end{array}$ & $\begin{array}{l}\text { Quality control } \\
\text { team }+ \\
\text { tracking team }\end{array}$ & rates $<100 \%$ \\
\hline Book completion rates & $\begin{array}{l}\text { Quality control } \\
\text { team }\end{array}$ & rates $<100 \%$ \\
\hline US Completion rates & $\begin{array}{l}\text { Quality control } \\
\text { team }\end{array}$ & Rates $<100 \%$ \\
\hline Proxy rates & $\begin{array}{l}\text { Quality control } \\
\text { team }\end{array}$ & rates $>3 \%$ \\
\hline Data review & $\begin{array}{l}\text { Quality control } \\
\text { team }\end{array}$ & $\begin{array}{l}\text { Compare against average or predetermined } \\
\text { thresholds: } \\
\text { Time of interviews (too short/too long) } \\
0 \text { Non-response rates (too high) } \\
0 \text { Variable missing rates (too high) } \\
\text { "Others" rates (too high) } \\
\text { "DK" rates (too high) } \\
\text { "Not applicable" rates (too high }\end{array}$ \\
\hline On demand audio checking & $\begin{array}{l}\text { Quality control } \\
\text { team }\end{array}$ & $\begin{array}{l}\text { HQ asks teams to send specific audio recording based } \\
\text { on data review when the regular audio recording is not } \\
\text { yet at HQ }\end{array}$ \\
\hline Individual (T2) tracking completion rates & Tracking team & \\
\hline Minikamades completion rates & Tracking team & \\
\hline
\end{tabular}

\section{Pretest of Household Tracking Procedures}

Because re-interviewing panel respondents was deemed to have been a key to the success of prior waves of IFLS, much effort was devoted to testing and training in procedures for finding households and respondents. We used the survey management information systems that we had developed for IFLS3 and 4 to make sure that all households and individuals had been interviewed as appropriate, that tracking had been done where it should have, and so forth. In May 2014 we conducted a field test for 7 days, in two locations: one in Semarang and one in Bantul, just south of Yogyakarta. We successfully tested both our tracking 
procedures and our management information system, as well as developed the training procedures to be

used. We tracked in actual enumeration areas and were able to find all of our target IFLS households, enumerated them and found split off households. This information was later passed on to the field teams.

\section{Health Measurement Pilot Test and Training}

During the main household pilot, we also conducted a pilot test of the new physical health measurements: the balance test for older adults. Unlike in previous rounds, in IFLS5 we did not use special teams for health workers. All interviewers were trained to conduct health measurement during the main household enumerators training.

\section{Pretest of the Community-Facility Survey}

The community-facility survey pretest was held on 6 to 12 January 2014 in Yogyakarta and followed by field practice interview in Solo from 12 to 17 January 2014. It was a full test of the instruments and procedures, in both rural and urban areas. There were 15 participants, plus the PI and 2 co-PIs.

\section{Field Staff for the IFLS5 Surveys}

The IFLS5 interviews were conducted by household and community-facility survey teams under the coordination of a field coordinator or assistant field coordinator. Seven field coordinators were assigned to head the teams in each of the province enumerated. They were senior staff who had been involved in previous waves of IFLS. In some provinces there were more than two teams under the same field coordinator, in which case the coordinator moved from team to team. Also the household team supervisors undertook some responsibility for the field coordinator tasks.

There were a total of 23 teams in the 13 provinces. The composition of the household and community-facility teams is as follows:

$\begin{array}{ll}\text { HHS Team } & \text { CFS Team } \\ \text { 1 Supervisor } & \text { 1 Supervisor/Data } \\ \text { 6-8 interviewers } & \text { Editors } \\ \text { 1 Data supervisor } & 3 \text { interviewers }\end{array}$

The interviewers were recruited from within the provinces in which were to interview by senior staff of Survey Meter, who traveled to visit the provinces. All applications were submitted to a Survey Meter web site.

Administrative selection were done prior the interview. The criteria for administrative selection include college GPA of at least 2.8, ability to work with computer, previous survey experience. After the candidates passed administrative selection they were called to conduct the next selection stage that was comprised of a cognition test and a computer skills test, and finally they were interviewed personally by Survey Meter staff.

Interviewers were selected to obtain an appropriate mix of language abilities. For example, the team that was sent to the island of Madura contained some Maduranese-speaking interviewers. Language ability was less of an issue for the community-facility teams, since most community-facility survey respondents were in a position of authority and thus likely to speak Bahasa Indonesia.

Team supervisors and data editors were selected among the pools of persons who had been working in previous surveys conducted by Survey Meter. They were selected based on criteria such as the previous experience and track record, knowledge of the local area, computer skills and leadership qualities. Many of them had experience in previous waves of IFLS. The names of the field staff in each province are listed in Table A.2.

\section{Training of Trainers}

Supervisory training was held for all senior personnel: supervisors, data editors and field coordinators of household and community-facility survey. The household team training of trainers was held in Solo, Central Java, from May 19 - June 1, 2014 with a total number of participants 46 persons, while the community facility team had their TOT training January 20 to February 2, 2015 also in Solo. Many of these personnel had participated during the household or community facility pre-test. This "training of trainers (TOT)" included reviewing all parts of the survey: household, community-facility, health, CAPI, tracking and the management 
information systems. The idea was to make everyone who had senior positions and would be involved in training of enumerators completely familiar with all aspects of the survey. Later, in the training of enumerators they assisted either as demonstrators or heads of groups during group discussion.

Each team (household and community-facility) was designated by a letter code. In addition, each team member received a two-digit numeric code, of which the first digit signifies the team member's job (see below for designations). The combination of the letter and numeric code uniquely identifies each field staff member. This information is recorded on every questionnaire book cover.

$$
\begin{aligned}
& \quad \begin{array}{l}
\text { Field Staff Codes } \\
01 \text { = Field Coordinator }
\end{array} \\
& 11=\text { HHS supervisor } \\
& 21=\text { Data/CAPI editors } \\
& 41=\text { CFS supervisor/CAPI editor } \\
& 31-38=\text { HHS interviewer } \\
& 51-53=\text { CFS interviewer }
\end{aligned}
$$

\section{Interviewer Training}

Household interviewer training was conducted in two phases and took place in Salatiga, Central Java. The training was divided in order to keep the number of trainees at any one time to a manageable level. Thirteen teams from South Kalimantan, South Sulawesi, West Nusa Tenggara, South Sumatra, East Java, Jakarta, and West Java, were trained in the first wave, from August 5 to September 12014 . Some 140 trainees took part of whom 112 were subsequently chosen as interviewers, data editors and supervisors for these teams, with some others being held in reserve as alternates, in case something happened to a team member, and others who were rejected. The second training, for 10 teams covering Central Java, Yogyakarta, Bali, North Sumatra, West Sumatra and Lampung ran during the period September 4 to October 1, 2014. There were 108 participants, out of which 98 were used as household enumerators, data editors and supervisors. Training for the community-facility survey ran from February 18 to March 10,2015 in Salatiga. We began with 106 trainees of whom 92 were chosen for field work.

Field work was divided into two phases, like the training. As soon as the first wave training was complete, the first wave teams went into the field. Likewise the second phase fieldwork began immediately after second phase training.

Each training session was divided into two parts. First there was classroom training, which involved lectures, nightly homework, demonstrations, group discussion and in-classroom practice with live respondents. "Dressrehearsal" field practice followed the classroom training, during which time the teams actually went into the field, near Salatiga, set up base camps, where they stayed and worked. Household interviewers received 19 days of classroom training and 4 days field practice. Household interviewer teams were assigned to interview certain households, and supervisors were responsible for making sure that the work got done, while CAPI editors check the quality of data. Community-facility survey interviewers were trained for 14 days in the classroom and 4 days in field practice. Similar method of training was also applied in Community and facility survey training of enumerators.

To facilitate the smooth running of CAPI system in the data collection, the first day of training was devoted for installation of the program onto the laptop and training introduction on standard operating procedures for CAPI that included how to operate CAPI for entry data, familiarization of all CAPI functions for entry data, modification of data, use of GPS, pictures, audio recording, back up and uploading data. Practice on the use of CAPI program during in class training was done during the demonstration, pair interview practice and "live respondent" interview. The substance of the questionnaire were given during the lectures that were usually delivered in the morning session, and a round robin using only paper questionnaires gave the participants opportunities to discuss questions with various simulation of cases that might came up in the field. This method of training ensures that the participants are well equipped with the skill of operating the CAPI program as well as good knowledge on the substance of the questionnaire 
A total of 23 pairs of teams (household and community-facility) were sent into the field; 210 persons working on household survey teams and 68 on community-facility survey teams (See Appendix Table A.2). An additional 12 staff worked in our central headquarters in Yogyakarta facilitating logging in and cataloging data, coordinating the logistics of sending money and supplies to teams, checking problems identified by teams, and using our management information system to check that questionnaires that were supposed to be filled out, were, and sending back lists of cases that needed completion (see Appendix Table A.3).

There were two phases of fieldwork, main field work and the tracking period. The main fieldwork periods went from September 2014 to first week of May 2015. As teams finished their main fieldwork period they began their long-distance tracking phase (from roughly mid-May to end of September). During main fieldwork, each pair of teams was assigned a route that would take them to 8-12 enumeration areas. Table A.3 indicates which teams worked where, and how many EAs were in each province. Teams worked in only one province, but some provinces required multiple teams. After the main fieldwork ended, some interviewers moved to different provinces to help locate and re-interview movers during the tracking phase.

Unlike in the previous rounds of IFLS where typically the household team worked in an enumeration area followed by the community and facility team, in IFLS5 the community and facility team started their field work after the household team finished their main field work. This method was facilitated by the CAPI system in that the sample of facilities to be visited by the community and facility teams that were drawn from the household survey and the frame and sampling could be done in advance. The facilities mentioned by household in the household survey could now be coded in advance by updating the codes of the facilities or assigning new codes for new facilities as the data from the household survey were received at the headquarter in Yogyakarta. This avoided duplicate codes and errors in the facility codes that were usually experienced in community and facility survey in prior waves and had to be corrected after the survey ended (before public release).

\section{Main Fieldwork}

In each EA, the following sequence of events took place:

1. The household supervisor (also the location assistant) made an advance visit to the EA to meet the leaders of the community, obtain local permissions, arrange a base camp, and scout for target IFLS households, and the location of IFLS households within the EA for interviewers to use while canvassing.

2. The household team arrived. Pairs of interviewers (typically one male, one female) were assigned households to contact and re-interview. ${ }^{19}$ Their initial task was to establish "first contact" with an IFLS target household member and complete the household roster. The supervisor would typically go with each team when they first arrived in an EA to help find the household for the first time. Interviewers were responsible for turning in a book T for every IFLS household target household, even if they were unable to locate the household or receive consent from the household to participate, and a book K for every household interviewed.

3. As household interviewers completed questionnaire books and performed health measurements, they checked for completeness and errors generated by the CAPI program and made corrections before submitting the data file to CAPI editors. After combining all data files from the enumerators the CAPI editors again checked the completeness and ran inconsistencies checks. When errors were found the CAPI editors give the list of errors to the interviewers to be corrected. Sometimes interviewers returned to the respondents to clarify answers. In addition CAPI editors also had responsibility to listen to randomly selected recorded interviews to further check the quality of data and to ensure that the interview had been done according to the established field procedure.

4. The household supervisor monitored progress using a variety of management information system forms, observed interviews that were randomly chosen, randomly visited households to check interviewers' work, listen to randomly selected recorded interview and handled financial and logistical issues.

\footnotetext{
${ }^{19}$ Male-female pairs were used because households appeared to feel more comfortable than when approached by two males, and it was more culturally appropriate to have female interviewers complete the questionnaire modules pertaining to pregnancy and contraception.
} 
5. The household supervisor in his/her role as location assistant, sometimes with the help of the 25 Field Coordinator, oversaw the collection of information about households or target respondents who moved, and worked with the team and the Field Coordinator to determine whether a mover could be tracked locally during main field work. If the mover was thought to be within a 45 minute trip by public transport, the team attempted to track the mover while working in the mover's origin EA (local tracking). In addition, for these local movers, the local community leader was sought out, usually by the household supervisor or the Field Coordinator, in order to fill out the Mini-CFS book.

6. The household supervisor also electronically transfered the data files to the central field headquarters in Yogyakarta. This was done by uploading data directly onto our field website, which was protected by security codes. The supervisor also copied the recording interview onto a $C D$ and mailed the CD with other MIS documents at the end of each EA. The supervisor also completed a financial report and mailed the receipts of expenses to IFLS headquarters in Yogyakarta.

7. Dried blood spots were stored in a cooler before they were packed using a "therapak" insulated envelope and mailed special mail to our headquarters so that they could be logged in and put into the deep freezer. They were not kept in the field for more than 3-4 days.

8. After the electronic data were received on our website the data were checked to make sure that all books that should have been filled in, were, and that data from those books were in the electronic files. Sometimes corrections were made in which case new files were uploaded to our Indonesia website.

9. After data checking was complete and the files deemed complete they were uploaded onto a security protected server at RAND under the supervision of Roald Euller, the chief RAND programmer on IFLS. If more changes were made later, new versions of the files were uploaded onto the RAND server.

10. The community-facility team began interview in an EA, after the completion of household interviews. The community-facility survey supervisor drew the facility sample, assigned interviews to the interviewers, completed the Service Availability Roster (SAR), and assigned identifier codes to facilities on the SAR.

11. The community-facility interviewers conducted their assigned interviews and submitted to the CAPI editor after all error and consistency checks had been done and corrected. The CAPI editor again checked the completeness and ran consistency checks. When errors were found the CAPI editors give the list to the interviewers for correction. Sometimes interviewers returned to the respondents to clarify answers. In addition CAPI editors also had the responsibility to listen to randomly selected recorded interviews to further check the quality of data and to ensure that the interview had been done according to the established field procedure.

12. The CFS supervisor monitored progress using a variety of management information system forms, observed interviews that were randomly chosen, randomly visited households to check interviewers' work, listened to randomly selected recorded interviews and handled financial and logistical issues.

13. When all community-facility interviews were completed the supervisor completed a financial report and mailed the receipts of expenses along with the $C D$ of recorded interviews that had not been uploaded onto the website to the headquarter office in Yogyakarta. Like the household data, CFS data were uploaded onto our IFLS data upload website at RAND and then downloaded by Euller.

\section{Tracking}

Once each team had completed work in all of its assigned EAs, the household interviewers were given additional tracking assignments for households or individuals that had not been located during the main fieldwork period but were thought to reside in that province. In addition to being provided with the names of the households and individuals that needed to be tracked, the teams were given the tracking forms $(T 1, T 2)$ that had been collected in the origin EA (with contact information, for example, from local informants) and in prior survey waves (a complete file on each household of where it had ever been found and contact information) about the potential whereabouts of each case. If an EA showed a low household re-contact rate that we thought could be raised through revisits (for example, if households had been located in the original EA but had not been able to participate at the time the team was there, or if information on movers was 
inadequate), the teams were asked to return and try to re-contact households or to obtain better information 26 on movers. Also, if a prime-aged, healthy person had not been found, so a proxy book used to acquire information, an interviewer was sometimes sent back to attempt to find and interview that person. Also if several persons in a household had been missed by the health workers, they were sent back to get measurements.

Managing the tracking information was centralized in Yogyakarta, and tracking assignments were made from there after consultation with the team's Field Coordinator. Tracking progress was monitored daily from Yogyakarta based on completion reports from the field. Records of each household's and target individual's interview status were maintained in an electronic database, which was developed from the survey data entered during the main fieldwork and updated as cases were completed. The fact that we had information on who needed to be tracked along with their whereabouts played an important role in the success of our tracking.

The tracking phase was one of the most arduous in terms of managing the work and keeping the staff motivated. We judged it important to centrally monitor success rates and set work priorities. As interviewers tired and remaining cases became more stubborn, we assigned smaller and smaller tracking teams. The most talented field supervisors were sent to particularly difficult areas, where they worked with tracking teams and on their own to pursue respondents' whereabouts. Teams and sometimes respondents were visited by the RAND project director and assistant directors, as well as by senior staff from the central office. Team prizes in the form of interviewer bonuses were offered to the five teams with the best records in finding respondents.

\section{Data Entry, Verification, and Data Cleaning}

\section{During Field Work: CAPI Editing, Interviewer Rechecks}

As we moved to CAPI the burden of entering the data and the first attempt at identifying errors generated by CAPI was the responsibility of the interviewers CAPI editors then combined all the data files submitted by the interviewers and again errors were checked. The CAPI editor then copied the error log if any and gave it back electronically to the interviewers to make corrections.

The CAPI editor was responsible for resolving error messages with the interviewer. Some errors could be resolved fairly easily. For example, the interviewer might mis-remember the sex of a respondent interviewed earlier in the day and verify that the inconsistency was due to a careless error. Other errors required the interviewer to return to the household and check with the respondent. For example, if in section TK, a person reported income from self-employment, the interviewers checked sections UT and NT to see if we had a corresponding entry there. If not they would go back to the household to re-check.

When the team's work was finished for an EA, the data were uploaded to our website and subsequently downloaded by Roald Euller at RAND. Uploading of the data to the IFLS website was done daily.

\section{- In Yogyakarta}

A team in Yogyakarta performed basic data quality checks, listening to randomly selected recorded interview to monitored re-contact rates, and provided feedback based on findings they found to the teams in the field.

\section{Post field work data checking}

Post field work data checking included the following:

1. Examining the data for duplicate pidlinks and fascodes and recommending fixes for those cases. There were several errors in pidlinks that were found, discussed in User's Guide Volume 2, that basically involved individuals who were thought to be new in IFLS5, but who were actually panel respondents.

2. Entering fascodes for facilities into the household data where they should appear, such as codes for the health facilities visited in modules RJ and RN.

3. Checking line numbers in AR, for instance of mothers and fathers, to be sure they were correct.

4. Corrections for data errors in the very early enumeration areas due to errors (corrected later) of the data entry program.

5. Checking for any sex changes for panel individuals (none were found).

6. Some facilities had duplicates in the data base, but appeared as separate facilities because their facility codes were different. This occurred when some EAs were located so closely together that 
some facilities could appear in mulitple EAs. In the field, it was sometimes difficult to know whether 27 the facility had appeared in other EAs or not, especially if the field teams for those EAs were different. In principal we want duplicate facilities in different EAs to have identical facility numbers. To allow for this, we did extensive checking on facility codes, comparing between names, addresses, locations, GPS data on locations, and also interviewer notes.

7. In the field we used 2013 BPS location codes that were preprogrammed into the data entry laptops. These codes were later updated to 2014 codes (appropriate for the 2014 SUSENAS). This required obtaining a crosswalk for the two years' codes and crosswalks going back to the last codes we had used for prior waves of IFLS. Unfortunately the crosswalks, obtained from BPS were incomplete and had to be updated by hand. This took time and care and was done by a small team in Yogyakarta under the supervison of Witoelar. Once this crosswalk was created, we created the variable SC21, which indicates whether the household has moved out of the village, out of the kecametan, kabupaten, or province.

\section{In Yogyakarta and Washington D.C.}

In Yogyakarta and Washington D.C. we did additional cleaning to correct remaining errors and to make the publicly available files as easy to use as possible.

\section{Occupation and sector codes}

We continued our practice to assign occupation and sector codes from the descriptions that respondents provided. Yudo Wicaksono, a post-doc at Survey Meter was dedicated to this task, supervised by Witoelar. This involved using a programmed dictionary of terms and assignments from those terms to 2-digit occupation and 1-digit sector codes. This was a fairly long and tedious iterative process. Roald Euller did the programming and sent outputs to Wicaksono to check and resolve.

\section{New PIDLINKS, COMMID and MKID}

As in prior waves, new pidlinks were created after lookups and checks for duplicate pidlinks. Also new COMMIDs and MKIDs had to be created for new 2014 movers. The latter two required the location codes to be updated as described, Witoelar took charge of this task.

\section{HTRACK and PTRACK}

New HTRACK and PTRACK files had to be created. To do this required constructing several new variables such as SC21, and variables such as RESULT14 and MOVER 14. See Volume 2 of the User's Guide for more details. This was done by Euller, under the supervision of Witoelar.

\section{Module Checks}

For each data module, we made an effort to

- Create or correct $X$ variables so that the special codes were preserved and the associated numeric or character variable contained only valid responses. X variables are associated typically with a numeric value and indicate whether or not the person was able to answer the question (see the User's Guide for more details about X variables).

- Check that TYPE variables exist in grids (see the User's Guide for details about TYPE variables).

- Check for duplicate observations.

- Find and drop any variables that might enable identification of a respondent.

\section{Created Variables and Files}

We created some variables and data files to make the data easier to use. For example:

- Variable MOVE14 summarizes the information on a household's current location relative to its location the last wave it was found in.

- Data files HTRACK14 and PTRACK14 indicate what data are available for households and 
individuals (respectively) in each survey wave. Population weights and complete location codes 28 for district and sub-district are also included, as are special survey variables allowing users to link the households to the communities where they live.

- The district and sub-district location codes based on BPS codification have been provided in order for users to link IFLS with other, national data sources such as SUSENAS or SAKERNAS. In addition, since BPS codes change across years, in some cases multiple year codes are available.

- Since the age and date of birth information can be very different in different questionnaires, we construct our "best guess" of each person's age using all of the data in IFLS5 and report this in PTRACK14. This was also done for IFLS2, 3 and 4 and we use the same algorithm, so that one has consistently derived best guesses for these two very important variables from each wave.

- Variable PPCHILD indicates whether a PP child preloaded roster was used. If so (PPCHILD = 1), a line number in the IFLS5 child roster refers to the same individual listed for that line number in the IFLS1, 2, 3 or 4 child roster. 


\section{Appendix B: Description of the IFLS5 Household Survey Questionnaire}

This appendix expands on the summary presented in Section 2 for those interested in more detail about the IFLS5 household survey instrument. Other details appear in the IFLS5 User's Guide (WR-/2-NIA/NICHD, 2016).

\section{Tracking Forms:}

The tracking forms, T-1 and T-2 and Book T are not released in the public files because they contain private information, but we describe them here because it is helpful to understand the tracking procedures. The tracking forms contain information needed to track and contact households or individuals who moved within the IFLS study area (form-1 for households and form-2 for individuals). The tracking forms were filled out whenever a tracking book, Book $\mathrm{T}$, indicated that the household or an individual within it could not be found (and the individual was one who was supposed to be tracked). The tracking forms contain information on the address and location of the household or individual being tracked; the name of informants in the origin and destination areas; the place of work of the head of household, the spouse or any other member of the household who works; and a sketch of the route taken to get to the tracking location.

\section{Book K: Control Book and Household Roster}

The interviewer completed this book, or a portion of it, for all households interviewed in IFLS4. Module SC indicates the precise location of the household. Much of this information is suppressed in the public-use data to protect respondent confidentiality.

Household roster. Module AR (the household roster) was preloaded into CAPI with the name and characteristics of each member of a household interviewed in any prior wave (the information came from the last wave in which the household was found). Module AR is designed as a cumulative roster of everyone who was ever found in this household. The interviewer updated the preloaded information on those who were household members in previous waves and added new household members. The roster was used to indicate whether each past member was still living in the household and to enter basic information on age, sex, marital status, relationship to the head of the household, presence in the household of the individual's mother, father, and spouse, religion, whether the respondent worked or was in school, earnings in the last year (although detailed, individually reported earnings information was collected in book 3A), and highest level of education. For individuals who had left the household since the last wave the household was found, information was collected on the reason for and date of departure (or death) and the person's current location. For individuals who joined the household since the last wave covered by the preprinted forms, information was collected on the reason for and date of entry into the household. For persons who died since 2007 a special, new exit interview was given to a proxy who knew the respondent well.

House characteristics. Module KRK contained interviewer observations regarding the dwelling and its sanitation.

Information on repeat visit. Module IK is not in the public use data because it contains private information. This information included the name and address of a local family or friend who might be able to provide location information in the future should the household move.

Questionnaire tracking form. Module FP is also not in the public use data set. It helped the teams track which household members needed to be tracked and which members answered books.

\section{Exit Form}

This was new in IFLS5 and designed to obtain more information about informants who died, in part to make IFLS more conformable with the Health and Retirement Study (HRS). We had limited information in Book K about respondents who died, notably their date of death, but not much other information about their lives in the period before death. Here we obtained information on the respondent's health and life conditions in the period immediately before death. Date of death was recorded along with some limited cause of death data. We also collected information on where the respondent died, whether the respondent was employed before death and if so at what, their health a year before death and a list of chronic health conditions and whether the respondent had been diagnosed with each of these, and when. We also obtained some limited information on the respondent's cognitive status before death, whether the respondent had fallen and seriously injured 
themselves in the two years before death, pain prevalence in the two years before death, ADL information 30 for the 3 months before death, smoking and drinking behaviors in the two years before death, out of pocket medical expenses in the 6 months before death and funeral expenses.

\section{Book 1: Household Expenditures and Knowledge of Health Facilities}

This book was answered by the spouse of the household head or by another person knowledgeable about household affairs.

Consumption. Module KS recorded information on expenditures for a variety of food and nonfood goods and services, including foods purchased and the value of foods consumed from self-production or transfers in the last week, personal care and household items bought during the last month, and durable goods bought in the last year. Quantities and purchase prices for the last purchase of several staples were also collected, for various foods. The KS expenditure categories were kept identical to that in IFLS2 and 3, so that household expenditures between these waves are comparable. Note that for non-foods there is a lack of comparability with IFLS1 because of the way in which the expenditure information on nonfoods was collected in 1993. In IFLS4 quantity information was added for rice and this was retained in IFLS5. Together with production information added to Section UT in Book 2, this will allow for users to calculate net production of rice, an important variable in the analysis of many policies.

Assistance. Module KSR, asked the respondent about assistance from key public transfer programs, new since 2007. Specifically we get details separately, about the receipt of subsidized rice in two programs: Raskin, a program of letting poor households access rice at subsidized programs, and market operations, which distributes rice and a few other foods to households. We collected information on receipt of two other programs, targeted towards the poor: an unconditional cash transfer programs, BLT 2008, which turned into BLSM, and a new conditional transfer program, set into place in late 2007.

Knowledge of health and family planning services. Module PP probed the respondent's knowledge of various outpatient health care providers, both public and private. The name and address of known facilities were collected and the respondent was queried about the distance, travel time, and cost of travel to the facility. This information was used to compile the sample frame of health facilities in the community-facility survey.

The crime module entered into IFL4 was dropped because very little information came out of it, there were very few reported cases. In COMFAS we have a module on local conflict.

\section{Book 2: Household Economy}

Book 2 was answered by the household head or other person knowledgeable about household affairs.

Household characteristics. Module KR included questions about the physical infrastructure of the household and participation in certain programs, especially public social safety net programs.

Family farm and nonfarm businesses. Modules UT and NT focused on household revenues, expenses, and value of assets of household-owned agricultural and nonagricultural businesses. In Section UT we asked about details of rice production. We ask the number of rice crops grown in a year on rice land and asked about each of the rice crops: area, production of paddy and production of milled rice equivalent. We also asked prices and values of production. Comparing milled rice production with rice consumption in Section KS will provide an estimate of net rice production. We also began using unfolding brackets to elicit net income from UT in the cases in which the farmer was not sure. Unfolding brackets have become commonly used in many advanced surveys. They have proven to cut answers of don't know. We started with a bracket that is based on information from IFLS4 supplemented with other sources such as SUSENAS and then allow the respondent to go to higher or lower brackets, depending on the first answer. CAPI randomizes the start point of the brackets, a procedure which has been found to cut potential statistical biases from this procedure. In the asset grid, both for UT and HR for the data files, we add variables to indicate the break points for each individual asset. For example, UT11p, we would now have UT11pA for farm land, and so forth. The data might be 111 which indicates the middle breakpoint followed by the lowest branch.

In Book NT we had three questions trying to elicit firm net income. In addition to a question on net profits, we asked questions on the value of production used for household consumption, the value of business net income used on household expenditures and the amount of cash left over. The sum of these three can be used as an estimate of net profits of the business, in addition to the direct question (see Lisa Daniels, 2001, "Testing alternative measures of microenterprise profits and net worth," Journal of International Development, 13:599-614. .We also add unfolding brackets to NT to elicit net profits when they are not known. . 
Household non-business assets. Module HR asked about the current value of household non-business assets (e.g., housing land, livestock, jewelry), as well as ownership shares. Unfolding brackets were introduced in IFLS4 and continued in IFLS5.

Household non-labor income. Module HI asked about household-level nonlabor income, by source.

Natural Disasters This section was new in IFLS4 and continued in IFLS5. In it we asked in detail about separate types of natural disasters in the past 5 years and their consequences. We asked about earthquakes, tsunami, floods, mudslides, as well as civil violence. We asked about losses from the disasters such as assets destroyed and expenses on medical injuries and funerals, whether household members had to move in response and if so to which type of housing facility. We also asked about assistance the household received and the source.

Borrowing history. BH was a new module in Book 3B in IFLS3 and was moved to Book 2 in IFLS4. It stayed in Book 2 in IFLS5. This means that BH is asked at the household level instead of the individual level. This was done to save time. The structure was kept as in 2007.

The section on Avian flu, added in IFLS4, was removed because it was not a major health issue in 2014 .

\section{Book 3A: Adult Information (part 1)}

This book elicited current and retrospective information from each household member age 15 and older. For age, the interviewer read the age that was pre-loaded from book $\mathrm{K}$ and pressed enter to confirm if the preloaded age was correct. If the respondent did not agree with the pre-loaded age:

1. If the individual respondent was NOT the same as the one who answered book $K A R$, then a warning message popped out, and the interviewer recorded the age provided by the individual respondent.

2. If the individual respondent was the same as the one who answered book $K A R$, then an error message popped out and the respondent had to correct the answer either in Book 3A or in book K. The age was forced to be consistent by CAPI. The same procedure was used for age in books 4,5 and US. Book $3 \mathrm{~B}$ was linked to Book $3 \mathrm{~A}$ and so no checking of age was done for $3 \mathrm{~B}$. This procedure was different from prior waves, and was allowed for more easily than before because of CAPI.

Education history. Module DL recorded the highest level of education attended and highest grade completed for new and panel respondents 50 years and older. Retrospective details by level of education are not collected for respondents 50 and over. For new respondents under 50 and panel respondents who had answered DLA in book 5 in IFLS4 (they had to be under 50), we get detailed retrospective information for each level of schooling that the respondent attended (elementary, junior high, senior high and postsecondary) in order to be able to construct schooling progression histories. The detailed information included for each level of schooling (primary, junior high school, senior high school and university) the start and stop dates, the number of grades completed within the level and if still enrolled which grade, details about specific grades failed, the type of school, the name and location of school (for those still enrolled), EBTANAS scores or their successor, the UAN/UN achievement test scores were collected for those still enrolled or those under 30. Details about school expenses, scholarships received, class size, travel time, and whether the respondent worked during school were collected for those enrolled currently or during the last year. Information on schooling interruptions, are also in Section DL.

Panel respondents under 50 who had answered DL in Book 3A in 2007 were asked the same details about their schooling since 2007 as new respondents and, separately, an abridged set of questions about their schooling before 2007. The abridged questions included all the questions for the new respondents except for the test scores and school address information. The latter two questions take a lot of time and so we did get economies by not getting them from panel respondents over 30 or currently enrolled.

The same structure was used for DLA in Book 5. This allows users to much more easily construct schooling transitions between levels.

Subjective welfare. Section SW asked subjective welfare questions. We continued to ask two kinds of questions, used first in IFLS3. We also asked a question on general happiness introduced in IFLS4, taken from the United States' General Social Survey and in IFLS5 we added a question on life satisfaction, with a 5 point ordinal scale. The questions from IFLS3 first includes a ladder question, similar to that used in the Russian Living Standards Monitoring Survey. It asked a person if there are six steps on a ladder, the poorest person being on step 1 and the richest on step 6, on which step would he/she place themselves now. In IFLS5 we have a showcard with a picture of the ladder, which we showed respondents to give them a 
better image of what we were after. We also asked people to place themselves on the same ladder five years ago and where they expect to be five years from now. In addition to the ladder questions we asked people about specific domains of their standard of living, such as their overall standard of living, and adequacy of food consumption and healthcare. For respondents with children, we also asked about the adequacy of their children's food consumption, healthcare and schooling. For each of these, we allowed answers of: it is less than adequate for their needs, just adequate, or more than adequate.

We added a new section, PNA, in IFLS5, which asks questions about hedonic well-being felt yesterday and was taken from the Health and Retirement Study (HRS). Dr. Arthur Stone and Dr. Jacqui Smith were heavily consulted on this section, that they designed for the HRS. A list of 12 words, both negative and positive feelings, were given and the respondent recorded on a 5 point ordinal scale whether they felt this feeling and how much, yesterday. The words included frustrated, angry, sad, happy and enthusiastic. The ordering of the first 11 words was randomized in CAPI, but the final word was always pain. After this more detailed questions about pain were included, including regarding the severity of any pain and on which body part the pain was felt. This section was heavily pretested to make sure the words translated easily into Indonesian. While this module is not the same as the Kahneman's day reconstruction method, it is an attempt to obtain at least some indication regarding hedonic well-being.

Individual nonlabor income and assets. To round out the information on individual-level economic wellbeing, module HR asked respondents about the current value of their non-business assets (e.g., land, livestock, jewelry), as well as asset ownership and ownership shares. Module $\mathrm{HI}$ asked about non-labor income by source. Unfolding brackets were introduced in IFLS4 and continued in IFLS5.

Marriage history. Module KW obtained a complete marriage history from new respondents, including the start and end dates of their unions, characteristics of former or non- resident spouses, and dowries and living arrangements in the first marriage. Panel respondents were asked about the current marriage and any other marriage that had begun within the past seven years. We added questions about current and past coresidence in IFLS4 and continued to ask about co-residence in IFLS5.

Household decision-making. Module PK asked respondents who were currently married and who had lived with their spouse in the past six months, about who made decisions within the household, and the relative status of the husband's and wife's families at the time of marriage.

Pregnancy summary. Module BR elicited, from ever-married new women respondents older than 49, information about all pregnancies (women 15 to 49 answered these questions in book 4).

Migration history. Module MG collected information on the geographic mobility of individuals, as well as the causes and consequences of migratory movements. Information was recorded about the respondent's location at birth, age 12, and each subsequent location where a move crossed a desa (village) boundary and lasted for 6 months or longer. For each move, data were collected on dates and locations, motivation for moving, and distance moved. Panel respondents were treated differently from new respondents, as was the case for other modules. They were asked about location changes since the time we saw them in 2007.

Employment history. Module TK asked in depth about respondents' current and retrospective labor market experience. Work was defined broadly to include formal and informal, full-time and part-time, and seasonal and year-round labor. Occupation, sector, type of employer, and hours and wages for up to two jobs were recorded for those employed at the time. An abridged set of employment information was collected for each of the years since 2007 (for primary job) and for the first job. Open-ended descriptions of occupation and industry were converted into standard ITC (2-digit) codes (see IFLS3 User's Guide for details).

In IFLS4 we had added to TK a sub-section on firings and quits in the last 5 years. This was kept in IFLS5. Special emphasis was placed on the receipt or not of severance pay, as dictated by Indonesian law under certain conditions. We asked questions about employer-based pensions. We got pension payment information detailed by whether the payment was a lump sum or an annuity, both of which are used in Indonesia..

Retirement. This was a new section for IFLS4, kept in IFLS5, inspired by the different Health and Retirement Study-type surveys around the world. We asked individuals 50 and older about whether they considered themselves to be retired, semi-retired or not and then got details about the retirement and pensions, if there were any. The earliest retirement age in Indonesia is 55 and it was thought that people younger than 50 would not be focused on retirement yet. As users will see from the data, retirement in a poor country like Indonesia is a fuzzy concept, with no set retirement ages for many jobs, especially in farming and other selfemployment. 
Risk and time preference. In IFLS4 we added a short section trying to elicit attitudes towards risk and time 33 preference. This was kept in IFLS5. Recent work in the Mexican Family Life Survey (MxFLS) has suggested that potential biases are not so severe using hypothetical questions compared to doing experiments with real payouts, sizable relative to current incomes. Our Section SI was patterned after the questions used in MxFLS. For both risk and time preferences, we used two sets of questions, one with smaller imaginary payouts, one with larger payouts. In IFLS5 we made one important change in both these sections. We randomized which set of questions were asked first, regarding the smaller or larger imaginary payouts. The smaller payouts, Rp800,000 per month is the certainty payout and this amount is considerably larger than mean monthly earned incomes. The larger certainty payout, Rp 4 million per month, is close to ten times mean monthly earnings.

Trust. Section TR was new in IFLS4, and again kept in IFLS5, with some changes. We asked questions about trust of neighbors. We started with general questions on trusting other people in the village, and went to specific questions about whether respondents would leave their children with their neighbors. We also used a series of questions on whether money found in a lost wallet would be returned to the rightful owner if certain types of people in the village found it. We also added questions on individual religiosity, such as how many times a day a person prays and how often they attended prayer meetings in the last 12 months. We dropped a question about keeping Halal because almost all Muslims in IFLS4 answered that they did. Other questions about religiosity were asked of Christians or Hindus. Finally, we asked questions on tolerance of people of different faiths, such as whether how respondent would feel about a group with a different faith or sect build a place of worship in the community, whether the respondent would rent a room to a person of differing faith or let such a person marry their child or close relative. We also asked about how important a candidate's religion or religiosity is in determining how the respondent would vote in an election. The election questions were changed a little from IFLS4 to make them more clear.

\section{Book 3B: Adult Information (part 2)}

This book elicited current and retrospective information from each household member age 15 and older.

Smoking. Module KM asked respondents whether they currently smoked, and if so, how much. Respondents who had quit smoking were asked when they quit and how much they had smoked before quitting. We asked about prices paid for different brands of tobacco.

Health status and physical performance. Module KK asked a variety of questions about health status. In IFLS5 we continued to revamp the ADLs and IADLs to make them conform better with the HRS. We now have 5 ADLs and 6 IADLS, plus 11 measures of physical functioning. If the respondent needed assistance with their physical functioning, we asked questions about who helped and how much, for up to 3 helpers. We also asked a set of questions on the types and times of physical activities engaged in, in all parts of life: work, home and exercise. These were taken from an international survey on physical activities. We again asked expectational life expectancy questions, taken from HRS, which we had included in IFLS4. Module CD asked about whether the respondent had been diagnosed with a set of chronic conditions like hypertension and heat attack. In other HRS surveys these are asked to be doctor diagnoses. Because in poor countries so many do not see doctors, we asked about any modern sector diagnosis, and asked the type of practitioner that gave it: doctor, nurse, paramedic, trained mid-wife. Module MA, from previous waves, asked about symptoms in the past four weeks and about experience with conditions symptomatic of heart disease, diabetes, and high blood pressure. We also asked questions in MA about automobile accidents and any falls a person may have had in the past two years.

Mental Health A new section, KP, was added in IFLS4, and kept in IFLS5, to ask questions related to depressive symptoms. IFLS1 and 3 had a set of 8 questions, but in order to make IFLS more comparable with international surveys, including the HRSs, we replaced our questions with those from the short CES-D scale, a series of 10 questions which is one of the major international scales of depressive symptoms.

Cognitive capacity In iFLS4 we added a section on cognition. This was added to in IFLS5. We started in section CO with questions from the Telephone Survey of Cognitive Status (TICS). We asked awareness of the date, using either a Gregorian, Islamic or lunar calendar. Then we asked awareness of the day of the week, and then a self-reported memory question, with answers excellent, very good, good, fair and poor. Then the respondent was asked to serially subtract $7 \mathrm{~s}$ from 100 (this was added in IFLS5). Then we gave an immediate and delayed word recall, of 10 nouns. These were read slowly to respondents and then the respondents were asked to repeat back the list, once immediately after the list was read and a second time some 4 to 5 minutes later after the respondent had completed Section MA. This is standard practice in other surveys that use word recall. We used 4 lists of words, which were randomized across individuals within the household, so that one person could not learn from another's experience. 
For respondents 50 and over we asked in Section COB for them to name as many animals as possible within 60 seconds. This is an often used measure of verbal fluency. We did not count imaginary animals nor repeated animals. However, different types of the same species, such as different types of monkees, were counted. We also did a timed count backwards from 20 as fast as possible for the same respondents 50 and above. We also asked respondents 50 and over to copy a drawing of two overlapping pentagons, to test whether they could follow simple instructions. This question was carried over from IFLS4.

Perhaps the most important addition to the cognition section is in module $\mathrm{COB}$, an adaptive number series test that was adopted from HRS, with changes, under the direction of Dr. John McArdle, with advice from Dr. Robert Willis. This was given to all respondents aged 15 and over. The HRS number series question has been shown to be highly correlated with financial wealth of the elderly in the US. Consequently this was thought to be a very important addition to IFLS.

There were 15 questions total in the number series test, but each respondent answered only 6 . The first three questions were the same for all respondents, but the next three depended on how many of the first three were answered correctly. Consequently in the data file, there are missings for 9 of the 15 questions, which 9 being different for different respondents. There is a variable that indicates whether the answer given was correct. A composite correct score based on psychometric analysis by John McArdle is being provided as well.

We were worried about the degree of difficulty of the HRS test in a low numeracy country like Indonesia. To adjust for this, we added some easier questions, keeping a number of the HRS questions to the answers could be later scaled to be comparable. This adjusted set of number series questions was pretested extensively in Indonesia, in two different provinces and both in rural and urban areas. As well the Mexican Health and Aging Study (MHAS) pretested the same questions in Mexico. A report analyzing these pretest data, written by McArdle, is available on the IFLS website.

For the pretest we received a grant from an NIA grant to the USC-UCLA Bio-demography Center. Separately Dr. Rebeca Wong pretested the same questions in Mexico, for MHAS, using funds from an NIA grant of Dr. Willis. The major issue we faced was that the HRS questions were potentially too difficult for a large portion of potential IFLS respondents. John McArdle, working with his colleagues and also Richard Woodcock, developed a series of questions that spanned the more difficult parts of the HRS questions but included easiest parts. The easiest question was the series 1,2,3, ?. There was also initial concern that respondents could not recognize numbers, so we also experimented with using pictures of common animals such as chickens. The problem with using pictures is that the respondents have to count them before answering the question, which was not required in HRS. We piloted both versions and found that respondents strongly preferred the numbers and that even those with no schooling could recognize numbers. We thus decided for the formal pretest to use numbers.

The Indonesian pretest was done in two places, one near Yogyakarta in central Java and one in Lombok, in West Nusa Tenggara, in the spring of 2013. Lombok is one of the poorest areas where we field IFLS and the place near Yogyakarta is a more central place. In each area we chose both an urban and a rural area for the pretest. We also stratified our respondents by age, trying to get a roughly equal number of men and women. Older, rural respondents in Indonesia will generally have little if any education, which is what we found. Our total pretest sample size was 393. Of these, 91 had no schooling and 188 had some or completed primary school. Still we had 54 who had some or completed senior high school, so we did cover the upper ranges of the cognition in our population. We found that even those with no schooling got some of the questions correct. Indeed there was a nice distribution of the number of correct answers even among those with no schooling. As one would hope, easier questions had a much larger proportion correct than harder questions. The report by McArdle summarizes these pretest results for both Indonesia and Mexico.

After the pretest, McArdle arranged the 15 questions into an adaptive format, which each person getting 6 questions. The same first three questions were asked of every respondent. The next three questions depended upon how many of the first three were answered correctly. This was programmed into CAPI so that each respondent got the correct second set of three questions. In addition to scoring each answer we are releasing a score based on an algorithm developed by McArdle and used by HRS.

Personality Section PSN is new in IFLS5. We used the Big Five Index 15 (BFI 15), which is a set of 15 adjectives representing all 5 of the big five personality groups, 3 words for each of the 5 . It is a subset of the $\mathrm{BFI} 44$. A five point ordinal scale was used to represent how well the respondent believed that attribute to represent them. This scale is used in many population surveys, such as the German socio-economic panel (GSOEP). We experimented in pretests with the 26 item scale used by HRS, which is the same as that used in MIDAS, but several of the words in that scale did not translate easily into Indonesian. We did not have that problem with the BFI 15 scale. Survey Meter staff did the initial translation of the 15 words into Indonesian. Then two independent outside translators were hired and re-translated back into English. The re-translations agreed except for 2 or so cases. For these, the Survey Meter staff translated again into Indonesian, then 
gave those translations back to the 2 outside translators who re-translated into English. This process continued until convergence of the English re-translations with the BFI 15 English. Four lists of the same 15 words were constructed and which list was used was determined randomly in CAPI. Dr. Brent Roberts provided significant advice for this module and Dr. Angela Duckworth provided advice as well.

Sleep Section TDR asked ten questions, five on sleep quality and five on sleep deprivation and its consequences. The questions were retrospective over the last 7 days. A five point ordinal scale was used to indicate agreement or not with the statements. These questions are a small subset of questions used by PROMIS. The adjectives were translated and re-translated following PROMIS guidelines. Survey Meter staff did the initial translation into Indonesian. Then two independent outside translators were hired and retranslated back into English. The English re-translation agreed with the Promis English. Dr. Joan Broderick provided extensive advice and help on this section.

Early Health and Childhood SES Sections EH and SA are new sections in IFLS5. IFLS has always included a substantial amount of retrospective questions, on marriage history, birth history, migration history, work history and so forth. For respondents who came into IFLS at mid-or older ages, we do not have information about health during childhood, nor about many family socio-economic circumstances during childhood. We have tried to fill in this gap with these two sections. We included a general health question about health before age 16 (on an excellent, very good, good, fair, poor scale). This question has been successfully used in several other studies including HRS and CHARLS. We asked about certain health conditions during childhood, including whether the respondent had certain childhood diseases and had to be hospitalized for over 1 month. For the socio-economic environment we asked about age 12, which is an age we have other background questions already in IFLS. We asked about the number of rooms in the dwelling, how many people lived there, whether the respondent was living with their biological mother and their biological father, whether their parents were still married, how many older and younger brothers and sisters lived in the household then, whether either parent smoked, drank heavily or had mental problems, the number of books in the household (on an ordinal scale) and the occupation of the main household breadwinner. These questions are a subset of questions from the life history modules of ELSA and SHARE, used by CHARLS for example.

Health insurance Section AK, was repeated from earlier waves, but we updated the list of health insurance programs that were checked.

Health benefits and health care utilization. Section RJ asked for information on health care utilization, including from whom and where medical care was received, how much it cost, who paid for it, how far the respondent traveled, and whether drugs were purchased. Detailed information was collected on outpatient visits during the last four weeks (module RJ) and on inpatient visits during the previous 12 months (module $\mathrm{RN}$ ). Following IFLS4, details of each visit were asked only for the last visit in the reference period, not all visits as was the practice in earlier waves. The number of visits in the reference period was asked, as was the total costs on all visits, in addition to the details on the last visit. At the end of RJ respondents were asked about preventive checks for prostate cancer, papsmears and mammograms. Respondents were also asked about the type and cost of any self-treatments administered in the previous four weeks (module PS).

Food Frequency In section FM we asked a series of questions about the frequency of specific types of foods eaten. The foods in the list were representative of foods intensive in iron and vitamin A, two micronutrients thought to be lacking in the Indonesian population. In IFLS5 we also added fast foods, fried and sweet snacks, to get at some unhealthy eating habits.

Community participation. Community development activities have long been important in Indonesia. Module PM asked about participation in, contributions of time and money to, and perceived benefits from, a slate of community development activities. We asked questions on voting participation, in the different levels of elections held in recent years, as well as expectations of whether the respondent plans to vote in the next elections, by type. Questions were included on participation in rotating credit schemes (arisan).

Non- resident family roster and transfers. Module BA recorded detailed information on the location and socio-demographic characteristics of non- coresident immediate kin for parents and children. This information included for instance whether the parents are alive, when they died if they did, and what they died of. In addition we continued to ask questions regarding transfers of money, goods, and time to and from nonresident parents and children in the last twelve months. Information on transfers to and from siblings, as a group, was also collected. For parents, BA covers only biological parents, transfers to and from non-biological parents living apart were collected in section TF. For siblings and children, Section BA included both biological and non-biological relations.

Transfers. Module TF was designed to fill a gap in the transfer information collected in IFLS. Specifically in TF we collect transfer information to and from spouses and non-biological parents who live outside the 
household, other family members living outside the household (besides those covered in BA- parents, siblings, children), and friends or neighbors.

Expectations Section EP was continued in IFLS5. We asked in it, parental expectations regarding specific aspects of their children's future. This included how much schooling the parents expect the children to complete, parents' expectations of their children's health and living standards. This was asked both in Book 3B and Book 4 so that all parents are covered.

\section{Book 4: Ever-Married Woman Information}

Book 4 was administered to all ever-married women 15 to 49 years old. Panel respondents who answered Book 4 in IFLS4 also answered in IFLS5 even though their age might be over 49, so long as they were under age 58 at the time of the IFLS5 interview. Modules KW, BR, BA (for children) and EP resembled the same modules described in books $3 \mathrm{~A}$ and $3 \mathrm{~B}$ but were administered to ever-married women as part of book 4 for the sake of efficiency. Module BF updated information on breastfeeding status for children who were still being breastfed at IFLS4. Module BX covered socio-economic information and data on transfers to and from adopted children living outside the household (in Book 4, transfers from biological children were covered in section $\mathrm{CH}$, again to enhance efficiency).

Pregnancy history. Module $\mathrm{CH}$ asked new respondents about all pregnancies and recorded the outcome and date. For live births respondents were asked the child's gender and name, whether the child was ever breastfed, and the length of breastfeeding. For pregnancies in the last five years, respondents were asked whether and where prenatal care was received, number of visits made in each trimester, services received during pregnancy and (except for miscarriages), length of labor, place of birth, and type of attendant. For pregnancies that did not end in a miscarriage, information was collected on the infant's size and weight at birth. For all live births, questions on the survival status and (if dead) date of death were asked. Some information about breastfeeding and the introduction of other foods was collected for children born in the last five years. Module $\mathrm{CH}$ also contains questions from Module BA on transfers to and from adult biological children living outside the household. IFLS5 panel respondents (those interviewed in IFLS4) were asked only about pregnancies after the pregnancy that produced the youngest child listed in IFLS4; which was preloaded into CAPI.

Contraceptive knowledge and use Information on contraceptive knowledge was collected in an enhanced section CX by asking respondents whether they had ever heard of a number of modern and traditional contraceptive methods, whether they had ever used each method, and, if appropriate, whether they knew the price and where to obtain the method. Questions were asked on some history of contraception use, what was used prior to the current method, whether complications had occurred and some details about visits to providers.

\section{Book 5: Child Information}

This book was administered to household members younger than 15. For children younger than 11, the mother, female guardian, or household caretaker answered the questions. Children between the ages of 11 and 14 were allowed to respond for themselves if they wished, but we always encouraged parents to attend so as to ensure better quality of answers. Topics included the child's educational history (module DLA), general health status and morbidities (module MAA), self-treatment (module PSA), and inpatient and outpatient utilization (modules RJA and RNA). Generally each module paralleled a module in the adult questionnaire (books $3 \mathrm{~A}$ and $3 \mathrm{~B}$ ), with age-appropriate modifications.

Section DLA allows users to track schooling progression for both children answering Book 5 as well as adults answering Book 3A. In section DLA we included questions about the child's work status for the last one month and ever. This included questions about the type of work done, the hours and earnings. Section BAA, obtained information on parents who live outside the household. This included information on their schooling and work.

\section{Book US: Physical Health Assessment}

In IFLS5 regular interviewers recorded physical measurements of health for household members. They were trained in taking physical measurements of health during their regular training. The interviewers visited each household to record various measures of physical health for each household member.

The measurements started with blood pressure (members 15 and older), taken three times on alternate arms. Then height and weight were taken for all members and for respondents 40 and over, lower leg length and upper arm length, waist and hip circumference were measured. Lower leg and upper arm length were taken to get more a more accurate proxy for attained adult height for older members who have begun to 
shrink. These limbs do not shrink with aging. Next, respondents 15 and older were timed while they rose from a sitting to a standing position five times (interviewers brought plastic stools for the respondents to sit on). They were then asked to squeeze in each hand a special dynamometer that measures grip strength. Grip strength was taken two times for each hand. Which hand is the dominant one was recorded.

Respondents 45 and older undertook balance tests and a timed walk. The balance tests followed the HRS procedures. There were two parts, a semi-tandem position which the respondent was asked to hold for 10 seconds. If the respondent could not perform that, they were asked to stand with feet side by side for 10 seconds. Those who were able to complete the semi-tandem balance test were asked to do a full tandem balance test, with the right foot directly in front of the left. This position was held for 60 seconds for respondents under 70 and 30 seconds for those 70 and over. The timed walk was over a flat, straight 2.5 meters and was done for respondents aged 60 and older. They were asked to walk at "normal" speed. The balance and timed walk were new in IFLS5 and added to better harmonize IFLS measurements on the elderly with the HRS. Then lung capacity was taken using a peak flow meter for members 9 years and older. Finally a finger prick was taken and blood drops drawn for testing hemoglobin using a hand held meter and dried blood spots taken for later measurement of C-reactive protein and HbA1c (members 1 year and older). After all the measurements were completed, the interviewers assessed each respondent's health status on a nine-point scale. Book US questionnaire shows pictures and has detailed descriptions of how each measurement was done. Interviewers were monitored by their supervisors from time to time to ensure that measurements were being performed according to the training instructions.

An Omron meter, HEM-7203 was used for taking blood pressure. Most of the time a normal sized cuff was used. Large cuffs were available is needed. Heights were measured using a Seca plastic height board, model 213. This measured heights to the nearest millimeter. Weights were taken using a Camry model EB1003 scale. This measured to the nearest tenth of a kilogram. Young children who could not stand were weighed in their mother's arms, then the mother was weighed alone and the difference in weight was attributed to the child. Lower leg length was measured using the Seca height board. A picture of how this was done is shown in Book US questionnaire. Upper arm length, waist and hip circumferences were measured with a tape measure, to the nearest millimeter. Grip strength was measured using a Baseline Smedley Spring type dynamometer. This was calibrated every day. Lung capacity was measured using a Vitalograph peak flow meter. Hemoglobin was measured using a Hemocue hand held meter, model Hb201+ with HB201 microcuvettes. The lancets were made by Hospital and Home Care. The dried blood spot cards were Whatman 903 Protein Saver Cards.

In IFLS4, a random sample of IFLS1 dynastic households were chosen to get dried blood spots. In IFLS5 we continued to collect dried blood spots on the same respondents sampled in IFLS4. In principle these blood spots can be analyzed for many different purposes. Our aim was to retest for C-reactive protein, a measure of body inflammation, which has been shown to be correlated with adult chronic diseases, including heart disease and $\mathrm{HbA1c}$, new to IFLS5, a longer run measure of diabetes. The blood spots were collected in conjunction with using the Hemocue system to measure blood hemoglobin. The first drops of blood were used with the hemoglobin and after drops were put onto the Whatman cards. Hand warmers were used prior to the prick to increase blood flow. The Whatman cards were allowed to dry for at least 4 hours in the household on a special drying rack and then put into a small ziplocked bag, together with a desicant. The ziplock bags with desicants helped to keep the blood samples dry. The samples were kept in a cooler with a plastic cooler bag until they could be mailed back to headquarters in Yogyakarta. Usually dbs cards were mailed twice per week. The mailings were in special envelopes that were insulated in order to keep the cards cool. The mail reached headquarters usually within two days, where they were put into a deep freezer (kept at $-40 \mathrm{C}$ ) for storage until they were assayed. Each ziplock bag had a label with the household and person identification numbers, age and sex. Each card had the person id.

\section{Book EK: Cognitive Assessment}

In IFLS3 and 4 respondents between the ages of 7 and 24 were administered cognitive tests to assess their general cognitive level, as well as skills in mathematics. Those tests had been redesigned from what was administered in IFLS2. Two levels of tests were given, EK1 was the less difficult, given to all respondents aged 7-14 and EK2, the harder test, to all respondents age 15-24. The tests had two parts: the first involved the matching of similar shapes, from the Raven's test, a test of fluid intelligence. The second was a numeracy test. EK1 has 12 questions from Raven's while EK2 has 8.

In IFLS5 we used the same tests. In IFLS5 we expanded the age range that EK2 was given to all respondents aged 15 and over whose $A R 01 \mathrm{i}=1$ (ie. who were administered individual books). This was done to get a measure of fluid intelligence for all adult household members. Respondents 60 and over did not take the arithmetic part of the test. Panel respondents who had taken EK1, were given EK1 again, and in addition took EK2, if they were 15 or over in 2014. 
This book was intended for adults who could not be given individual books. There were typically two types of individuals who got proxy books: very busy persons, usually prime-aged men who were constantly working, or away from the house; and persons who were too ill to answer (usually older persons). This results in various types of selection if proxy books are not used, depending on what the question is. On the other hand, the quality of answers in the proxy books is likely to be worse than the answers we obtain from the individuals themselves in individual books. The proxy book contains

shortened versions of questions from books 3A, 3B, and 4. Questions that we felt could not be answered accurately by proxy response were dropped. New questions were added in IFLS5. 


\section{Appendix C: Description of the IFLS5 Community-Facility Survey Questionnaire}

This appendix expands on the summary presented in Sec. 3 for those interested in more detail about the community-facility instrument. The IFLS5 User's Guide contains additional information.

\section{Book 1: Community History and Characteristics}

In a group interview, the village or municipal head (Kepala Desa) and other community leaders were asked detailed questions about their community, past and present.

Sampling information. Up to six names were gotten of people who could answer the informant book. Of these 2 were later chosen randomly. This information is not in the public release.

Transportation. Module A determined the location of various institutions (market, bus stop, post office, telephone, administrative city) relative to the village leader's office, and the mode, time, and cost associated with using public transportation to reach those institutions. Questions were also asked about the availability of public transportation within the village and the availability of the main route to the community during the year.

Electricity. Module B determined the availability of electricity within the village, the approximate proportion of households using electricity, the most important sources of electricity (public versus private, individual generator, local community group), and the frequency of blackouts.

Water sources and sanitation. Module $C$ determined primary and secondary sources of water for drinking, cooking, bathing, and laundry. If a piped water system existed, the module probed the date of its establishment, its source, the frequency of disruptions, and the most common source of drinking water before the system was installed. Other questions concerned the adequacy of water sources during the dry season and alternative sources should the primary source be inadequate. Respondents were also queried about the existence and establishment date of sewage systems, the most common and other types of toilets, and methods of garbage disposal. If a garbage collection system existed, the start up date and monthly subscription fee were asked.

Agriculture and industry. In rural enumeration areas, module D identified the three primary agricultural crops, the extent of irrigation, number of rice crops, the existence of animal husbandry projects, whether the village benefited from agricultural extension projects (and their duration), and male, female, and child wage rates for agricultural work. In both rural and urban areas module $D$ queried village leaders about local factories. For up to five factories, the product, location, date of establishment, and wage rates (for males, females, and children) were collected. Finally, the module determined whether the village had a public employment project and, if so, the associated wage rates.

Community history and climate. Module $\mathrm{E}$ recorded any change that had occurred in the name of the village and the typical dates of the rainy season. Descriptions and dates were collected of significant village events since 2000 (e.g., major infrastructure changes). The leaders were also asked to estimate the proportion of the population affected by the event.

Natural disasters: This module, F, collected information on natural disasters of various types (earthquake, volcano eruptions, tsunami, floods, drought, fires) in the last 5 years. We asked about the types and severity of infrastructure damage.

Credit institutions. Module $\mathrm{G}$ collected data on the presence, date of establishment, and ownership of formal credit institutions in the village, the distance to the nearest credit institution before a credit source was established within the village, whether an informal money lender existed in the village and, if so, the monthly interest rates for loans of various amounts.

School availability. Module I collected information on the current availability of elementary, junior high, and senior high schools. This is used to update the Service Availability Roster (SAR).

History of health services availability. Module $\mathrm{J}$ asked about outreach activities in the village conducted by staff from the area health center (including mass immunization campaigns since 1995) and about healthrelated volunteer activities in the village. This is used to update the Service Availability Roster (SAR). 
Community development activities. Module PMKD queried leaders on the existence of various community development activities, when they began, and the estimated number of community members involved in the activities.

Subjective well-being. Module SW asked the subjective views of the leaders about the economic condition of the community before and after economic crisis, using the same 6 step ladder question used in module SW of household book 3A. We also asked about changes in welfare since the 1998 financial crisis.

Poverty alleviation programs. Module PAP was completely updated for IFLS5. It collected data about recent public social safety net programs. These included two rice subsidy programs: Raskin and Market Operations; health insurance subsidies; unconditional cash transfers and conditional cash transfers. We asked about information campaigns about each program, about eligibility criteria, population coverage in the village, how the program was distributed (equal parts per household, targeted to eligible groups, usually the poor).

Perception on public services and infrastructure. Module PPS asked the perceptions of the village leader about the existing public infrastructure and recent changes.

Government and Decentralization Section GD asked about involvement of the village authorities regarding investments in local infrastructure, and regarding how much budget flexibility the village authorities have without having to get approval from the District officials.

Social interactions. In Section TR we asked about local conflicts and conflict resolution, crime in the village and local attitudes of trust of others in the community.

\section{Book 2: Community Statistics}

The interviewer recorded current community characteristics by being shown statistical records in the village head's office and through direct observation.

Direct observation. Module OL asked the interviewer to record observations about indicators of village; cleanliness, prosperity, and social cohesion (e.g., whether farm animals roamed freely in the village, whether public areas were well maintained).

Statistics. Modules KA, PL, ST, PR, LU, and KD recorded the village's forest cover and changes, pollution, types of land certification, number of households, employment structure, conventions of housing construction, housing prices, and village finance for last budget year. Module KD, on village finances can be compared to the same in IFLS3, just before the new regional autonomy laws (decentralization) went into effect. It contained information on the sources of village finance, including amounts received from the central and district governments; on the types of expenditures; on village lands and their disposition.

Market prices. Prices are now in 3 books: one, Market, contains price information collected from visits to up to a large local market. A second, Shops/stalls, collects data from 2 local shops and street stalls, so there are two of these books per EA. A third price book, Informant, collects prices from a group of up to 3 local informants, but only one set of prices all in one book. Prices are collected on many foods and on a few nonfood items. We made a big effort to specify specific quality of the goods, and to check different sources so that we would not have so many missing values, which is common in collecting price data.

\section{Book PKK: Village Women's Organization}

This book was addressed to the head of the village women's group, the PKK. Several book 1 modules (or adaptations) were administered to obtain an additional perspective on community history and characteristics (see the descriptions of book 1 modules E, I, J, and PMKD), with emphasis on the histories of local schools and health facilities. These are used in adding to the SAR. In addition, the women's group head was asked to provide information on the operation of community-based assistance programs and food subsidies.

\section{Book SAR: Service Availability Roster}

The SAR gathered in one place information on all the schools and health facilities that had been available to residents of IFLS communities since 1993. It included:

- Facilities listed in SAR IFLS4, which includes facilities listed in IFLS1, 2, 3 and 4 
- Facilities identified by household respondents in IFLS5 household modules PP and AR but not mentioned in SAR IFLS4

- Any other facility mentioned by the head of the village/township or the women's group head in IFLS5; community-facility books 1 or PKK

For each facility mentioned, the head of the village/township or the women's group head was asked to estimate the distance, travel time, and travel cost to the facility.

Book Informant: Community Informant. This book collected information on poverty alleviation programs in the community, perceptions on community infrastructure, local governance and decentralization and community social interactions. Special attention was paid to assessment of the quality of services available to the community and to the quality of local government. Two local informants were randomly selected from a list of 6 types of informants: school principal or senior teachers; health professionals; youth activists; religious leaders; local political party activists; and local business leaders. Specifically, two of the six types of informants were selected randomly. Within each group there were two suggested names, one of whom was considered the more logical choice. That person was approached first, then the second if the first was unable or unwilling to cooperate. A third category was randomly selected as a backup category if needed.

Poverty Alleviation Program. Module PAP collects similar information on the existence and working of poverty alleviation programs as in Book 1 . We collected information on the existence, date started, eligibility criteria used in fact in that village, what fraction of the population were covered, and how much they received. We also asked the informants their views regarding the transparency and fairness of the programs. Programs covered included the rice distribution program, Raskin, the rice market operations program, the unconditional cash transfer and the conditional cash transfer.

Perception on public infrastructure and services. This module, PPS, asked informants to judge the state of local infrastructure and whether it has gotten better or worse. We also included governance and corruption questions here, regarding the goodness of local governance now, at the local and district levels, and changes. Also we asked about local corruption by different local groups, including the local politicians and the police.

Conflict. In this module we asked about the existence of local conflict and how well they were resolved.

\section{Book Puskesmas}

This book was addressed to the director of the local government health center (puskesmas), or his/her designee. It covered both the local health centers (puskesmas) and sub-centers (puskesmas pembantu). It was the most comprehensive of the three health facility questionnaires (book Puskesmas, book Private Practice, and book Posyandu), reflecting the fact that this stratum provided the most elaborate array of services of the facility types we interviewed and conducted outreach activities. In IFLS5 we divided Book Puskesmas into two books, so that two interviewers could be working at the same time. The modules were the same as prior waves, but divided across the books. Book A contained some questions pertaining to the head of the Puskesmas, while Book B contained the rest.

Head of the Facility. Module A collected information about the director of the health center (typically a physician), such as age, tenure in position, education, and ability to speak the local language. The module also attempted to ascertain how much time the director spent examining patients, performing outside administrative duties, and conducting outreach activities. This module also asked if and how changing circumstances such as due to the economic crisis, affected the facility's service. This section is now in Book A.

Development of the facility. Module B, administered to the professional staff member with the longest tenure at the facility, asked about the facility's development, including the dates when certain broad classes of service became available (e.g., inpatient, dental, pharmaceutical, laboratory), as well as characteristics of the current facility's infrastructure. This section is in Book B.

Service availability. Module $C$ asked about which services were available, how often, and at what price. For supplies like medicines and vaccines, we checked whether they were in stock on the day of the interview and we asked about stock outages in the prior 6 months. These questions were moved from module $F$ in prior waves. The module also asked about outreach activities and referral practices. This section is in Book B.

Staff. Module D recorded the number and training levels of full- and part-time staff. Information was also collected on the amount of time doctors, nurses, paramedics and midwives spent treating patients and whether those staff practiced privately and whether they were in attendance that day and if not why. This section is in Book B. 
Equipment and supplies. Module $E$ asked about the availability of various items of basic equipment needed to provide primary health care, such as stethoscopes, thermometers, and suturing material. It also addressed the availability of basic laboratory materials such as Giemsa dyeing solutions and centrifuges. This section is in Book B.

Resources of Puskesmas. Module SDP collected data about the budget in the last budget year and the source of the budget in detail. It asked about how patient fees were divided between the facility and the district health ministry (where fees often went). This section is in Book A.

Health insurance for the poor. New in IFLS4, Module AKM asked about a new health card for the poor, ASKESKIN, which in principal provides for free or subsidized health care for eligible poor people. We ask for prices charged to ASKESKIN card holders for different services provided by the PUSKESMAS. This section is in Book A.

Decision-making. Module DM was added in IFLS3 to inquire about the locus of control over specific decisions for the puskesmas. It was intended to serve as a baseline for future waves which might obtain how the new 2001 decentralization laws have changed this locus of control. We asked about whether the central health ministry, district health ministry, district planning office or the puskesmas itself controlled decisions over services offered, staffing, fees and the purchase of equipment and medicines. This section is in Book A.

Direct observation. Module F asked interviewers to record their observations about the cleanliness of the examination rooms, laboratory, and vaccine storage room. This section is in Book B.

Family planning services. Module $\mathrm{G}$ asked about the characteristics and scope of the center's family planning services. This section is in Book B.

Health Vignettes. Module $\mathrm{H}$ added back health vignettes, asked of the professional health staff. Four different cases were asked: about prenatal care, child health (diarrhea), adult health (upper respiratory) and adult diabetes. We began with a description of the case. Then we asked what questions the provider would ask, then what questions they would ask about medical history, then what things would be checked in a physical exam, then what laboratory tests would be performed. First the answers were spontaneous, and we checked against a prepared list.. We then prompted against the prepared list of questions to see if the provider agreed or not. Not all of our questions were considered good practice, some are considered unnecessary. In the public use data we provide which answers are considered correct and which not. Which practitioner answered the questions depended on the head of the facility. We asked which practitioner in each facility was trained in each type of case and who generally got those types of referrals. For private facilities it was not always possible to administer all four cases, though generally we were able to do so in the puskesmas. The health vignettes were answered first on paper and later put into CAPI.

\section{Book Private Practice}

This book focuses on private doctors, clinics, private and village midwives, nurses and paramedics. Book Private Practice had the same modules as book Puskesmas except that some modules were scaled down to reflect the differences in the scope and types of services provided. This book had a special module for the village midwife, which asked about various activities (module BD). Not all of the vignettes were asked of the private practice professional, depending on what their specialties were.

\section{Book Traditional Practitioners}

This book was re-inserted into IFLS4 and continued in IFLS5. Two traditional practitioners were sampled in each EA, one a traditional (untrained) midwife and another traditional practitioner. We focused on their herbal medicinal practices, plus practices such as acupuncture. If they practiced with charms and used witchcraft, we also covered that, but practitioners who practiced exclusively witchcraft were not included.

\section{Book Posyandu}

This book contained questions administered to volunteers who staffed the community health post (posyandu). Up to 2 posyandu were sampled within each EA. Book Posyandu recorded information on community's utilization of the post and general health care in the community (module A), specific services provided (module B), characteristics of the volunteer staff, including their general education and health training (module $\mathrm{C}$ ) and the availability of specific medications, supplies, and equipment (module D). Modules asked about the sources of posyandu resources (module SDP) and the posyandu revitalization program (module PRP).

Book Posyandu Lancia. This book, which was new in IFLS4 is similar to the posyandu book, but concentrated on posyandu for the elderly. Up to 2 posyandu lancia were surveyed in IFLS5, up from one in 
IFLS4. Sometimes the same posyandu has both services. We separately sampled the two types of posyandu. If the main posyandu and the posyandu lancia from the same facility were sampled, we kept both, and gave the facility code of the posyandu to both. That way users can tell if the facilities are from the same parent posyandu.

\section{Book School}

This book is addressed to different school levels: SD (elementary school), SMP (junior high school), and SMU (senior high school). It was administered to the school principal or his/her designee. In IFLS5 the school book was divided into four parts. The modules were the same as in prior waves, but divided across the books. Book A was for the principal. Book B was for the teacher chosen to be interviewed. Book $\mathrm{C}$ was for the school test results, and Book D for interviewer observations. Dividing up the book this way meant that multiple interviewers could be working on different sub books at the same time.

Module A recorded characteristics of the school principal, for example, age, education level, experience in education, tenure in current job, current activities, and whether he or she held another position. One set of questions collected details about school feeding programs.

Module B recorded characteristics of the school, such as date of establishment, length of time in session per day and per year, administration and religious orientation, and whether particular facilities (gymnasium, library) were available.

Module SC asked about the School Committee. This module was new in IFLS4, as the School Committee was a new institution. We asked about whether the committee exists for this school, who are members, and some of the tasks that the committee is undertaking.

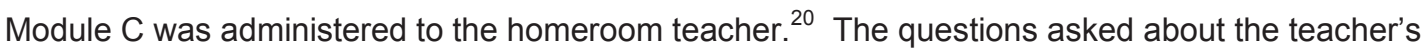
background, hours worked and salary, whether the teacher had applied for or gotten teacher certification, whether other jobs were held simultaneously, what curriculum was used, and the adequacy of books and instructional materials.

Module D recorded both the interviewer's direct observations and respondent's answers to questions about the quality of classroom infrastructure in grade 6,9 or 12, depending on the level of the school.

Module E recorded student expenditures for school year 2014/15.

Module $\mathrm{F}$ recorded math and language scores on UAN (the national successor to EBTANAS) achievement tests for a random sample of 25 students

Module G recorded counts of teachers and students in school year 2014/15.

Module $\mathrm{H}$ is an observation sheet for interviewers to record who was present during the interviews with the homeroom teacher and whether the respondents were able to answer the questions well.

\section{Book Mini-CFS}

This book was new in IFLS3, continued and expanded each in IFLS4 and IFLS5. It was intended to give users at least some information on the communities where IFLS mover respondents live. Respondents who lived in one of the 321 IFLS1 communities have available the regular community-facility books to provide information on their communities. Respondents who lived outside these 321 IFLS1 communities now have Mini-CFS to describe a little about their community conditions. This book, combined questions from parts of books I and II (Modules S, A, B, C, D, H, I, J, F, E, SW, PAP, TR, W), to provide data about the total population, the condition of the main road, availability of electricity and water, the number of schools by level, the number of health facilities by type, the main sources of income, the main crops grown, the price of rice, male and female wages, the availability of industries and social safety net programs in the village. This book was collected by the household interviewing teams while they were conducting long distance tracking.

\footnotetext{
${ }^{20}$ In elementary schools this module was administered with respect to grade 4; in junior and senior high schools the designated level was grade 3 .
} 


\begin{tabular}{|c|c|}
\hline A-D & \\
\hline ADL & Activities of daily Living \\
\hline Apotik Hidup & The plant, usually used for traditional medicine \\
\hline$A P P K D / P A K$ & Village Revenue and Expenditure/Village Budget Management \\
\hline Askabi & Public assurance for acceptor of control birth \\
\hline Arisan & $\begin{array}{l}\text { A kind of group lottery, conducted at periodic meetings. Each member } \\
\text { contributes a set amount of money, and the pool is given to the tenured member } \\
\text { whose name is drawn at random. }\end{array}$ \\
\hline Bahasa Indonesia & Standard national language of Indonesia. \\
\hline Bidan & $\begin{array}{l}\text { Midwife, typically having a junior high school education and three years of } \\
\text { midwifery training. }\end{array}$ \\
\hline Bidan Desa & $\begin{array}{l}\text { Midwife in village, Indonesia government's project to provide health service of } \\
\text { maternal case in village such as; pregnancy check, delivery, contraception, etc. }\end{array}$ \\
\hline bina keluarga balita & child development program. \\
\hline bina keluarga remaja & youth development program \\
\hline bina keluarga manula & ageing care program \\
\hline BLT & $\begin{array}{l}\text { Bantuan Langsung Tunai (Direct Cash Assistance), unconditional cash transfer } \\
\text { program, later renamed as BLSM. }\end{array}$ \\
\hline BLSM & $\begin{array}{l}\text { Bantuan Langsung Sementara Masyarakat. (Direct Temporary Assistance for } \\
\text { the People ), unconditional cash transfer program replacing BLT. }\end{array}$ \\
\hline Book & Major section of an IFLS questionnaire (e.g., book K). \\
\hline BPS & Badan Pusat Statistik, Indonesia Central Bureau of Statistics. \\
\hline BP3 & $\begin{array}{l}\text { Board of management and development of education, an school organization } \\
\text { that has responsible on education tools supplies. Usually it consists of teachers } \\
\text { and student's parents. }\end{array}$ \\
\hline BUMN/BUMD & National committee/ Regional committee \\
\hline CAFE & $\begin{array}{l}\text { Computer-Assisted Field Editing, a system used for the first round of data entry } \\
\text { in the field, using laptop computers and software that performed some range and } \\
\text { consistency checks. Inconsistencies were resolved with interviewers, who were } \\
\text { sent back to respondents if necessary. }\end{array}$ \\
\hline CAPI & $\begin{array}{l}\text { Computer Assisted Personal Interviewing, a system in which computers are } \\
\text { used in administering survey questionnaires. With CAPI, interviewers use a } \\
\text { portable computer/tablet to enter the data directly during face-to-face interview. }\end{array}$ \\
\hline CES-D Scale & $\begin{array}{l}\text { Center for Epidemiologic Studies Depression Scale, a short self-report scale } \\
\text { designed to measure depressive symptoms. }\end{array}$ \\
\hline CFS & IFLS Community-Facility Survey. \\
\hline CHRLS & China Health and Retirement Study. \\
\hline CPPS-UGM & Center for Population and Policy Studies of Gajah Mada University \\
\hline CSPro & $\begin{array}{l}\text { The Census and Survey Processing System (CSPro). The software used for } \\
\text { entering, editing, tabulating, and disseminating census and survey data }\end{array}$ \\
\hline COMMID & Community ID. This is a unique identifier for a community or Enumeration Area. \\
\hline DBO & Operational Aids for School from Social Safety Net Program \\
\hline Dana Sehat & $\begin{array}{l}\text { Fund for health service that was collected from community of village to be used } \\
\text { for the community }\end{array}$ \\
\hline Dasa Wisma & $\begin{array}{l}\text { A group of community per } 10 \text { houses, but practically } 10-20 \text { houses, to run Village } \\
\text { programs }\end{array}$ \\
\hline data file & $\begin{array}{l}\text { File of related IFLS3 variables. For HHS data, usually linked with only one HHS } \\
\text { questionnaire module. }\end{array}$ \\
\hline DBS & Dried Blood Sample. \\
\hline Desa & Rural township, village. Compare kelurahan. \\
\hline DHS & $\begin{array}{l}\text { Demographic and Health Surveys fielded in Indonesia in 1987, 1991, 1994, } \\
1997 .\end{array}$ \\
\hline
\end{tabular}




\begin{tabular}{|c|c|}
\hline E-L & \\
\hline EA & Enumeration Area. \\
\hline EBTA & $\begin{array}{l}\text { Regional Achievement Test, administered at the end of each school level, } \\
\text { covered Agama, bahasa daerah, kesenian, ketrampilan, etc, exception subject of } \\
\text { EBTANAS. }\end{array}$ \\
\hline EBTANAS & $\begin{array}{l}\text { Indonesian National Achievement Test, administered at the end of each school } \\
\text { level (e.g., after grade } 6 \text { for students completing elementary school). Covered } 5 \\
\text { subject; Bahasa Indonesia, Mathematic, PPKN, IPA, IPS }\end{array}$ \\
\hline ELSA & English Longitudinal Study of Ageing. \\
\hline GSOEP & German Socio-Economic Panel \\
\hline $\mathrm{HH}$ & Household. \\
\hline HHID & Household identifier. In IFLS1 called CASE; in IFLS2 called HHID97. \\
\hline HHS & $\begin{array}{l}\text { IFLS Household Survey. IFLS1-HHS and IFLS2-HHS refer to the } 1993 \text { and } \\
1997 \text { waves, respectively. IFLS3-HHS refers to the } 2000 \text { wave. }\end{array}$ \\
\hline HRS & Health and Retirement Study fielded in the US \\
\hline HTRACK & $\begin{array}{l}\text { An IFLS data file indicating what data are available for households in each } \\
\text { survey wave. }\end{array}$ \\
\hline IADL & Instrumental Activities of daily Living. \\
\hline IDT & Presidential Instruction on Undeveloped Village \\
\hline IDUL FITRI & A muslim celebration that marks the end of fasting month, Ramadan. \\
\hline IFLS & $\begin{array}{l}\text { Indonesia Family Life Survey. IFLS1, IFLS2, IFLS3, IFLS4, and IFLS5 refer to } \\
\text { the } 1993,1997,2000,2007 \text { and } 2014 \text { waves, respectively. IFLS2+ refers to the } \\
25 \% \text { subsample wave in } 1998 .\end{array}$ \\
\hline $\begin{array}{l}\text { IFLS1 re-release, } \\
\text { IFLS1-RR (1999) }\end{array}$ & $\begin{array}{l}\text { Revised version of IFLS1 data released in conjunction with IFLS2 and } \\
\text { designed to facilitate use of the two waves of data together (e.g., contains IDs } \\
\text { that merge with IFLS2 data). Compare original IFLS1 release. }\end{array}$ \\
\hline interviewer check & $\begin{array}{l}\text { Note in a questionnaire for the interviewer to check and record a previous } \\
\text { response in order to follow the proper skip pattern. }\end{array}$ \\
\hline JPS & Social Safety Net \\
\hline JPS-BK & Social Safety Net program for Health Service \\
\hline Kangkung & Leafy green vegetable, like spinach. \\
\hline Kabupaten & $\begin{array}{l}\text { District, political unit between a province and a kecamatan (no analogous unit in } \\
\text { U.S. usage). }\end{array}$ \\
\hline kartu sehat & $\begin{array}{l}\text { Card given to a (usually poor) household by a village/municipal administrator that } \\
\text { entitles household members to free health care at a public health center. The } \\
\text { fund was from Social Safety Net program }\end{array}$ \\
\hline Kecamatan & Subdistrict, political unit analogous to a U.S. county. \\
\hline $\begin{array}{l}\text { Kejar Paket } A \text {, } \\
\text { Kejar Paket } B\end{array}$ & Informal School to learn reading and writing equivalent to elementary school \\
\hline Kelurahan & urban township (compare desa). \\
\hline Kepala desa & Village head \\
\hline Kepala Kelurahan & Municipality Head \\
\hline $\begin{array}{l}\text { klinik, } \\
\text { klinik swasta, } \\
\text { klinik umum }\end{array}$ & Private health clinic. \\
\hline Kotamadya & Urban district; urban equivalent of kabupaten. \\
\hline
\end{tabular}


Process of manually checking the paper questionnaire against a computergenerated set of error messages produced by various consistency checks. LU specialists had to provide a response to each error message; often they corrected the data. 


\begin{tabular}{|c|c|}
\hline M-P & \\
\hline Madrasah & $\begin{array}{l}\text { Islamic school, generally offering both religious instruction and the same } \\
\text { curriculum offered in public school. }\end{array}$ \\
\hline Madya & $\begin{array}{l}\text { Describes a posyandu that offers basic services and covers less than } 50 \% \text { of the } \\
\text { target population. Compare pratama, purnama, and mandiri. }\end{array}$ \\
\hline Main respondent & An IFLS1 respondent who answered an individual book $(3,4$ or 5$)$ \\
\hline Mandiri & $\begin{array}{l}\text { Describes a full-service posyandu that covers more than } 50 \% \text { of the target } \\
\text { population. Compare pratama, madya, and purnama. }\end{array}$ \\
\hline Mantri & Paramedic. \\
\hline mas kawin & $\begin{array}{l}\text { Dowry-money or goods-given to a bride at the time of the wedding (if Muslim, } \\
\text { given when vow is made before a Muslim leader or religious officer). }\end{array}$ \\
\hline MHAS & Mexican Health and Aging Study \\
\hline MIDAS & Multiple Intelligences Developmental Assessment Scales \\
\hline Mini-CFS & $\begin{array}{l}\text { The miniature version of the community survey fielded in non-IFLS1 } \\
\text { communities }\end{array}$ \\
\hline Module & Topical subsection within an IFLS survey questionnaire book. \\
\hline MxFLS & Mexican Family Life Survey \\
\hline NCR pages & $\begin{array}{l}\text { Treated paper that produced a duplicate copy with only one impression. NCR } \\
\text { pages were used for parts of the questionnaire that required lists of facilities. }\end{array}$ \\
\hline Origin household & $\begin{array}{l}\text { Household interviewed in IFLS1 that received the same ID in IFLS2, } 2+\text { and } 3 \\
\text { and contained at least one member of the IFLS1 household. Compare split-off } \\
\text { household. }\end{array}$ \\
\hline original IFLS1 release & $\begin{array}{l}\text { Version of IFLS1 data released in } 1995 . \text { If this version is used to merge IFLS1 } \\
\text { and IFLS2 data, new IFLS1 IDs must be constructed. Compare IFLS1 re- } \\
\text { release. }\end{array}$ \\
\hline "other" responses & Responses that did not fit specified categories in the questionnaire. \\
\hline Panel respondent & Person who provided detailed individual-level data in IFLS2. \\
\hline peningset & $\begin{array}{l}\text { Gift of goods or money to the bride-to-be (or her family) from the groom-to-be (or } \\
\text { his family) or to the groom-to-be (or his family) from the bride-to-be (or her } \\
\text { family). Not considered dowry (see mas kawin). }\end{array}$ \\
\hline perawat & Nurse. \\
\hline pesantren & $\begin{array}{l}\text { School of Koranic studies for children and young people, most of whom are } \\
\text { boarders. }\end{array}$ \\
\hline PID & $\begin{array}{l}\text { Person identifier. In IFLS1 called PERSON; in IFLS2 called PID97; in IFLS3 } \\
\text { called PID00. }\end{array}$ \\
\hline PTRACK & $\begin{array}{l}\text { An IFLS data file indicating what data/books are available for individuals in each } \\
\text { survey wave. }\end{array}$ \\
\hline PIDLINK & ID that links individual IFLS2 respondents to their data in IFLS1. \\
\hline PKK & Family Welfare Group, the community women’s organization. \\
\hline PODES & $\begin{array}{l}\text { Potensi Desa (Village Potential Statistics) a data set that provides information } \\
\text { about village/desa characteristics for all of Indonesia. The PODES is completed } \\
\text { as part of a census of community infrastructure regularly administered by the } \\
\text { BPS. Retained at village administrative offices and used as a data source for } \\
\text { CFS book } 2 \text {. }\end{array}$ \\
\hline Posyandu & Integrated health service post, a community activity staffed by village volunteers. \\
\hline Posyandu Lansia & $\begin{array}{l}\text { Integrated health service post serving elderly. Similar to Posyandu, it is staffed } \\
\text { by village volunteers. }\end{array}$ \\
\hline $\begin{array}{l}\text { praktek swasta, } \\
\text { praktek umum }\end{array}$ & Private doctor in general practice. \\
\hline pratama & $\begin{array}{l}\text { Describes a posyandu that offers limited or spotty service and covers less than } \\
50 \% \text { of the target population. Compare madya, purnama, and mandiri. }\end{array}$ \\
\hline
\end{tabular}




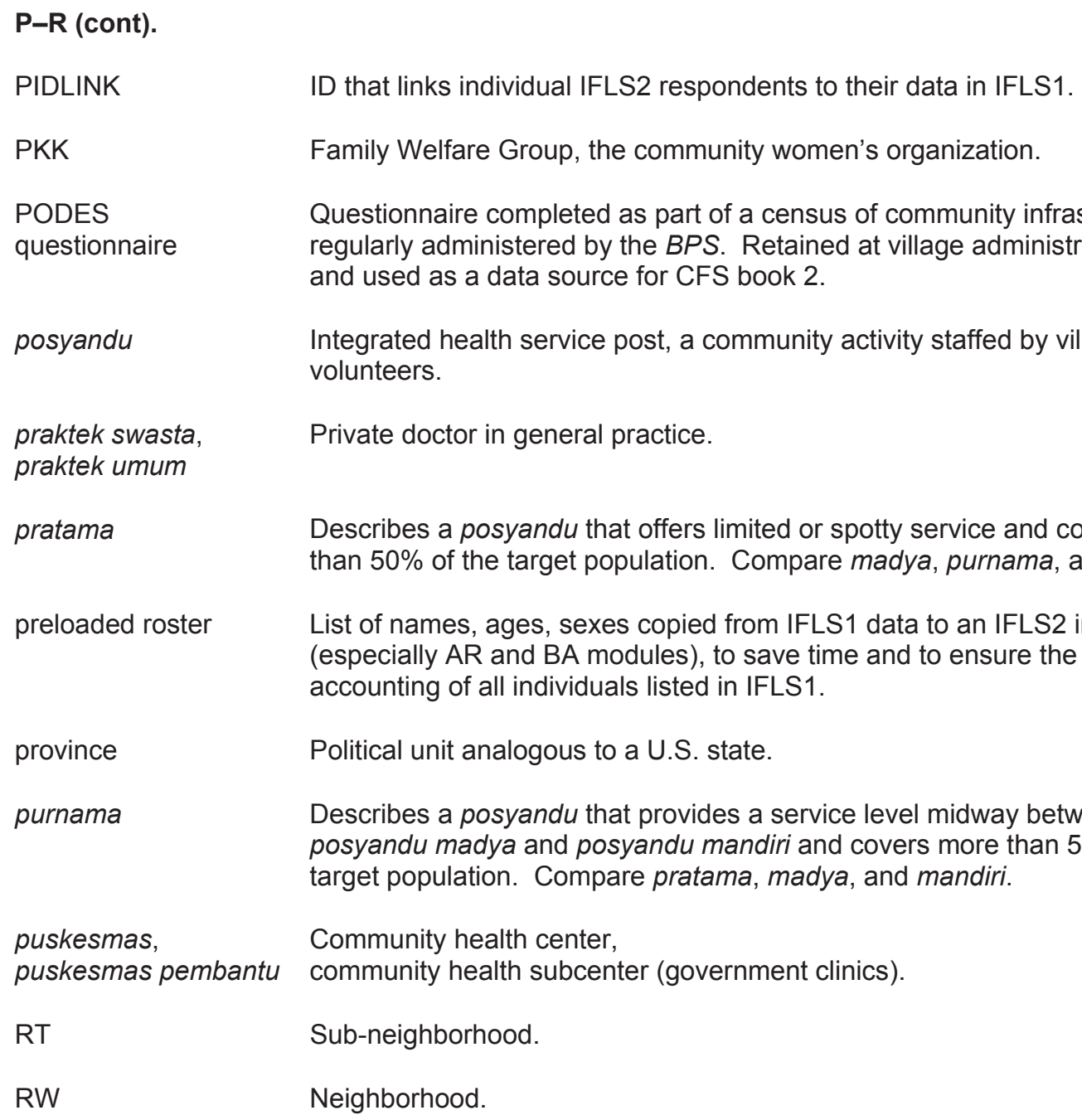

S-Z

SAR

Service Availability Roster, CFS book.

SD Elementary school (sekolah dasar), both public and private.

SDI Sampling form 1, used for preparing the facility sampling frame for the CFS.

SDII Sampling form 2, used for drawing the final facility sample for the CFS.

Sinse Traditional practitioner. 
S-Z (cont.)

SMK

SMP

SMU

special codes

split-off household

SPRT

\section{SUSENAS}

system missing data

Tabib

target household

target respondent

tracking status

tukang pijat

Version

warung
Senior vocation high school (sekolah menengah kejuruan).

Junior high school (sekolah menengah pertama), both public and private. The same meaning is conveyed by SLTP (sekolah lanjutan tingkat pertama).

Senior high school (sekolah menengah umum), both public and private. The same meaning is conveyed by SMA (sekolah menengah atas) and SLTA (sekolah lanjutan tingkat atas).

Codes of $5,6,7,8,9$ or multiple digits beginning with 9 . Special codes were entered by interviewer to indicate that numeric data are missing because response was out of range, questionable, or not applicable; or respondent refused to answer or didn't know.

New household interviewed in IFLS2, 2+ or 3 because it contained a target respondent. Compare origin household.

Special filter paper for finger prick blood samples.

Socioeconomic survey of 60,000 Indonesian households, whose sample was the basis for the IFLS sample.

Data properly absent because of skip patterns in the questionnaire.

Traditional practitioner.

Origin household or split-off household in IFLS2 or 2+

IFLS1 household member selected for IFLS3 either because he/she had provided detailed individual-level information in IFLS1 (i.e., was a panel respondent) or had been age 26 or older in IFLS1 or met other criteria, see text.

Code in preloaded household roster indicating whether an IFLS1 household member was a target respondent $(=1)$ or not $(=3)$.

Traditional masseuse.

A variable in every data file that indicates the date of that version of the data. This variable is useful in determining whether the latest version is being used.

Small shop or stall, generally open-air, selling foodstuffs and sometimes prepared food. 


\begin{tabular}{|c|c|c|c|c|c|c|c|c|c|c|c|c|}
\hline & IFLS1 & $\begin{array}{c}\text { IFLS2 } \\
\text { target } \\
\text { households } \\
\text { contacted }\end{array}$ & $\begin{array}{l}\text { Re- } \\
\text { contact } \\
\text { rate } \\
(\%)\end{array}$ & $\begin{array}{c}\text { IFLS3 } \\
\text { target } \\
\text { households }\end{array}$ & $\begin{array}{c}\text { IFLS3 } \\
\text { target } \\
\text { households } \\
\text { contacted }\end{array}$ & $\begin{array}{c}\mathrm{Re}- \\
\text { contact } \\
\text { rate (\%) }\end{array}$ & $\begin{array}{c}\text { IFLS4 } \\
\text { target } \\
\text { households }\end{array}$ & $\begin{array}{c}\text { IFLS4 } \\
\text { Target } \\
\text { Contacted }\end{array}$ & $\begin{array}{c}\text { Re- } \\
\text { contact } \\
\text { rate (\%) }\end{array}$ & $\begin{array}{c}\text { IFLS5 } \\
\text { target } \\
\text { households }\end{array}$ & $\begin{array}{c}\text { IFLS5 } \\
\text { Target } \\
\text { Contacted }\end{array}$ & $\begin{array}{c}\text { Re- } \\
\text { contact } \\
\text { rate (\%) }\end{array}$ \\
\hline IFLS2 split-off households & - & 877 & - & 865 & 819 & 94.7 & 876 & 769 & 87.8 & 703 & 650 & 92.5 \\
\hline IFLS2+ splitoff households & - & - & - & 344 & 309 & 89.8 & 335 & 295 & 88.1 & 243 & 224 & 92.2 \\
\hline IFLS3 splitoff households & - & - & - & & 2,646 & & 2,648 & 2,302 & 86.9 & 2,164 & 1,923 & 88.9 \\
\hline IFLS3 target households & & & & 8,347 & & 95 & & & & & & \\
\hline IFLS4 splitoff households & & & & & & & & 4,033 & & 4033 & 3687 & 91.4 \\
\hline IFLS4 target households & - & - & - & & & & 10,994 & 9,962 & 90.6 & & & \\
\hline IFLS5 target households & & & & & & & & & & 14,274 & 12,916 & 90.5 \\
\hline IFLS5 splitoff households & - & & & & & & & & & & 4,015 & \\
\hline Total households & 7,224 & 7,698 & & & 10,574 & & & 13,995 & & & 16,931 & \\
\hline
\end{tabular}

Source: IFLS2, IFLS3, IFLS4, IFLS5

Number of households contacted includes those whose members all died and households that recombined into other households since the last survey.

Table 2.1b 1993 Dynasty Recontact Rates, IFLS1-IFLS5 (based on 93 members found alive and book T

\begin{tabular}{|c|c|c|c|c|c|c|c|c|c|c|c|}
\hline & \multirow{2}{*}{$\begin{array}{c}\text { IFLS1 } \\
\mathrm{HH}\end{array}$} & \multicolumn{2}{|c|}{ IFLS2 } & \multicolumn{2}{|c|}{ IFLS3 } & \multicolumn{2}{|c|}{ IFLS4 } & \multicolumn{2}{|c|}{ IFLS5 } & \multicolumn{2}{|c|}{ All rounds } \\
\hline & & $\mathrm{HH}$ & $\begin{array}{c}\text { Re-contact } \\
\text { rates }(\%)\end{array}$ & $\mathrm{HH}$ & $\begin{array}{c}\text { Re- } \\
\text { contact } \\
\text { rates (\%) }\end{array}$ & $\mathrm{HH}$ & $\begin{array}{c}\text { Re-contact } \\
\text { rates }(\%)\end{array}$ & $\mathrm{HH}$ & $\begin{array}{c}\mathrm{Re}- \\
\text { contact } \\
\text { rates }(\%)\end{array}$ & $\mathrm{HH}$ & $\begin{array}{c}\mathrm{Re}- \\
\text { contact } \\
\text { rates }(\%)\end{array}$ \\
\hline Dynasty contacted & 7,224 & 6,821 & 94.4 & 6,883 & 95.3 & 6,761 & 93.6 & 6,647 & 92.0 & 6,341 & 87.8 \\
\hline Dynasty interviewed & & 6,752 & 93.5 & 6,787 & 94 & 6,553 & 90.7 & 6,555 & 90.7 & 6,275 & 86.9 \\
\hline Dynasty died (cumulative) & & 69 & 1 & 97 & 1.3 & 211 & 2.9 & 317 & 4.4 & - & - \\
\hline Dynasty not contacted & & 403 & 5.6 & 341 & 4.7 & 463 & 6.4 & 577 & 8.0 & - & - \\
\hline
\end{tabular}

Source: IFLS2, IFLS3, IFLS4, IFLS5

Number of dynasties contacted includes those whose members all died and households that recombined into other households since the last survey. 


\begin{tabular}{|c|c|c|c|c|c|c|c|c|c|c|c|c|c|c|c|}
\hline & \multirow[b]{3}{*}{ Provinces $^{\text {a }}$} & \multirow{2}{*}{\multicolumn{3}{|c|}{1990 Population }} & \multirow{3}{*}{$\begin{array}{l}\text { IFLS } \\
1 \mathrm{HH} \\
\text { Ivwd }\end{array}$} & \multirow{2}{*}{\multicolumn{4}{|c|}{$\begin{array}{c}\text { IFLS2 Households } \\
\begin{array}{c}\text { Interviewed, died, or joined other } \\
\text { hh }\end{array} \\
\end{array}$}} & \multirow[b]{3}{*}{$\begin{array}{l}\text { Inter- } \\
\text { viewe } \\
\quad \mathrm{d}\end{array}$} & \multicolumn{5}{|c|}{ IFLS3 Households } \\
\hline & & & & & & & & & & & \multicolumn{4}{|c|}{ Interviewed, died, or joined other hh } & \multirow[b]{2}{*}{$\begin{array}{l}\text { Inter- } \\
\text { viewed }\end{array}$} \\
\hline & & $N(000)^{b}$ & $\%$ & $\begin{array}{l}\text { IFL } \\
\text { S } \\
\text { EAs }\end{array}$ & & $\begin{array}{c}\% \\
\text { IFLS } \\
1 \mathrm{HH} \\
\end{array}$ & $\begin{array}{c}\# \\
\text { IFLS1 } \\
\text { HH } \\
\end{array}$ & $\begin{array}{l}\text { Any } \\
\text { split- } \\
\text { off } \mathrm{HH}\end{array}$ & Total & & $\begin{array}{c}\% \\
\text { IFLS1 } \\
\text { HH }\end{array}$ & $\begin{array}{c}\# \\
\text { IFLS1 } \\
\text { HH } \\
\end{array}$ & $\begin{array}{l}\text { Any } \\
\text { split-off } \\
\text { HH }\end{array}$ & Total & \\
\hline 11 & Aceh & 3,476 & 1.9 & & & & & & & & & & & & \\
\hline 12 & North Sumatra & 10,391 & 5.7 & 26 & 563 & 89.5 & 504 & 44 & 548 & 545 & 90.7 & 507 & 241 & 748 & 738 \\
\hline 13 & West Sumatra & 4,041 & 2.2 & 14 & 351 & 93.7 & 329 & 50 & 379 & 374 & 93.9 & 325 & 192 & 517 & 507 \\
\hline 14 & Riau & 3,372 & 1.9 & & & & & & & & & & & & \\
\hline 15 & Jambi & 2,059 & 1.1 & & & & & & & & & & & & \\
\hline 16 & South Sumatra & 6,403 & 3.5 & 15 & 349 & 91.1 & 318 & 55 & 373 & 371 & 96.0 & 332 & 229 & 561 & 550 \\
\hline 17 & Bengkulu & 1,213 & 0.7 & & & & & & & & & & & & \\
\hline 18 & Lampung & 6,108 & 3.4 & 11 & 274 & 94.5 & 259 & 38 & 297 & 297 & 93.8 & 257 & 164 & 421 & 414 \\
\hline 31 & DKI Jakarta & 8,352 & 4.6 & 40 & 731 & 87.8 & 642 & 65 & $\begin{array}{r}707 \\
1,20\end{array}$ & 698 & 84.5 & 610 & 355 & 965 & 958 \\
\hline 32 & West Java & 5,973 & 19.8 & 52 & 1,111 & 96.0 & 1,066 & 141 & $\begin{array}{r}7 \\
1,00\end{array}$ & 1,191 & 97.6 & 1,067 & 603 & 1670 & 1,658 \\
\hline 33 & Central Java & 8,733 & 15.8 & 37 & 878 & 98.9 & 868 & 135 & 3 & 991 & 99.2 & 859 & 523 & 1382 & 1,362 \\
\hline 34 & DI Yogyakarta & 2,923 & 1.6 & 22 & 478 & 94.4 & 451 & 49 & $\begin{array}{r}500 \\
1,12\end{array}$ & 494 & 92.8 & 438 & 203 & 641 & 636 \\
\hline 35 & East Java & 32,713 & 18.0 & 45 & 1,044 & 96.2 & 1,004 & 117 & 1 & 1,111 & 99.0 & 1,025 & 462 & 1487 & 1,465 \\
\hline 51 & $\begin{array}{l}\text { Bali } \\
\text { West Nusa }\end{array}$ & 2,798 & 1.5 & 14 & 340 & 94.7 & 322 & 43 & 365 & 364 & 95.9 & 325 & 160 & 485 & 482 \\
\hline 52 & $\begin{array}{l}\text { Tenggara } \\
\text { East Nusa }\end{array}$ & 3,416 & 1.9 & 16 & 407 & 98.8 & 402 & 54 & 456 & 447 & 99.5 & 396 & 278 & 674 & 668 \\
\hline 53 & Tenggara & 3,306 & 1.8 & & & & & & & & & & & & \\
\hline 54 & East Timor & 762 & 0.4 & & & & & & & & & & & & \\
\hline 61 & West Kalimantan & 3,292 & 1.8 & & & & & & & & & & & & \\
\hline 62 & Central Kalimantan & 1,431 & 0.8 & & & & & & & & & & & & \\
\hline 63 & South Kalimantan & 2,636 & 1.5 & 13 & 323 & 91.6 & 296 & 51 & 347 & 344 & 95.6 & 306 & 202 & 508 & 488 \\
\hline 64 & East Kalimantan & 1,930 & 1.1 & & & & & & & & & & & & \\
\hline 71 & North Sulawesi & 2,504 & 1.4 & & & & & & & & & & & & \\
\hline 72 & Central Sulawesi & 1,735 & 1.0 & & & & & & & & & & & & \\
\hline 73 & South Sulawesi & 7,045 & 3.9 & 16 & 375 & 95.7 & 359 & 36 & 395 & 392 & 94.6 & 352 & 163 & 515 & 509 \\
\hline 74 & Southeast Sulawesi & 1,382 & 0.8 & & & & & & & & & & & & \\
\hline 81 & Maluku & 1,885 & 1.0 & & & & & & & & & & & & \\
\hline 82 & Irian Jaya & 1,671 & 0.9 & & & & & & & & & & & & \\
\hline & Total & 181,548 & $\begin{array}{r}100 . \\
0\end{array}$ & 321 & 7,224 & 94.4 & 6,820 & 878 & $\begin{array}{r}7,69 \\
8 \\
\end{array}$ & 7,619 & 95.2 & 6,799 & 3,775 & 10,574 & 10,435 \\
\hline
\end{tabular}




\begin{tabular}{|c|c|c|c|c|c|c|c|c|c|c|c|c|c|c|c|c|c|}
\hline & \multirow[b]{3}{*}{ Provinces $^{\text {a }}$} & \multirow{2}{*}{\multicolumn{3}{|c|}{1990 Population }} & \multirow{3}{*}{$\begin{array}{l}\text { IFLS } \\
1 \mathrm{HH} \\
\text { Ivwd }\end{array}$} & \multirow{2}{*}{\multicolumn{5}{|c|}{$\begin{array}{c}\text { IFLS4 Households } \\
\text { Interviewed, died, or joined other hh }\end{array}$}} & \multicolumn{5}{|c|}{$\begin{array}{l}\text { IFLS5 Households } \\
\end{array}$} & \multirow{2}{*}{\multicolumn{2}{|c|}{$\begin{array}{l}\text { Dynasties } \\
\text { contacted }\end{array}$}} \\
\hline & & & & & & & & & & & \multicolumn{4}{|c|}{ Interviewed, died, or joined other hh } & \multirow[b]{2}{*}{$\begin{array}{c}\text { Interview } \\
\text { ed }\end{array}$} & & \\
\hline & & $\mathrm{N}(000)^{\mathrm{b}}$ & $\%$ & $\begin{array}{c}\text { IFL } \\
\text { S } \\
\text { EAs }\end{array}$ & & $\begin{array}{c}\% \\
\text { IFLS1 } \\
\mathrm{HH}^{\mathrm{c}}\end{array}$ & $\begin{array}{c}\text { \# IFLS1 } \\
\mathrm{HH}^{\mathrm{d}}\end{array}$ & $\begin{array}{l}\text { Any } \\
\text { split- } \\
\text { off HH }\end{array}$ & Total & $\begin{array}{c}\text { Inter- } \\
\text { viewed }\end{array}$ & $\begin{array}{c}\% \\
\text { IFLS1 } \\
\text { HH }\end{array}$ & $\begin{array}{c}\# \\
\text { IFLS1 } \\
\text { HH }\end{array}$ & $\begin{array}{c}\text { Any } \\
\text { split- } \\
\text { off } \mathrm{HH}\end{array}$ & Total & & $\#$ & $\%$ \\
\hline 11 & Aceh & 3,476 & 1.9 & & & & & & & & & & & & & & \\
\hline 12 & North Sumatra & 10,391 & 5.7 & 26 & 563 & 87.6 & 493 & 532 & 1025 & 998 & 86.1 & 483 & 899 & 1,382 & 1,335 & 497 & 88.3 \\
\hline 13 & West Sumatra & 4,041 & 2.2 & 14 & 351 & 89.5 & 314 & 421 & 735 & 714 & 88.7 & 305 & 542 & 847 & 791 & 321 & 91.5 \\
\hline 14 & Riau & 3,372 & 1.9 & & & & & & & & & & & & & & \\
\hline 15 & Jambi & 2,059 & 1.1 & & & & & & & & & & & & & & \\
\hline 16 & South Sumatra & 6,403 & 3.5 & 15 & 349 & 86.2 & 301 & 435 & 736 & 712 & 85.5 & 295 & 620 & 915 & 882 & 308 & 88.3 \\
\hline 17 & Bengkulu & 1,213 & 0.7 & & & & & & & & & & & & & & \\
\hline 18 & Lampung & 6,108 & 3.4 & 11 & 274 & 93.4 & 256 & 329 & 585 & 569 & 94.1 & 257 & 503 & 760 & 733 & 263 & 96.0 \\
\hline 31 & DKI Jakarta & 8,352 & 4.6 & 40 & 731 & 75.4 & 551 & 637 & 1,188 & 1,147 & 68.5 & 492 & 748 & 1,240 & 1,170 & 540 & 73.9 \\
\hline 32 & West Java & 35,973 & 19.8 & 52 & 1,111 & 93.4 & 1,038 & 1,227 & 2,265 & 2,207 & 90.7 & 991 & 1,643 & 2,634 & 2,496 & 1,035 & 93.2 \\
\hline 33 & Central Java & 28,733 & 15.8 & 37 & 878 & 95.7 & 840 & 973 & 1,813 & 1,733 & 97.8 & 846 & 1,410 & 2,256 & 2,164 & 860 & 97.9 \\
\hline 34 & DI Yogyakarta & 2,923 & 1.6 & 22 & 478 & 91.0 & 435 & 382 & 817 & 786 & 89.2 & 420 & 542 & 962 & 926 & 430 & 90.0 \\
\hline 35 & East Java & 32,713 & 18.0 & 45 & 1,044 & 96.6 & 1,009 & 932 & 1,941 & 1,869 & 96.3 & 992 & 1,318 & 2,310 & 2,204 & 1,015 & 97.2 \\
\hline 51 & Bali & 2,798 & 1.5 & 14 & 340 & 92.9 & 316 & 330 & 646 & 625 & 92.6 & 313 & 485 & 798 & 765 & 318 & 93.5 \\
\hline 52 & West Nusa Tenggara & 3,416 & 1.9 & 16 & 407 & 98.0 & 399 & 484 & 883 & 858 & 99.8 & 400 & 786 & 1,186 & 1,147 & 406 & 99.8 \\
\hline 53 & East Nusa Tenggara & 3,306 & 1.8 & & & & & & & & & & & & & & \\
\hline 54 & East Timor & 762 & 0.4 & & & & & & & & & & & & & & \\
\hline 61 & West Kalimantan & 3,292 & 1.8 & & & & & & & & & & & & & & \\
\hline 62 & Central Kalimantan & 1,431 & 0.8 & & & & & & & & & & & & & & \\
\hline 63 & South Kalimantan & 2,636 & 1.5 & 13 & 323 & 93.8 & 303 & 376 & 679 & 653 & 91.9 & 294 & 475 & 769 & 739 & 302 & 93.5 \\
\hline 64 & East Kalimantan & 1,930 & 1.1 & & & & & & & & & & & & & & \\
\hline 71 & North Sulawesi & 2,504 & 1.4 & & & & & & & & & & & & & & \\
\hline 72 & Central Sulawesi & 1,735 & 1.0 & & & & & & & & & & & & & & \\
\hline 73 & South Sulawesi & 7,045 & 3.9 & 16 & 375 & 90.9 & 341 & 341 & 682 & 664 & 92.5 & 344 & 527 & 871 & 852 & 352 & 93.9 \\
\hline 74 & Southeast Sulawesi & 1,382 & 0.8 & & & & & & & & & & & & & & \\
\hline 81 & Maluku & 1,885 & 1.0 & & & & & & & & & & & & & & \\
\hline \multirow[t]{2}{*}{82} & Irian Jaya & 1,671 & 0.9 & & & & & & & & & & & & & & \\
\hline & Total & 1,548 & 100.0 & 321 & 7,224 & 91.3 & 6,596 & 7399 & 13,995 & 13,535 & 90.2 & 6,432 & 10,498 & 16,930 & 16.204 & 6,647 & 92.0 \\
\hline
\end{tabular}

a. Boldface denotes IFLS provinces in 1993. In 1999, East Timor voted for independence from Indonesia and became the soverign state of Timor Leste.

Also since 1999, a number of new provinces has been formed.

b. Source of population rumber is the BPS 1990 Population Census.

c. The percentage is out of IFLS1 HH with at least some members living in the last survey.

d. Includes IFLS1 HH whose members had all died or joined other IFLS households by the time of the survey. 
Table 2.3a Households interviewed since last survey

\begin{tabular}{|c|c|c|c|c|c|c|}
\hline Relocation & $\begin{array}{l}\text { All } \\
\text { Households } \\
\text { Interviewed }\end{array}$ & $\%$ & $\begin{array}{l}\text { IFLS1 Origin } \\
\text { Households }\end{array}$ & $\%$ & $\begin{array}{c}\text { Split-off } \\
\text { Households* }\end{array}$ & $\%$ \\
\hline Did not move & 8,530 & 53.6 & 4,787 & 79.5 & 3,735 & 37.8 \\
\hline Moved within village/township & 1,741 & 11.0 & 213 & 3.5 & 1,531 & 15.5 \\
\hline Moved within kecamatan & 1,862 & 11.7 & 638 & 10.6 & 1,225 & 12.4 \\
\hline Moved within kabupaten & 1,127 & 7.1 & 140 & 2.3 & 988 & 10.0 \\
\hline Moved within province & 1,361 & 8.6 & 104 & 1.7 & 1,260 & 12.8 \\
\hline Moved to another IFLS province & 1,065 & 6.7 & 117 & 1.9 & 950 & 9.6 \\
\hline Moved to non-IFLS province & 213 & 1.3 & 22 & 0.4 & 193 & 2.0 \\
\hline Total & 15,902 & 100.0 & 6,021 & 100.0 & 9,881 & 100.0 \\
\hline
\end{tabular}

*For new split-off households, location in the last survey is the location of the household where the individual was found in the last survey.

Table 2.3b Households interviewed since IFLS1

\begin{tabular}{|c|c|c|c|c|c|c|}
\hline Relocation & $\begin{array}{c}\text { All } \\
\text { Households } \\
\text { Interviewed }\end{array}$ & $\%$ & $\begin{array}{l}\text { IFLS1 Origin } \\
\text { Households }\end{array}$ & $\%$ & $\begin{array}{c}\text { Split-off } \\
\text { Households }\end{array}$ & $\%$ \\
\hline Did not move & 6,734 & 42.4 & 4,696 & 78.0 & 2,029 & 20.5 \\
\hline Moved within village/township & 1,911 & 12.0 & 226 & 3.8 & 1,688 & 17.1 \\
\hline Moved within kecamatan & 1,341 & 8.4 & 269 & 4.5 & 1,073 & 10.9 \\
\hline Moved within kabupaten & 1,816 & 11.4 & 278 & 4.6 & 1,539 & 15.6 \\
\hline Moved within province & 2,212 & 13.9 & 268 & 4.5 & 1,948 & 19.7 \\
\hline Moved to another IFLS province & 1,550 & 9.8 & 256 & 4.3 & 1,296 & 13.1 \\
\hline Moved to non-IFLS province & 336 & 2.1 & 28 & 0.5 & 308 & 3.1 \\
\hline Total & 15,902 & 100.0 & 6,021 & 100.0 & 9,881 & 100.0 \\
\hline
\end{tabular}

*For split-off households, location in IFLS1 is the location of the original IFLS1 dynasty. 
Table 2.4a IFLS5: Individuals in All Interviewed Households

\begin{tabular}{|c|c|c|c|c|c|c|c|c|c|c|c|c|c|c|c|c|c|c|}
\hline \multirow[b]{3}{*}{ Age group $^{a}$} & \multicolumn{6}{|c|}{ Both Males and Females } & \multicolumn{6}{|c|}{ Males } & \multicolumn{6}{|c|}{ Females } \\
\hline & \multirow{2}{*}{$\begin{array}{l}\text { Total } \\
\text { ind. in } \\
\mathrm{HHs}^{\mathrm{b}}\end{array}$} & \multirow{2}{*}{$\begin{array}{l}\text { Ivw } \\
\text { targets }^{c}\end{array}$} & \multicolumn{3}{|c|}{ Interviewed } & \multirow{2}{*}{$\begin{array}{l}\text { Exit } \\
\text { form } \\
\text { ivws }^{d}\end{array}$} & \multirow{2}{*}{$\begin{array}{l}\text { Total } \\
\text { ind. in } \\
\mathrm{HHs}^{\mathrm{b}}\end{array}$} & \multirow{2}{*}{$\begin{array}{c}\text { Ivw } \\
\text { targets }^{\mathrm{c}}\end{array}$} & \multicolumn{3}{|c|}{ Interviewed } & \multirow{2}{*}{$\begin{array}{l}\text { Exit } \\
\text { form } \\
\text { ivws }\end{array}$} & \multirow{2}{*}{$\begin{array}{c}\text { Total } \\
\text { ind. in } \\
\mathrm{HHs}^{\mathrm{b}}\end{array}$} & \multirow{2}{*}{$\begin{array}{l}\text { Ivw } \\
\text { targets }^{c}\end{array}$} & \multicolumn{3}{|c|}{ Interviewed } & \multirow{2}{*}{$\begin{array}{l}\text { Exit } \\
\text { form } \\
\text { ivws }\end{array}$} \\
\hline & & & Direct & Proxy & Total & & & & Direct & Proxy & Total & & & & Direct & Proxy & Total & \\
\hline Age $0-4$ & 6131 & 5818 & 5633 & - & 5633 & 0 & 3169 & 3011 & 2916 & - & 2916 & 0 & 2962 & 2807 & 2717 & - & 2717 & 0 \\
\hline Age 5-9 & 5,776 & 5,443 & 5,296 & - & 5,296 & 16 & 2,958 & 2,797 & 2,722 & - & 2,722 & 8 & 2,818 & 2,646 & 2,574 & - & 2,574 & 8 \\
\hline Age $10-14$ & 5,370 & 4,938 & 4,821 & - & 4,821 & 23 & 2,777 & 2,536 & 2,464 & - & 2,464 & 8 & 2,593 & 2,402 & 2,357 & - & 2,357 & 15 \\
\hline Age $15-19$ & 4,392 & 3,948 & 3,608 & 150 & 3,758 & 19 & 2,154 & 1,942 & 1,732 & 96 & 1,828 & 11 & 2,237 & 2,006 & 1,876 & 54 & 1,930 & 8 \\
\hline Age $20-29$ & 8,867 & 8,092 & 7,186 & 454 & 7,640 & 97 & 4,125 & 3,714 & 3,145 & 307 & 3,452 & 58 & 4,737 & 4,378 & 4,040 & 146 & 4,186 & 39 \\
\hline Age $40-49$ & 7,050 & 6,295 & 5,604 & 326 & 5,930 & 219 & 3,567 & 3,249 & 2,766 & 253 & 3,019 & 132 & 3,482 & 3,046 & 2,838 & 73 & 2,911 & 87 \\
\hline Age 50-59 & 5,209 & 4,259 & 3,787 & 249 & 4,036 & 291 & 2,405 & 1,997 & 1,738 & 138 & 1,876 & 163 & 2,803 & 2,262 & 2,049 & 111 & 2,160 & 128 \\
\hline Age 60-69 & 3,077 & 2,389 & 1,984 & 260 & 2,244 & 402 & 1,473 & 1,143 & 964 & 108 & 1,072 & 223 & 1,604 & 1,246 & 1,020 & 152 & 1,172 & 179 \\
\hline Age $70-79$ & 1,612 & 1,315 & 832 & 432 & 1,264 & 645 & 694 & 570 & 397 & 159 & 556 & 299 & 918 & 745 & 435 & 273 & 708 & 346 \\
\hline Age $80+$ & 679 & 522 & 145 & 354 & 499 & 803 & 270 & 209 & 72 & 128 & 200 & 352 & 409 & 313 & 73 & 226 & 299 & 45 \\
\hline Total & 58,337 & 52,568 & 47,348 & 2,800 & 50,148 & 2,662 & 28,595 & 25,897 & 22,888 & 1,628 & 24,516 & 1,346 & 29,730 & 26,671 & 24,457 & 1,171 & 25,628 & 910 \\
\hline
\end{tabular}

a. Age is age of household member in 2014 .

c. Interview targets are those with ar01i=1, conditional on living in the household.

d. Exit interviews were administered to those who died whose ar01i=1.

Table 2.bc IFLS5: Individuals in 1993 Original Households

\begin{tabular}{|c|c|c|c|c|c|c|c|c|c|c|c|c|c|c|c|}
\hline \multirow[b]{3}{*}{ Age group $^{a}$} & \multicolumn{5}{|c|}{ Both Males and Females } & \multicolumn{5}{|c|}{ Males } & \multicolumn{5}{|c|}{ Females } \\
\hline & \multirow{2}{*}{$\begin{array}{l}\text { Total ind. } \\
\text { in } \mathrm{HHs}^{\mathrm{b}}\end{array}$} & \multicolumn{3}{|c|}{ Interviewed } & \multirow{2}{*}{$\begin{array}{l}\text { Exit form } \\
\text { ivws }\end{array}$} & \multirow{2}{*}{$\begin{array}{l}\text { Total ind. } \\
\text { in } \mathrm{HHs}^{\mathrm{b}}\end{array}$} & \multicolumn{3}{|c|}{ Interviewed } & \multirow{2}{*}{$\begin{array}{l}\text { Exit form } \\
\text { ivws }\end{array}$} & \multirow{2}{*}{$\begin{array}{c}\text { Total ind. in } \\
\mathrm{HHs}^{\mathrm{b}}\end{array}$} & \multicolumn{3}{|c|}{ Interviewed } & \multirow{2}{*}{$\begin{array}{l}\text { Exit form } \\
\text { ivws }\end{array}$} \\
\hline & & Direct & Proxy & Total & & & Direct & Proxy & Total & & & Direct & Proxy & Total & \\
\hline Age $0-4$ & 1,730 & 1,668 & - & 1,668 & 0 & 896 & 863 & - & 863 & 0 & 834 & 805 & - & 805 & 0 \\
\hline Age 5-9 & 1,720 & 1,668 & - & 1,668 & 5 & 865 & 836 & - & 836 & 1 & 855 & 832 & - & 832 & 4 \\
\hline Age $10-14$ & 1,849 & 1,812 & - & 1,812 & 12 & 920 & 898 & - & 898 & 5 & 929 & 914 & - & 914 & 7 \\
\hline Age $15-19$ & 1,781 & 1,597 & 78 & 1,675 & 11 & 912 & 796 & 52 & 848 & 7 & 869 & 801 & 26 & 827 & 4 \\
\hline Age $20-29$ & 3,407 & 2,914 & 233 & 3,147 & 70 & 1,757 & 1,449 & 159 & 1,608 & 42 & 1,645 & 1,464 & 73 & 1,537 & 28 \\
\hline Age $30-39$ & 2,621 & 2,189 & 209 & 2,398 & 92 & 1,324 & 1,039 & 143 & 1,182 & 66 & 1,294 & 1,149 & 66 & 1,215 & 26 \\
\hline Age $40-49$ & 2,995 & 2,662 & 153 & 2,815 & 147 & 1,252 & 1,061 & 97 & 1,158 & 75 & 1,742 & 1,601 & 56 & 1,657 & 72 \\
\hline Age 50-59 & 3,505 & 3,139 & 193 & 3,332 & 252 & 1,550 & 1,357 & 102 & 1,459 & 136 & 1,954 & 1,782 & 91 & 1,873 & 116 \\
\hline Age $60-69$ & 2,123 & 1,771 & 217 & 1,988 & 354 & 1,008 & 850 & 93 & 943 & 192 & 1,115 & 921 & 124 & 1,045 & 162 \\
\hline Age $70-79$ & 1,194 & 757 & 392 & 1,149 & 587 & 519 & 360 & 146 & 506 & 265 & 675 & 397 & 246 & 643 & 322 \\
\hline Age 80+ & 456 & 128 & 310 & 438 & 736 & 181 & 63 & 111 & 174 & 327 & 275 & 65 & 199 & 264 & 409 \\
\hline Total & 23,381 & 20,305 & 1,785 & 22,090 & 2,266 & 11,184 & 9,572 & 903 & 10,475 & 1,116 & 12,187 & 10,731 & 881 & 11,612 & 1,150 \\
\hline
\end{tabular}

a. Age is age of household member in 2014. 
b. All household members living in the household..

c. All household members in 1993 original $\mathrm{HH}$ are interview targets.

d. Exit interviews were administered to those who died whose ar01i=1.

Table 2.4c IFLS5: Individuals in 1997, 1998, 2000, 2007, and 2014 Split-off Households

\begin{tabular}{|c|c|c|c|c|c|c|c|c|c|c|c|c|c|c|c|c|c|c|}
\hline \multirow[b]{3}{*}{ Age group } & \multicolumn{6}{|c|}{ Both Males and Females } & \multicolumn{6}{|c|}{ Males } & \multicolumn{6}{|c|}{ Females } \\
\hline & \multirow{2}{*}{$\begin{array}{l}\text { Total } \\
\text { ind. in } \\
\mathrm{HHs}^{\mathrm{b}}\end{array}$} & \multirow{2}{*}{$\begin{array}{c}\text { Ivw } \\
\text { targets }^{\mathrm{c}}\end{array}$} & \multicolumn{3}{|c|}{ Interviewed } & \multirow{2}{*}{$\begin{array}{l}\text { Exit } \\
\text { form } \\
\text { ivws }\end{array}$} & \multirow{2}{*}{$\begin{array}{l}\text { Total } \\
\text { ind. in } \\
\mathrm{HH}^{\mathrm{b}}{ }^{\mathrm{b}}\end{array}$} & \multirow{2}{*}{$\begin{array}{c}\text { Ivw } \\
\text { targets }^{c}\end{array}$} & \multicolumn{3}{|c|}{ Interviewed } & \multirow{2}{*}{$\begin{array}{l}\text { Exit } \\
\text { form } \\
\text { ivws }\end{array}$} & \multirow{2}{*}{$\begin{array}{l}\text { Total } \\
\text { ind. in } \\
\mathrm{HHs}^{\mathrm{b}}\end{array}$} & \multirow{2}{*}{$\begin{array}{c}\text { Ivw } \\
\text { targets }^{\mathrm{c}}\end{array}$} & \multicolumn{3}{|c|}{ Interviewed } & \multirow{2}{*}{$\begin{array}{l}\text { Exit } \\
\text { form } \\
\text { ivws }\end{array}$} \\
\hline & & & Direct & Proxy & Total & & & & Direct & Proxy & Total & & & & Direct & Proxy & Total & \\
\hline Age $0-4$ & 4,401 & 4,088 & 3,965 & - & 3,965 & 0 & 2,273 & 2,115 & 2,053 & - & 2,053 & 0 & 2,128 & 1,973 & 1,912 & - & 1,912 & 0 \\
\hline Age 5-9 & 4,056 & 3,723 & 3,628 & - & 3,628 & 11 & 2,093 & 1,932 & 1,886 & - & 1,886 & 7 & 1,963 & 1,791 & 1,742 & - & 1,742 & 4 \\
\hline Age $10-14$ & 3,521 & 3,089 & 3,009 & - & 3,009 & 11 & 1,857 & 1,616 & 1,566 & - & 1,566 & 3 & 1,664 & 1,473 & 1,443 & - & 1,443 & 8 \\
\hline Age 15-19 & 2,611 & 2,171 & 2,011 & 72 & 2,083 & 8 & 1,242 & 1,030 & 936 & 44 & 980 & 4 & 1,368 & 1,141 & 1,075 & 28 & 1,103 & 4 \\
\hline Age $30-39$ & 7,553 & 6,933 & 6,263 & 366 & 6,629 & 55 & 3,679 & 3,407 & 2,933 & 296 & 3,229 & 26 & 3,873 & 3,526 & 3,329 & 70 & 3,399 & 29 \\
\hline Age $40-49$ & 4,055 & 3,307 & 2,942 & 173 & 3,115 & 72 & 2,315 & 2,000 & 1,705 & 156 & 1,861 & 57 & 1,740 & 1,307 & 1,237 & 17 & 1,254 & 15 \\
\hline Age $50-59$ & 1,704 & 756 & 648 & 56 & 704 & 39 & 855 & 447 & 381 & 36 & 417 & 27 & 849 & 309 & 267 & 20 & 287 & 12 \\
\hline Age 60-69 & 954 & 266 & 213 & 43 & 256 & 48 & 465 & 135 & 114 & 15 & 129 & 31 & 489 & 131 & 99 & 28 & 127 & 17 \\
\hline Age $70-79$ & 418 & 121 & 75 & 40 & 115 & 58 & 175 & 51 & 37 & 13 & 50 & 34 & 243 & 70 & 38 & 27 & 65 & 24 \\
\hline Age $80+$ & 223 & 66 & 17 & 44 & 61 & 67 & 89 & 28 & 9 & 17 & 26 & 25 & 134 & 38 & 8 & 27 & 35 & 4 \\
\hline Total & 34,956 & 29,210 & 27,043 & 1,015 & 28,058 & 396 & 17,411 & 14,718 & 13,316 & 725 & 14,041 & 230 & 17,543 & 14,492 & 13,726 & 290 & 14,016 & 128 \\
\hline
\end{tabular}

a. $\quad$ Age is age of household member in 2014 .

c. Interview targets are those with ar01i=1, conditional on living in the household

d. Exit interviews were administered to those who died whose ar01i $=1$. 
Table 2.5 Status of IFLS1 HH Members in IFLS5

\begin{tabular}{|c|c|c|c|c|c|c|c|c|c|}
\hline & $\begin{array}{l}\text { Total } \\
\text { IFLS1 } \\
\text { Members }\end{array}$ & $\begin{array}{l}\text { Still in } \\
\text { origin } \mathrm{HH}\end{array}$ & $\begin{array}{l}\text { Returned } \\
\text { to orign } \\
\mathrm{HH}\end{array}$ & $\begin{array}{l}\text { Moved } \\
\text { from } \\
\text { origin HH, } \\
\text { found } \\
\text { elswehere }\end{array}$ & $\begin{array}{l}\text { Died } \\
\text { since } \\
\text { IFLS1 } \\
\end{array}$ & $\begin{array}{l}\text { Found } \\
\text { or died } \\
\text { in } \mathrm{HH} \\
\text { that } \\
\text { were } \\
\text { found } \\
\end{array}$ & $\begin{array}{l}\text { Moved } \\
\text { from } \\
\text { orgin } \mathrm{HH} \text {, } \\
\text { not found }\end{array}$ & $\begin{array}{l}\text { In HH that } \\
\text { were not } \\
\text { found }\end{array}$ & $\begin{array}{l}\% \text { found } \\
\text { or died in } \\
\text { HH that } \\
\text { were } \\
\text { found }\end{array}$ \\
\hline \multicolumn{10}{|c|}{ IFLS1 household roster members } \\
\hline Total & 33,081 & 11,040 & 948 & 8,667 & 4,538 & 25,193 & 4,353 & 3,535 & $76 \%$ \\
\hline Interviewed in IFLS5 & 19,732 & 10,485 & 879 & 8,368 & 1,622 & 19,732 & & & \\
\hline \multicolumn{10}{|l|}{ IFLS1 main respondent } \\
\hline Total & 22,019 & 9,031 & 575 & 4,415 & 3,939 & 17,960 & 1,642 & 2,417 & $82 \%$ \\
\hline Interviewed in IFLS5 & 13,461 & 8,640 & 541 & 4,280 & 1,406 & 13,461 & & & - \\
\hline \multicolumn{10}{|c|}{ IFLS1 household members by age group } \\
\hline \multicolumn{10}{|l|}{ Age $0-4$} \\
\hline Total & 3,586 & 1,152 & 154 & 1,238 & 109 & 2,653 & 662 & 271 & $74 \%$ \\
\hline Interviewed & 2,170 & 1,076 & 145 & 1,202 & 33 & 2,423 & & & \\
\hline \multicolumn{10}{|l|}{ Age 5-9 } \\
\hline Total & 3,737 & 718 & 243 & 1,663 & 89 & 2,713 & 759 & 247 & $73 \%$ \\
\hline Interviewed & 2,259 & 681 & 228 & 1,615 & 28 & 2,524 & & & \\
\hline \multicolumn{10}{|l|}{ Age $10-14$} \\
\hline Total & 4,197 & 594 & 182 & 2,063 & 124 & 2,963 & 898 & 325 & $71 \%$ \\
\hline Interviewed & 2,463 & 553 & 169 & 2,004 & 40 & 2,726 & & & \\
\hline \multicolumn{10}{|l|}{ Age $15-19$} \\
\hline Total & 3,616 & 472 & 127 & 1,393 & 152 & 2,144 & 1,038 & 426 & $59 \%$ \\
\hline Interviewed & 1,787 & 448 & 114 & 1,333 & 47 & 1,895 & & & \\
\hline \multicolumn{10}{|l|}{ Age $20-29$} \\
\hline Total & 5,406 & 2,067 & 113 & 1,532 & 266 & 3,978 & 741 & 647 & $74 \%$ \\
\hline Interviewed & 3,439 & 2,030 & 106 & 1,467 & 115 & 3,603 & & & \\
\hline \multicolumn{10}{|l|}{ Age $30-39$} \\
\hline Total & 4,542 & 2,872 & 75 & 442 & 469 & 3,858 & 173 & 454 & $85 \%$ \\
\hline Interviewed & 3,158 & 2,793 & 65 & 424 & 232 & 3,282 & & & \\
\hline \multicolumn{10}{|l|}{ Age 40-49 } \\
\hline Total & 2,917 & 1,700 & 26 & 171 & 651 & 2,548 & 45 & 296 & $87 \%$ \\
\hline Interviewed & 1,772 & 1,637 & 26 & 164 & 305 & 1,827 & & & \\
\hline \multicolumn{10}{|l|}{ Age 50-59 } \\
\hline Total & 2,467 & 973 & 18 & 101 & 1026 & 2,118 & 31 & 301 & $86 \%$ \\
\hline Interviewed & 1,041 & 962 & 17 & 97 & 433 & 1,076 & & & \\
\hline \multicolumn{10}{|l|}{ Age 60-69 } \\
\hline Total & 1,615 & 274 & 8 & 54 & 941 & 1,277 & 5 & 332 & $79 \%$ \\
\hline Interviewed & 320 & 268 & 7 & 53 & 287 & 328 & & & \\
\hline \multicolumn{10}{|l|}{ Age $70-79$} \\
\hline Total & 722 & 34 & 2 & 8 & 489 & 533 & 1 & 188 & $74 \%$ \\
\hline Interviewed & 45 & 34 & 2 & 8 & 87 & 44 & & & \\
\hline \multicolumn{10}{|l|}{ Age $80+$} \\
\hline Total & 276 & 4 & 0 & 2 & 222 & 228 & 0 & 48 & $83 \%$ \\
\hline Interviewed & 4 & 3 & 0 & 1 & 15 & 4 & & & \\
\hline
\end{tabular}

a. Percentage is out of total IFLS1 household members.

b. "Interviewed" means interviewed with individual book for individuals who were alive, and Exit Form for those who have died .

c. Age is age of household member in 1993. 
Table 2.6a. Current IFLS5 Household Members

\begin{tabular}{|c|c|c|c|c|c|c|c|c|c|c|c|}
\hline & & $\begin{array}{l}\text { Original } \\
\text { IFLS1 } \\
\text { household } \\
\text { members }\end{array}$ & $\begin{array}{l}\text { IFLS1 "Main } \\
\text { Respondents" }\end{array}$ & $\begin{array}{c}\text { New } \\
\text { IFLS2 } \\
\text { nembers }\end{array}$ & $\begin{array}{c}\text { New } \\
\text { IFLS2+ } \\
\text { members }\end{array}$ & $\begin{array}{c}\text { New } \\
\text { IFLS3 } \\
\text { members }\end{array}$ & $\begin{array}{c}\text { New } \\
\text { IFLS4 } \\
\text { nembers }\end{array}$ & $\begin{array}{c}\text { New } \\
\text { IFLS5 } \\
\text { members }\end{array}$ & $\begin{array}{c}\text { All IFLS5 } \\
\text { household } \\
\text { members }\end{array}$ & $\begin{array}{c}\text { Panel } \\
\text { roster } \\
\text { members }\end{array}$ & $\begin{array}{c}\text { Panel } \\
\text { members } \\
\text { interviewed }^{\mathrm{b}}\end{array}$ \\
\hline \multirow[t]{3}{*}{ Total } & & 20,648 & 14,254 & 3,404 & 556 & 4,782 & 11,956 & 16,979 & 58,325 & 17,295 & 11,889 \\
\hline & Male & 9,646 & 6,388 & 1,645 & 281 & 2,384 & 6,050 & 8,589 & 28,595 & 7,973 & 5,216 \\
\hline & Female & 11,002 & 7,866 & 1,759 & 275 & 2,398 & 5,906 & 8,390 & 29,730 & 9,322 & 6,673 \\
\hline \multicolumn{12}{|l|}{ Male $^{\mathrm{c}}$} \\
\hline & Children $0-14$ & 0 & 0 & 0 & 0 & 303 & 3,504 & 4,534 & 8,341 & 0 & 0 \\
\hline & Adult 15 and above & 9,646 & 6,388 & 1549 & 241 & 1,784 & 1,857 & 2,476 & 17,553 & 7,973 & 5,216 \\
\hline & Adult 40 and above & 4,934 & 3,513 & 458 & 90 & 568 & 628 & 490 & 7,168 & 4,177 & 3,406 \\
\hline \multicolumn{12}{|c|}{ Female $^{c}$} \\
\hline & Children $0-14$ & 0 & 0 & 0 & 0 & 261 & 3,310 & 4,283 & 7,854 & 0 & 0 \\
\hline & Adult 15 and above & 1,102 & 7,866 & 1,637 & 237 & 1,794 & 1,816 & 2,327 & 8,913 & 9,322 & 6,673 \\
\hline & Adult 40 and above & 6,048 & 4,854 & 435 & 65 & 403 & 338 & 311 & 7,600 & 5,374 & 4,303 \\
\hline
\end{tabular}

a. Household roster members in IFLS1, IFLS2, IFLS3, IFLS4, and IFLS5

b. Household members with individual book interview in IFLS1, IFLS2, IFLS3, IFLS4, and IFLS5

c. Age is age in 2014 
Table 2.6b. Ever IFLS Members

\begin{tabular}{|c|c|c|c|c|c|c|c|c|c|}
\hline & & $\begin{array}{l}\text { Original } \\
\text { IFLS1 } \\
\text { household } \\
\text { members }\end{array}$ & $\begin{array}{l}\text { IFLS1 "Main } \\
\text { Respondents" }\end{array}$ & $\begin{array}{c}\text { New } \\
\text { IFLS2 } \\
\text { nembers }\end{array}$ & $\begin{array}{c}\text { New } \\
\text { IFLS2+ } \\
\text { members }\end{array}$ & $\begin{array}{c}\text { New } \\
\text { IFLS3 } \\
\text { members }\end{array}$ & $\begin{array}{c}\text { New } \\
\text { IFLS4 } \\
\text { members }\end{array}$ & $\begin{array}{c}\text { New } \\
\text { IFLS5 } \\
\text { members }\end{array}$ & $\begin{array}{c}\text { Ever IFLS } \\
\text { household } \\
\text { members }\end{array}$ \\
\hline \multirow[t]{3}{*}{ Total } & & 33,081 & 22,019 & 6,694 & 1,458 & 9,907 & 15,581 & 16,979 & 83,700 \\
\hline & Male & 16,087 & 10,448 & 3,240 & 737 & 4,914 & 7,852 & 8,589 & 41,419 \\
\hline & Female & 16,994 & 11,571 & 3,454 & 721 & 4,993 & 7,729 & 8,390 & 42,281 \\
\hline \multicolumn{10}{|l|}{ Male $^{a}$} \\
\hline & Children $0-14$ & 352 & 213 & 1,255 & 177 & 1,756 & 4,446 & 4,974 & 12,960 \\
\hline & Adult 15 and above & 15,735 & 10,235 & 1,985 & 538 & 3,147 & 3,356 & 3,602 & 28,363 \\
\hline & Adult 40 and above & 6,832 & 5,927 & 695 & 175 & 1,048 & 883 & 1,063 & 10,696 \\
\hline \multicolumn{10}{|c|}{ Female $^{a}$} \\
\hline & Children $0-14$ & 357 & 201 & 1,256 & 170 & 1,633 & 4,274 & 4,698 & 12,388 \\
\hline & Adult 15 and above & 16,637 & 11,370 & 2,198 & 529 & 3,347 & 3,404 & 3,677 & 29,792 \\
\hline & Adult 40 and above & 7,654 & 6,741 & 753 & 182 & 1,116 & 912 & 1,082 & 11,699 \\
\hline
\end{tabular}

a. Age is age in 2014 
Table 2.7 Household Survey Questionnaire

Respondent $\quad$ Module Remarks

Book T: Tracking Record
\begin{tabular}{llll}
\hline All respondents & Cover & Contact results & Results of contact with the households. \\
& SC & $\begin{array}{l}\text { Sampling and enumeration } \\
\text { record }\end{array}$ & Not in public release.
\end{tabular}

Book K: Control Book and Household Roster

Household head, SC Sampling and enumeration

spouse, or record

knowledgeable other

person

AR Household roster

For panel respondents, preprinted with the names of all previous IFLS household members.

KRK Housing characteristics (Interviewer's observation)

IK Information about where

Not in public release. the respondents moved

FP Interview book check and

Manually filled in IFLS4 but automtically filled tracking form in by CAPI in IFLS5. Not in public release.

CP See Note at end of table.

\section{Book EF: Exit Form}

Surviving household E

member or other

knowledgeable person.
Exit form: information on New in IFLS5. respondents who died after the last interview in 2007.

\section{Book 1: Expenditures and Knowledge of Health Facilities}

Wife of household head, household head, or other knowledgeable person

KS

KSR

CR

PP

$\mathrm{CP}$
Crime

Household expenditures

Assistance received by household

Knowledge of outpatient care providers

See Note at end of table.
Same as IFLS4.

New questions about government assistance programs were added in IFLS4 and updated in IFLS5.

Available in IFLS4, removed in IFLS5.

\section{Book 2: Household Economy}

Household head, wife of KR Housing characteristics household head, or other household member
New questions about household participation in government assistance programs were added in IFLS5. 
ND

$\mathrm{BH}$

$\mathrm{CP}$
Detailed questions about rice harvest were added in IFLS4, updated in IFLS5. Additions made in IFLS to cover fisheries.

Available in IFLS4, removed in IFLS5.

Same as IFLS4, except in IFLS5 the detailed questions are asked only up to two of the most important non-farm businesses the household owns.

Same as IFLS4.

Pension income is added back in IFLS5.

Same as IFLS4.

Same as IFLS4.

\begin{tabular}{|c|c|c|c|}
\hline \multicolumn{4}{|c|}{ Book 3A: Adult Information (part 1) } \\
\hline $\begin{array}{l}\text { Each household member } \\
\text { age } 15 \text { and older. }\end{array}$ & $\mathrm{DL}$ & Education history & $\begin{array}{l}\text { Minor changes from IFLS4 in the questions } \\
\text { about UAN (national exams). }\end{array}$ \\
\hline \multirow[t]{10}{*}{$\begin{array}{l}\text { (IFLS1: administered to } \\
\text { only a subset of adult } \\
\text { household members) }\end{array}$} & PNA & $\begin{array}{l}\text { Positive and negative } \\
\text { affects to measure hedonic } \\
\text { well-being }\end{array}$ & $\begin{array}{l}\text { New in IFLS5, except for the questions about } \\
\text { pain which had already been added in IFLS4. }\end{array}$ \\
\hline & SW & Subjective well-being & Same as IFLS4 \\
\hline & $\mathrm{HR}$ & $\begin{array}{l}\text { Individual assets and } \\
\text { nonlabor income }\end{array}$ & Same as previous waves. \\
\hline & $\mathrm{HI}$ & Nonlabor income & Pension income is added back in IFLS5. \\
\hline & $\mathrm{KW}$ & Marital history & $\begin{array}{l}\text { Same as IFLS4. Panel respondents were } \\
\text { asked detailed questions about the current } \\
\text { marriage and any other marriage that was } \\
\text { current in } 2007 \text { or begun later. }\end{array}$ \\
\hline & PK & $\begin{array}{l}\text { Household decision- } \\
\text { making (married } \\
\text { respondents) }\end{array}$ & Same as IFLS4. \\
\hline & BR & $\begin{array}{l}\text { Pregnancy summary } \\
\text { (women age } 50 \text { and older) }\end{array}$ & $\begin{array}{l}\text { Panel respondents excluded (had already } \\
\text { answered these questions). }\end{array}$ \\
\hline & MG & Migration history & $\begin{array}{l}\text { Panel respondents were asked about all } \\
\text { migrations since } 2007 \text {. }\end{array}$ \\
\hline & TK & Employment history & $\begin{array}{l}\text { Respondents were asked about current work } \\
\text { and work since } 2007 \text {. Detailed questions on } \\
\text { contracts, severance pay, and, pension were } \\
\text { added in IFLS4 and kept in IFLS5. }\end{array}$ \\
\hline & RE & Retirement & Same as IFLS4. \\
\hline
\end{tabular}


SI

TR

$\mathrm{CP}$
Risk and time preferences

Trust
Same as IFLS4.

Same as IFLS4.

See Note at end of table.

\section{Book 3b: Adult Information (part 2)}

Each household member KM

age 15 and older.

(IFLS1: administered to only a subset of adult household members)

KK
Tobacco smoking

KP

$\mathrm{CO}$

$\mathrm{COB}$

VG

CD

MA

PSN

TDR

$\mathrm{EH}$

SA

AK

PS

RJ

RN

FM

BA

TF
Health conditions and physical performance

Depression scale

Cognitive test

Cognitive Capacity B

Health Vignettes

Chronic conditions

Acute morbidity

Personality traits

Sleep problems

Early Health

Childhood History/SocioEconomic conditions

Health Insurance

Self-treatment

Outpatient visits

Inpatient visits

Food intake frequency tables

Community participation

Non-coresident family roster and transfers

Transfer to/from outside household member
Few additions in IFLS4 on smoking behavoir that can be used as a measure of nicotine dependence.

Heavily revised in IFLS4 and modified in IFLS5. Few additions on ADLs and IADLs in IFLS5.

Same as IFLS4.

New in IFLS4 and updated in IFLS5.

New in IFLS 5.

Available in IFLS4 but dropped in IFLS5

Available in IFLS4 and IFLS5. List of chronic conditions updated.

Same as IFLS4.

New in IFLS5, using the Big Five Index 15 (BFI 15).

New in IFLS5

New in IFLS5

New in IFLS5.

Updated with new government programs in IFLS5 .

Same as IFLS4.

Additional questions on health expenditures in IFLS5.

Additional questions on health expenditures in IFLS5.

Some additions in IFLS5 include fast foods, and sweet snacks.

Redesigned in IFLS4 and no change in IFLS5

For panel respondents, preprinted with the names of IFLS1, 2 and 3 family members.

Non-biological parents added in IFLS4. 
CP See Note at end of table.

\begin{tabular}{|c|c|c|c|}
\hline \multirow{8}{*}{$\begin{array}{l}\text { Each ever-married } \\
\text { woman age } 15-49 \text {. } \\
\text { (IFLS1: administered to } \\
\text { only a subset of ever- } \\
\text { married woman age } 15- \\
\text { 49) }\end{array}$} & $\mathrm{KW}$ & Marital history & $\begin{array}{l}\text { Co-habitation added in IFLS4. Panel } \\
\text { respondents were asked detailed questions } \\
\text { about the current marriage and any other } \\
\text { marriage that was current in } 2007 \text { or begun } \\
\text { later. }\end{array}$ \\
\hline & $\mathrm{BR}$ & Pregnancy summary & Same as previous waves. \\
\hline & BA & $\begin{array}{l}\text { Non-coresident children } \\
\text { and transfers }\end{array}$ & $\begin{array}{l}\text { For panel respondents, preprinted with the } \\
\text { names of IFLS1,2,3 and } 4 \text { family members }\end{array}$ \\
\hline & $\mathrm{BF}$ & Breastfeeding update & Same as previous waves \\
\hline & $\mathrm{CH}$ & $\begin{array}{l}\text { Pregnancy and infant } \\
\text { feeding history }\end{array}$ & $\begin{array}{l}\text { Panel respondents were asked only about } \\
\text { pregnancies after the pregnancy that } \\
\text { produced the youngest child listed in IFLS4. }\end{array}$ \\
\hline & $\mathrm{BX}$ & $\begin{array}{l}\text { Non-co resident adopted } \\
\text { child roster }\end{array}$ & Same as IFLS4. \\
\hline & $\mathrm{CX}$ & $\begin{array}{l}\text { Contraceptive knowledge } \\
\text { and use }\end{array}$ & Same as IFLS4. \\
\hline & $\mathrm{CP}$ & See Note at end of table. & \\
\hline
\end{tabular}

\begin{tabular}{llll}
\hline \multicolumn{2}{l}{ Book 5: Child Information } & & \\
\hline Each child, age 0-14 & DLA & Child education history & Same as IFLS4. \\
$\begin{array}{l}\text { (usually answered by } \\
\text { the mother if the child } \\
\text { was less than 11 year) }\end{array}$ & MAA & Child acute morbidity & Same as previous waves. \\
$\begin{array}{l}\text { IFLS1: administered to } \\
\text { only 2 children of } \\
\text { household head }\end{array}$ & RJA & Child self-treatment & Same as previous waves. \\
& FMA & Food intake frequencies & Same as IFLS4. \\
& RNA & Child inpatient visits & Same as IFLS4. \\
& BAA & Parental information & Same as IFLS4. \\
& CP & See Note at end of table. &
\end{tabular}

\section{Book Proxy: Adult Information by Proxy}

Someone who answered for the intended respondent to book 3A, 3B, or 4 in his/her absence
Shortened versions of other modules:

Book 3A-KW, MG, DL, PNA ,TK

Book 3B-PM, KM, KK, MA, AK, CD, RJ, $\mathrm{RN}, \mathrm{BH}, \mathrm{TF}$

Book 4-BR, CH, CX, BA 
CP See Note at end of table.

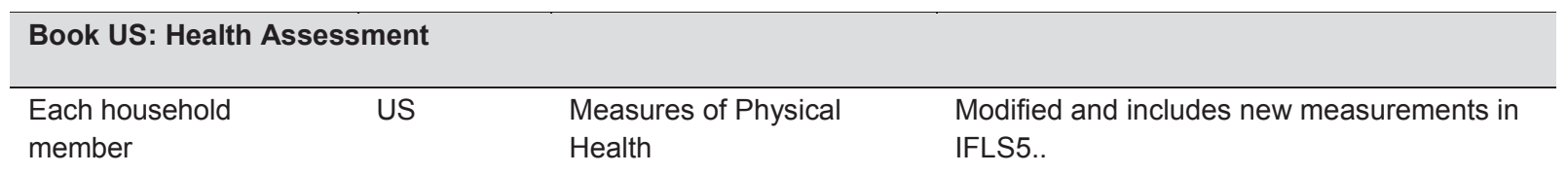

\begin{tabular}{lll}
\hline Book EK: Cognitive Assessment & \\
\hline $\begin{array}{l}\text { Each household } \\
\text { member }\end{array}$ & $\begin{array}{l}\text { Skills in abstract reasoning } \\
\text { and in numeracy }\end{array}$ & $\begin{array}{l}\text { IFLS5 extends the age range for those taking } \\
\text { EK2 test. }\end{array}$ \\
& $\begin{array}{l}\text { EK1 is given to respondents aged 7-14. EK2 } \\
\text { is given to all respondents aged 15 and } \\
\text { above. Respondents aged } 60 \text { and over were } \\
\text { not given the arithmetic part of the test. }\end{array}$
\end{tabular}

Note: Every book includes a cover page on which information is included regarding time and date of interview, interviewer code and the result of the interview. The CP module at the end of nearly every book asked the interviewer to record the conditions of the interview (who else was present, whether others provided assistance in answering questions), the respondent's level of attention, and any other relevant information about the interview environment. The interviewer could also add information to explain or clarify the respondent's answers. 
Table 2.8 IFLS5 Household Survey Completion Times, by Questionnaire Book

\begin{tabular}{|c|c|c|c|c|}
\hline & Book & $\begin{array}{c}\text { Median } \\
\text { completion } \\
\text { time (minute) }\end{array}$ & $\begin{array}{c}\% \text { Books } \\
\text { Completed in } \\
\text { One Visit }\end{array}$ & $\begin{array}{c}\text { \# Books } \\
\text { Completed }\end{array}$ \\
\hline $\mathrm{K}$ & Control Book & 21 & 98.41 & 15,920 \\
\hline 1 & $\begin{array}{l}\text { Household expenditures, health } \\
\text { facility knowledge }\end{array}$ & 41 & 97.13 & 15,348 \\
\hline 2 & Household economy & 24 & 98.08 & 15,351 \\
\hline $3 \mathrm{~A}$ & Adult information & 39 & 96.03 & 36,384 \\
\hline 3B & Adult information & 41 & 96.09 & 36,378 \\
\hline 4 & Ever-married woman information & 16 & 99.00 & 13,057 \\
\hline 5 & Child information & 15 & 98.85 & 16,197 \\
\hline $3 P$ & Proxy Book for Adults & 27 & 98.65 & 2,819 \\
\hline US & Health assesment & 14 & 99.75 & 52,568 \\
\hline EK & Cognitive assesment $7-14$ year old & 2 & 99.89 & 14,941 \\
\hline EK & Cognitive assesment $15-24$ year old & 2 & 99.91 & 36,372 \\
\hline FE & Exit form & 8 & 98.41 & 2,332 \\
\hline
\end{tabular}

Table 2.9 IFLS5 Household Survey Completion Times, by Respondent Type and Questionnaire Part

\section{Median completion time (minute)}

Respondent type

Married women, age 15-49

157

Unmarried women, age 15-49

Women, age 50+

Married men

Unmarried men

Children, age 11-14

Questionnaire part:

Book 3A for panel respondents 38

Book 3A for new respondents $\quad 41$

Book 3B for panel respondents $\quad 46$

Book 3B for new respondents $\quad 34$


Table 3.1 Community and Facility Survey Interviews Completed in IFLS1, IFLS2, IFLS3, IFLS4, and IFLS5 by Respondent and Facility Types

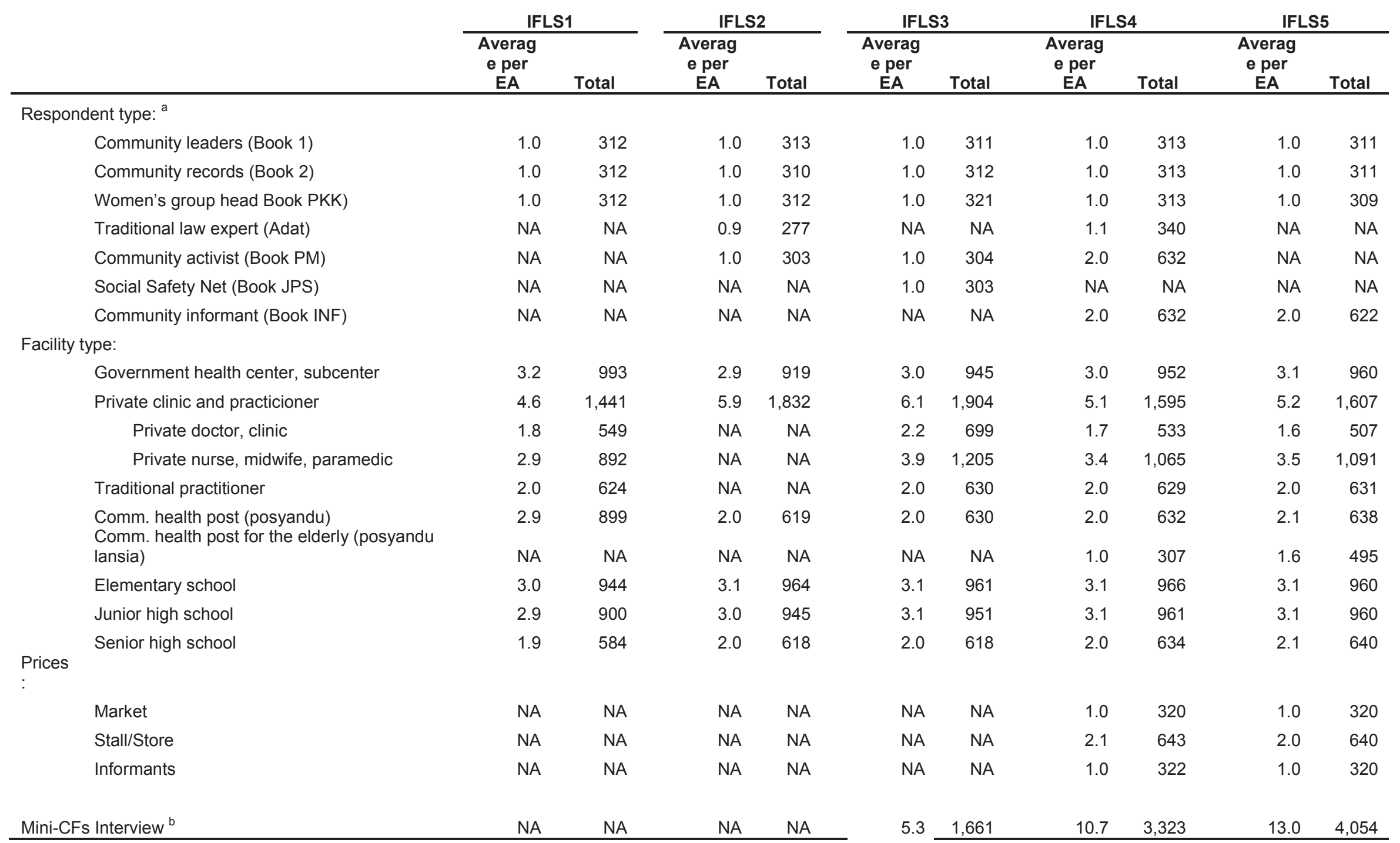


${ }^{a}$ For respondent and facility types, per EA means per IFLS original enumeration areas.

${ }^{b}$ For mini-CFs interviews, per EA means per community for households that moved out of the 321 original enumeration areas

Table 3.2 CFS Interviews in IFLS5 by Province and Facility Type

\begin{tabular}{|c|c|c|c|c|c|c|c|c|c|}
\hline IFLS Province ${ }^{a}$ & $\begin{array}{l}\text { Community } \\
\text { Health } \\
\text { Centers }\end{array}$ & $\begin{array}{l}\text { Private } \\
\text { Doctor, } \\
\text { Clinic }\end{array}$ & $\begin{array}{l}\text { Private } \\
\text { nurse, } \\
\text { midwife, } \\
\text { paramedic }\end{array}$ & $\begin{array}{l}\text { Traditional } \\
\text { Practice }\end{array}$ & $\begin{array}{l}\text { Community } \\
\text { Health Post }\end{array}$ & $\begin{array}{l}\text { Community } \\
\text { Health Post } \\
\text { for the } \\
\text { Elderly }\end{array}$ & $\begin{array}{l}\text { Elementary } \\
\text { School }\end{array}$ & $\begin{array}{l}\text { Junior } \\
\text { High } \\
\text { School }\end{array}$ & $\begin{array}{l}\text { Senior } \\
\text { High } \\
\text { School }\end{array}$ \\
\hline North Sumatra & 78 & 40 & 90 & 52 & 51 & 31 & 78 & 78 & 52 \\
\hline West Sumatra & 42 & 24 & 46 & 28 & 28 & 25 & 42 & 42 & 28 \\
\hline South Sumatra & 45 & 9 & 66 & 30 & 30 & 24 & 45 & 45 & 30 \\
\hline Lampung & 33 & 11 & 44 & 22 & 22 & 16 & 33 & 33 & 22 \\
\hline DKI Jakarta & 120 & 117 & 83 & 80 & 80 & 75 & 120 & 120 & 79 \\
\hline West Java & 153 & 86 & 169 & 102 & 102 & 64 & 153 & 153 & 103 \\
\hline Central Java & 110 & 43 & 140 & 74 & 73 & 66 & 111 & 109 & 74 \\
\hline DI Yogyakarta & 67 & 52 & 60 & 44 & 45 & 42 & 66 & 68 & 44 \\
\hline East Java & 135 & 56 & 169 & 90 & 89 & 78 & 135 & 135 & 90 \\
\hline Bali & 42 & 25 & 45 & 28 & 28 & 14 & 42 & 42 & 28 \\
\hline West Nusa Tenggara & 48 & 8 & 72 & 32 & 32 & 20 & 48 & 48 & 32 \\
\hline South Kalimantan & 39 & 9 & 55 & 26 & 26 & 19 & 39 & 39 & 26 \\
\hline South Sulawesi & 48 & 27 & 52 & 31 & 32 & 21 & 48 & 48 & 32 \\
\hline
\end{tabular}

52

32

21 Belitung Province, facilities in

West Java include those in Banten, and facilties in South Sulawesi include those in West Sulawesi. 


\begin{tabular}{|c|c|c|c|c|c|c|}
\hline & & $\begin{array}{c}\text { Community } \\
\text { Health } \\
\text { Centers } \\
\end{array}$ & $\begin{array}{c}\text { Privace clinics } \\
\text { and } \\
\text { practitioners }\end{array}$ & $\begin{array}{c}\text { Elementary } \\
\text { school }\end{array}$ & $\begin{array}{c}\text { Junior high } \\
\text { school }\end{array}$ & $\begin{array}{c}\text { Senior high } \\
\text { school }\end{array}$ \\
\hline IFLS1 & All facilities interviewed in IFLS1 & 993 & 1,439 & 944 & 900 & 584 \\
\hline \multirow[t]{4}{*}{ IFLS2 } & All facilities interviewed in IFLS2 & 921 & 1,831 & 963 & 945 & 618 \\
\hline & Interviewed in IFLS1 & 662 & 582 & 612 & 498 & 258 \\
\hline & $\%$ IFLS1 facilities reinterviewed & $67 \%$ & $40 \%$ & $65 \%$ & $55 \%$ & $44 \%$ \\
\hline & New facilities in IFLS2 & 259 & 1,249 & 351 & 447 & 360 \\
\hline \multirow[t]{6}{*}{ IFLS3 } & All facilities interviewed in IFLS3 & 943 & 1,955 & 960 & 951 & 618 \\
\hline & Interviewed in IFLS1 & 627 & 174 & 504 & 453 & 193 \\
\hline & Interviewed in IFLS2 & 634 & 398 & 555 & 537 & 217 \\
\hline & Ever interviewed in IFLS1 or IFLS2 & 732 & 481 & 641 & 647 & 284 \\
\hline & \% ever in IFLS (1-2) reinterviewed & $78 \%$ & $25 \%$ & $67 \%$ & $68 \%$ & $46 \%$ \\
\hline & New facilities in IFLS3 & 211 & 1,474 & 319 & 304 & 334 \\
\hline \multirow{7}{*}{ IFLS4 } & All facilities interviewed in IFLS4 & 952 & 1,625 & 966 & 961 & 634 \\
\hline & Interviewed in IFLS1 & 519 & 86 & 378 & 368 & 160 \\
\hline & Interviewed in IFLS2 & 513 & 203 & 402 & 435 & 169 \\
\hline & Interviewed in IFLS3 & 554 & 470 & 402 & 476 & 177 \\
\hline & Ever interviewed in IFLS1, IFLS2, or IFLS3 & 661 & 558 & 518 & 604 & 274 \\
\hline & $\%$ ever in IFLS (1-3) reinterviewed & $69 \%$ & $34 \%$ & $54 \%$ & $63 \%$ & $43 \%$ \\
\hline & New facilities in IFLS4 & 291 & 1,067 & 448 & 357 & 360 \\
\hline \multirow[t]{8}{*}{ IFLS5 } & All facilities interviewed in IFLS5 & 961 & 1,618 & 963 & 964 & 641 \\
\hline & Interviewed in IFLS1 & 519 & 63 & 237 & 208 & 58 \\
\hline & Interviewed in IFLS2 & 487 & 120 & 265 & 262 & 86 \\
\hline & Interviewed in IFLS3 & 519 & 250 & 271 & 329 & 94 \\
\hline & Interviewed in IFLS4 & 509 & 339 & 340 & 397 & 156 \\
\hline & $\begin{array}{l}\text { Ever interviewed in IFLS1, IFLS2, IFLS3, or } \\
\text { IFLS4 }\end{array}$ & 685 & 464 & 389 & 455 & 202 \\
\hline & \% ever in IFLS (1-4) reinterviewed & $71 \%$ & $29 \%$ & $40 \%$ & $47 \%$ & $32 \%$ \\
\hline & New facilities in IFLS5 & 276 & 1,154 & 574 & 509 & 439 \\
\hline \multicolumn{2}{|c|}{ Facilities interviewed in all rounds of IFLS (1-5) } & 314 & 12 & 180 & 148 & 31 \\
\hline
\end{tabular}


Tabel 3-4 Community Questionnaire

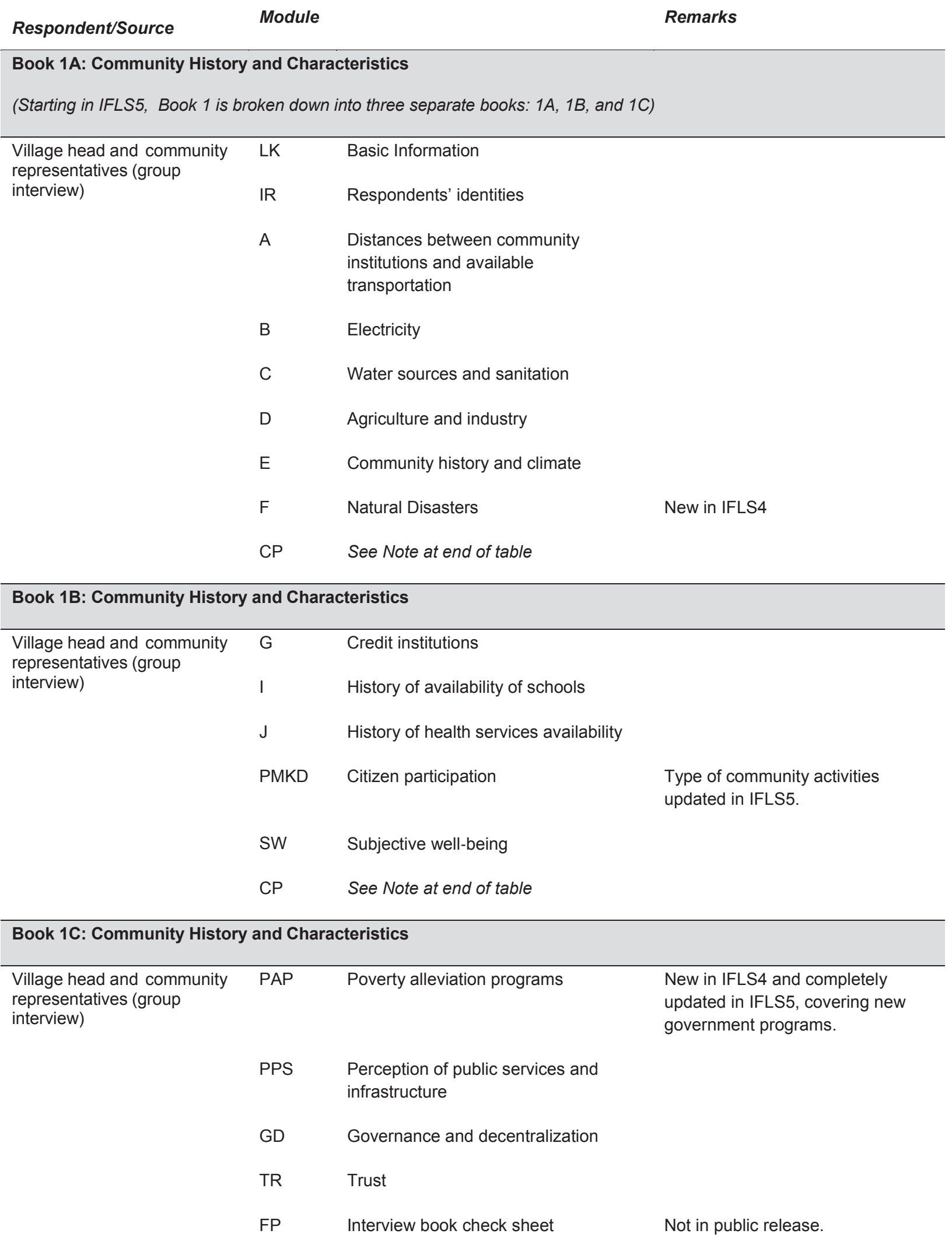


CP See Note at end of table

\begin{tabular}{|c|c|c|c|}
\hline \multicolumn{4}{|c|}{ Book LSPM: People Characteristics } \\
\hline Community representatives & LSPM & $\begin{array}{l}\text { Community participation sampling } \\
\text { sheet }\end{array}$ & Not in public release \\
\hline \multicolumn{4}{|l|}{ Book 2: Community Statistics } \\
\hline \multirow[t]{10}{*}{ Community statistical records } & LK & Basic information & \\
\hline & KA & Nature and the use of land & \\
\hline & PL & Pollution & \\
\hline & ST & Land certification & \\
\hline & PR & Housing and population & \\
\hline & LU & Employment & \\
\hline & $\mathrm{KD}$ & Village budget & $\begin{array}{l}\text { Budget categories updated in } \\
\text { IFLS5. }\end{array}$ \\
\hline & SD & Data Source & \\
\hline & OL & Interviewer's direct observation & \\
\hline & $\mathrm{CP}$ & See Note at end of table & \\
\hline
\end{tabular}

\begin{tabular}{l|l|l}
\hline \multicolumn{3}{|l}{ Book PKK: Village Women's Organization } \\
\hline Head of women's group & LK & Basic information \\
& KR & Respondent's characteristics \\
& I & Availability of schools \\
& J & $\begin{array}{l}\text { History of health services } \\
\text { availability }\end{array}$
\end{tabular}

PM Community development and participation

Type of community activities updated in IFLS5.

PAP Poverty alleviation programs

New in IFLS4 and completely updated in IFLS5, covering new government programs.

KSR Welfare Assistance

CP See Note at end of table 
Filled by interviewer based on information from IFLS4 SAR, IFLS5 household modules AR, PP, and IFLS5

community-facility book 1 and book PKK
List of health and school facilities by type, serving local community
Same as IFLS4.

\begin{tabular}{lll}
\hline \multicolumn{2}{l}{ Book Informant: Public Perception on Government Programs and Public } \\
$\begin{array}{lll}\text { Sampled community/NGO } \\
\text { activist }\end{array}$ & LK & Basic information \\
& PAP & Pespondent's identity \\
$\begin{array}{l}\text { This book was first } \\
\text { introduced in IFLS4 }\end{array}$ & & \\
& PPS & Perception on public infrastructure \\
& & and services \\
& GD & Governance and decentralization \\
& TR & Trust
\end{tabular}

\section{Book Puskesmas A: Community Health Center}

Starting in IFLS5, Book Puskesmas is broken down into three separate books: Puskesmas $A, B$, and C

Community Health Center LK $\quad$ Basic information
director or designee

director or designee

New in IFLS4 and completely updated in IFLS5, covering new government programs.

KR Respondent characteristics

A Information from head of facility

SDP Other resources available

(funding)

AKM Health insurance for the poor New in IFLS4 and updated in IFLS5.

DM Decision making

CP See Note at end of table

\begin{tabular}{lll}
\hline Book Puskesmas B: Government Health Center \\
\hline $\begin{array}{l}\text { Community Health Center } \\
\text { director or designee }\end{array}$ & D & Staff roster \\
& H & Health case vignettes \\
& CP & See Note at end of table
\end{tabular}




\begin{tabular}{|c|c|c|}
\hline \multicolumn{3}{|c|}{ Book Puskesmas C: Government Health Center } \\
\hline \multirow{6}{*}{$\begin{array}{l}\text { Community Health Center } \\
\text { director or designee }\end{array}$} & B & Development of facility \\
\hline & $\mathrm{C}$ & Services available \\
\hline & $\mathrm{E}$ & Equipment and supplies available \\
\hline & $\mathrm{F}$ & $\begin{array}{l}\text { Direct observation (e.g., } \\
\text { cleanliness) }\end{array}$ \\
\hline & G & Family planning services \\
\hline & $\mathrm{CP}$ & See Note at end of table \\
\hline \multicolumn{3}{|c|}{ Book Private Practice: Doctors, Health clinics and other private health service providers } \\
\hline \multirow{10}{*}{$\begin{array}{l}\text { Private doctors, head of } \\
\text { clinics, nurse, midwives. }\end{array}$} & LK & Basic information \\
\hline & PB & Joint practices \\
\hline & A & $\begin{array}{l}\text { General information about } \\
\text { respondent and the provider }\end{array}$ \\
\hline & $\mathrm{B}$ & $\begin{array}{l}\text { Practice schedule and service } \\
\text { available }\end{array}$ \\
\hline & $\mathrm{PH}$ & Pharmacy \\
\hline & $\mathrm{C}$ & Equipment available \\
\hline & $\mathrm{BD}$ & Village midwives \\
\hline & $E$ & $\begin{array}{l}\text { Direct observation(cleanliness, } \\
\text { availability of rooms, etc) }\end{array}$ \\
\hline & $\mathrm{H}$ & Health case vignettes \\
\hline & $\mathrm{CP}$ & See Note at end of table \\
\hline \multicolumn{3}{|c|}{ Book Traditional Practitioner } \\
\hline \multirow{5}{*}{$\begin{array}{l}\text { Volunteer staff member of } \\
\text { community health service } \\
\text { post }\end{array}$} & LK & Control sheet \\
\hline & $A$ & General \\
\hline & $\mathrm{B}$ & Practice activities \\
\hline & $\mathrm{C}$ & Traditional midwife \\
\hline & $\mathrm{CP}$ & See Note at end of table \\
\hline Book Prices: Market & & \\
\hline
\end{tabular}




\begin{tabular}{|c|c|c|}
\hline Sampled community & LK & Control sheet \\
\hline & $\mathrm{H}$ & Prices \\
\hline & $\mathrm{CP}$ & See Note at end of table \\
\hline Book Prices: Shops/Stall & & \\
\hline Sample of shops/stalls & LK & Control sheet \\
\hline & $\mathrm{H}$ & Prices \\
\hline & $\mathrm{CP}$ & See Note at end of table \\
\hline Book Prices: Informant & & \\
\hline Volunteer staff member & LK & Control sheet \\
\hline service post. & $\mathrm{H}$ & Prices \\
\hline & $\mathrm{CP}$ & See Note at end of table \\
\hline Book Posyandu: Commur & ty Chil & lealth Post \\
\hline Volunteer staff member of & LK & Basic information \\
\hline post. & $\mathrm{KR}$ & Respondent's characteristics \\
\hline & A & $\begin{array}{l}\text { Facility utilization and community } \\
\text { health }\end{array}$ \\
\hline & B & Services available \\
\hline & C & Staff available \\
\hline & $\mathrm{D}$ & $\begin{array}{l}\text { Health instruments (equipment, } \\
\text { supplies, medications) }\end{array}$ \\
\hline & SDP & Other sources available (funding) \\
\hline & PRP & Revitalization program \\
\hline & $\mathrm{CP}$ & See Note at end of table \\
\hline Book Posyandu Lansia: & ommu & y Elderly Health Post \\
\hline $\begin{array}{l}\text { Volunteer staff member } \\
\text { of community health }\end{array}$ & LK & Basic information \\
\hline service post & $\mathrm{KR}$ & Respondent's characteristics \\
\hline $\begin{array}{l}\text { This book was first } \\
\text { introduced in IFLS4. }\end{array}$ & $A$ & General \\
\hline & B & Services available \\
\hline
\end{tabular}




$\begin{array}{ll}\text { C } & \text { Staff available } \\ \text { D } & \begin{array}{l}\text { Health instruments (equipment, } \\ \text { supplies, medications) }\end{array} \\ \text { SDP } \quad \text { Posyandu resources available } \\ \text { CP } \quad \text { See Note at end of table }\end{array}$

\begin{tabular}{lll}
\hline Book School A: Elementary, Junior High and Senior High Schools (Principal book) \\
\begin{tabular}{lll} 
Starting in IFLS5, Book School is broken down into four separate books: School A, B, C, and D \\
KR & Basic information \\
\hline Krincipal or designee & Respondent characteristics \\
A & Principal \\
SC & $\begin{array}{l}\text { School characteristics } \\
\text { E }\end{array}$ & $\begin{array}{l}\text { Average expenditures per student } \\
\text { during academic years of } \\
2013 / 2014\end{array}$ \\
H & $\begin{array}{l}\text { Observation sheet during the } \\
\text { interview ilFLS4 }\end{array}$ \\
CP & See Note at end of table
\end{tabular}
\end{tabular}

\begin{tabular}{lll}
\hline Book School B: Elementary, Junior High and Senior High Schools (Teacher book) \\
\hline Home-room teacher & C & Teacher characteristics \\
& CP & $\begin{array}{l}\text { Observation sheet during the } \\
\text { interview }\end{array}$ \\
CP & See Note at end of table
\end{tabular}

\begin{tabular}{|c|c|c|}
\hline Book School C: E & $y, \mathrm{Ju}$ & figh and Senior High Schools (Scl \\
\hline $\begin{array}{l}\text { School registrar/ } \\
\text { administration }\end{array}$ & $\mathrm{F}$ & $\begin{array}{l}\text { Statistics and UAS/UAN (national } \\
\text { exam) scores }\end{array}$ \\
\hline & $\mathrm{CP}$ & See Note at end of table \\
\hline Book School D: E & $\mathrm{y}, \mathrm{Ju}$ & High and Senior High Schools (Obs \\
\hline Direct observation & $\mathrm{D}$ & Direct observation on classrooms \\
\hline & G & Number of Teachers and Students \\
\hline & $\mathrm{H}$ & $\begin{array}{l}\text { Observation sheet during the } \\
\text { interview }\end{array}$ \\
\hline
\end{tabular}


CP See Note at end of table

\section{Book Mini-CFS: Community characteristics for non-IFLS communities}

Village head and staff Questions from books 1A, 1B, and 1C,

modules LK, IR, S, A, B, C, D, I, J, F, E, SW,

PAP, TR

CP See Note at end of table

Note: All community-facility books include a book cover. The CP module at the end of nearly every book asked the interviewer to record the conditions of the interview (who else was present, whether others provided assistance in answering questions), the respondent's level of attention, and any other relevant information about the interview environment. The interviewer could also add information to explain or clarify the respondent's answers. 
Table A.1

Timeline of IFLS5 Activities, 2012-2016

\begin{tabular}{|c|c|c|}
\hline Year & Date & Activities \\
\hline 2012 & Oct - April 2013 & $\begin{array}{l}\text { - Redesigning and development of Household Survey } \\
\text { and Community and Facility Survey questionnaires } \\
\text { - CAPI programming started }\end{array}$ \\
\hline \multirow[t]{6}{*}{2013} & Oct 2012 - April & $\begin{array}{l}\text { Continuing redesign and development of Household Survey } \\
\text { and Community and Facility Survey questionnaires }\end{array}$ \\
\hline & May - August 31 & Piloting new modules of the Household Survey \\
\hline & September 1- 14 & $\begin{array}{ll}\text { - } & \text { Finalizing Household Survey CAPI program } \\
\text { - } & \text { CAPI preparation (hardware) }\end{array}$ \\
\hline & Oct 21 - 2nd November & Pretesting the Household Survey \\
\hline & Nov $4-16$ & Revising Household Survey CAPI program \\
\hline & Mid Nov - Dec & Finalizing Community and Facility Survey CAPI program \\
\hline \multirow[t]{10}{*}{2014} & January $6-17$ & Pretesting the Community and Facility Survey \\
\hline & Mid Jan - mid May & $\begin{array}{l}\text { - Revising Community and Facility Survey CAPI program } \\
\text { - Preparation of Manuals } \\
\text { - } \text { Recruitment } \\
\text { - Obtaining permission }\end{array}$ \\
\hline & Feb $12-16$ & Pretesting the tracking protocols of movers \\
\hline & Feb 24- 28 & Testing all questions \\
\hline & March 24 - April 17 & Pretesting the training of the enumerators \\
\hline & May 19 -May 31 & Training of Trainers - Household Survey \\
\hline & June 28 - July 27 & Ramadhan \\
\hline & July28 - August 5 & ledul Fitri break \\
\hline & August $6-2$ Sept & Training of Enumerators Wave 1 - Household Survey \\
\hline & Sept 5 - April 2015 & Fieldwork Wave 1 Household Survey - Main Survey \\
\hline
\end{tabular}




\begin{tabular}{|l|l|l|}
\hline & Sept 5 -Oct 1 & Training of Enumerators Wave 2 - Household Survey \\
\hline $\mathbf{2 0 1 5}$ & Oct 3 - April 2015 & Fieldwork Wave 2 Household Survey - Main Survey \\
\hline & Feb 18- 10 March & Training of Trainers - Community and Facility Survey \\
\hline & March 13- July 30 & Training of Enumerators - Community and Facility Survey \\
\hline & First week of May - end of September & Fong distance tracking of Movers \\
\hline & March & Pre- testing the laboratory analyses of CRP \\
\hline & June - October & Data cleaning - Household Field Data \\
\hline $\mathbf{2 0 1 6}$ & July- October & Data cleaning - Community Facility Field Data \\
\hline & October - March 2016 & Preparation of public use \\
\hline & End of March 2016 2015 - March 2016 & Continuing the preparation of public use data \\
\hline
\end{tabular}




\section{Field Staff for IFLS5 Surveys}

This table lists the names of all staff who participated in field operations for the IFLS5. There was no health worker since enumerators also performed health measurement

Household Survey Teams

\begin{tabular}{|c|c|c|c|c|c|}
\hline Team & North Sumatera A & & Team & North Sumatera B & \\
\hline Team Coordinator & Naryanta & M & Team Coordinator & Naryanta. & $M$ \\
\hline HH Supervisor & Muhammad Fahrezal Silli & M & HH Supervisor & Arif Pranoto & M \\
\hline CAPI Supervisor & Arif Setiawan & M & CAPI Supervisor & Pebriani Tarigan & $\mathrm{F}$ \\
\hline Interviewer & Ferri Irawan & M & Interviewer & Purnomo Sigit & M \\
\hline Interviewer & Suprafti & $\mathrm{F}$ & Interviewer & Linda Megawati Habeahan & $\mathrm{F}$ \\
\hline Interviewer & Budi Hardiansyah Siregar & $M$ & Interviewer & Darwin Yosep Saragih & $M$ \\
\hline Interviewer & Ermin Junita Zebua & $\mathrm{F}$ & Interviewer & Retno Asih & $\mathrm{F}$ \\
\hline Interviewer & Arif Ari Cahyono & M & Interviewer & Nur Rohman & $M$ \\
\hline \multirow[t]{3}{*}{ Interviewer } & \multirow[t]{3}{*}{ Amanda Wahyu Nuraningrum } & \multirow[t]{3}{*}{$\mathrm{F}$} & Interviewer & Elismayanti Rambe & $\mathrm{F}$ \\
\hline & & & Interviewer & Ardiansyah Fajar Riyadi & M \\
\hline & & & Interviewer & Rizky Wiraswasti Novitasari & $\mathrm{F}$ \\
\hline Team & \multicolumn{2}{|l|}{ West Sumatera } & Team & \multicolumn{2}{|l|}{ South Sumatera } \\
\hline Team Coordinator & Naryanta & M & Team Coordinator & Naryanta & $M$ \\
\hline HH Supervisor & Fajar Kurniawan & M & HH Supervisor & Parzunaidi & $M$ \\
\hline CAPI Supervisor & Ginanjar Dwi Pratiwi & $\mathrm{F}$ & CAPI Supervisor & Muharis & $M$ \\
\hline Interviewer & Sukardi & M & Interviewer & Muhammad Agung Widodo & M \\
\hline Interviewer & Riska Yolanda & $\mathrm{F}$ & Interviewer & Novia Dwinugraheni & $\mathrm{F}$ \\
\hline Interviewer & Asral Fuadi & M & Interviewer & Pramudya Nugraha & M \\
\hline Interviewer & Anastasya Hannie Wuryanie & $\mathrm{F}$ & Interviewer & Winda Nora Afrianty & $\mathrm{F}$ \\
\hline Interviewer & Flani Rancono & M & Interviewer & M. Alfath Qaaf & M \\
\hline Interviewer & Lilis Handayani & $\mathrm{F}$ & Interviewer & Hernung Saktyorini & $\mathrm{F}$ \\
\hline Interviewer & Afiyan Widyastomo & M & Interviewer & Bahruddin & M \\
\hline Interviewer & Nur Aida & $\mathrm{F}$ & Interviewer & Laura Novianti & $\mathrm{F}$ \\
\hline Team & Lampung & & Team & DKI Jakarta A & \\
\hline Team Coordinator & Naryanta & $M$ & Team Coordinator & Tri Rahayu & $\mathrm{F}$ \\
\hline HH Supervisor & Ade Apri Hendrawanto & M & HH Supervisor & Andi Ahmad Alamsyah & M \\
\hline CAPI Supervisor & Andri Dwiyanto & M & CAPI Supervisor & Yanti Rohaniyawati & $\mathrm{F}$ \\
\hline Interviewer & Mujiono & M & Interviewer & Resita Aprilia Sandhi & $\mathrm{F}$ \\
\hline Interviewer & Harista Wenijayanti & $\mathrm{F}$ & Interviewer & Yunikasari Harbowo & $\mathrm{F}$ \\
\hline Interviewer & Danu Wijaya & M & Interviewer & Ilham Maulana Insan & $M$ \\
\hline Interviewer & Herlina Levilia & $\mathrm{F}$ & Interviewer & Yunita & $\mathrm{F}$ \\
\hline Interviewer & Dody Prayoga & M & Interviewer & Jasmaryadi & $M$ \\
\hline \multirow[t]{3}{*}{ Interviewer } & \multirow[t]{3}{*}{ Bertha Wilis J } & \multirow[t]{3}{*}{$\mathrm{F}$} & Interviewer & Santa Maria Gultom & $\mathrm{F}$ \\
\hline & & & Interviewer & Ali Musta'in & M \\
\hline & & & Interviewer & Fenzy Putri Liewenti & $\mathrm{F}$ \\
\hline
\end{tabular}




\begin{tabular}{llc}
\multicolumn{1}{c}{ Team } & DKI Jakarta B \\
Team Coordinator & Tri Rahayu & $\mathrm{F}$ \\
HH Supervisor & Faqih Anatomi & $\mathrm{M}$ \\
CAPI Supervisor & Bastomi Busro & $\mathrm{M}$ \\
Interviewer & Mukhrizal Arif & $\mathrm{M}$ \\
Interviewer & Rissa Nurashri Habibu & $\mathrm{F}$ \\
Interviewer & Subagiyo & $\mathrm{M}$ \\
Interviewer & Alista Br. Simanjuntak & $\mathrm{F}$ \\
Interviewer & Asril Jamil & $\mathrm{M}$ \\
Interviewer & Ayu Novelisa & $\mathrm{F}$ \\
Interviewer & Salman Fariz & $\mathrm{M}$ \\
Interviewer & Junaidah & $\mathrm{F}$
\end{tabular}

$\begin{array}{ll}\text { Team } & \text { West Java B } \\ \text { Team Coordinator } & \text { Tri Rahayu } \\ \text { HH Supervisor } & \text { Wildan Sukarno } \\ \text { CAPI Supervisor } & \text { Rahmat Tri Susanto } \\ \text { Interviewer } & \text { Dani Ramdani } \\ \text { Interviewer } & \text { Rini Febriani } \\ \text { Interviewer } & \text { Hari Hadiyatullah } \\ \text { Interviewer } & \text { Eriska Fitriani } \\ \text { Interviewer } & \text { Agam Amrullah } \\ \text { Interviewer } & \text { Sarwinda } \\ \text { Interviewer } & \text { Rizka Mubarokati }\end{array}$

(2)

\begin{tabular}{|c|c|c|c|c|c|}
\hline Team & West Java D & & Team & Central Java A & \\
\hline Team Coordinator & Jejen Fauzan & $M$ & Team Coordinator & Jejen Fauzan & $M$ \\
\hline HHs Supervisor & Sugiyanto & $M$ & HHs Supervisor & Yudono Setiawan & M \\
\hline Data Supervisor & Erlis Herliawati & $\mathrm{F}$ & Data Supervisor & Kusmaintan Widya Lestari & $\mathrm{F}$ \\
\hline Interviewer & Dita Meliani & $\mathrm{F}$ & Interviewer & Irkham Ma'ruf Muflikhin & M \\
\hline Interviewer & Rina Febriana & $\mathrm{F}$ & Interviewer & Dinar Ratna Timurfi & $\mathrm{F}$ \\
\hline Interviewer & Ujang Memet Supratman & $M$ & Interviewer & Dewi Ratnaningrum & $\mathrm{F}$ \\
\hline Interviewer & Ayu Sujiarti & $\mathrm{F}$ & Interviewer & Ega Wisnu Selia & $\mathrm{F}$ \\
\hline Interviewer & Juwandi & $M$ & Interviewer & Dewi Andarwati & $\mathrm{F}$ \\
\hline Interviewer & Zaima Amalia & $\mathrm{F}$ & Interviewer & Nuruz Zahro Al-Jannah & $\mathrm{F}$ \\
\hline Team & Central Java B & & Team & Central Java C & \\
\hline Team Coordinator & Jejen Fauzan & $\mathrm{M}$ & Team Coordinator & Jejen Fauzan & $M$ \\
\hline HH Supervisor & Slamet Subadrodin & $M$ & HH Supervisor & Galih Mahendra & M \\
\hline CAPI Supervisor & Faroh Dina & $\mathrm{F}$ & CAPI Supervisor & Dwi Syamsiati & $\mathrm{F}$ \\
\hline Interviewer & Haris Wahyu Hidayat & $\mathrm{M}$ & Interviewer & Henis Ika Prasongko & M \\
\hline Interviewer & Adetya Shela Ningrum & $\mathrm{F}$ & Interviewer & Dewi Masitoh Nur & $\mathrm{F}$ \\
\hline Interviewer & Ardin Wido Nartyas & $M$ & Interviewer & Hasan Rifai & M \\
\hline Interviewer & Nur Isnaini Ulfah Fauzi & $\mathrm{F}$ & Interviewer & Setyaningrum & $\mathrm{F}$ \\
\hline Interviewer & Yuyun Naifular & $\mathrm{F}$ & Interviewer & Nailatus Syafaah & $\mathrm{F}$ \\
\hline
\end{tabular}

$\begin{array}{llc}\text { Team } & \text { West Java A } & \\ \text { Team Coordinator } & \text { Tri Rahayu } & \mathrm{F} \\ \text { HH Supervisor } & \text { Ulil Absor } & \mathrm{M} \\ \text { CAPI Supervisor } & \text { Melya Anggraeni } & \mathrm{F} \\ \text { Interviewer } & \text { Yanuar Suwardani } & \mathrm{M} \\ \text { Interviewer } & \text { Gilang Permata Sari } & \mathrm{F} \\ \text { Interviewer } & \text { Indra Yudhika Zulmi } & \mathrm{M} \\ \text { Interviewer } & \text { Nita Pratiwi } & \mathrm{F} \\ \text { Interviewer } & \text { Andri Trihadi } & \mathrm{M} \\ \text { Interviewer } & \text { Nina Suryani } & \mathrm{F} \\ \text { Interviewer } & \text { Kholid Asyrofie } & \mathrm{M} \\ \text { Interviewer } & \text { Septiyarini } & \mathrm{F} \\ \text { Interviewer } & \text { Onyan Nur Aeyla } & \mathrm{F}\end{array}$

\section{Team}

West Java C

Team Coordinator Tri Rahayu

F

$\mathrm{HH}$ Supervisor

Ahmad Tofik

M

CAPI Supervisor

Larasati Ayu Ansuda

F

Interviewer

Epnu Suyono

M

Interviewer

Siti Patimah

$\mathrm{F}$

M Interviewer

Abdul Hamid

M

Interviewer

Rien Suci Putriastini

Iryadi

$\mathrm{F}$

Interviewer

Nur Ramadhani

M

F 


\begin{tabular}{|c|c|c|c|c|c|}
\hline Interviewer & Amirul Wardati & $\mathrm{F}$ & Interviewer & Sri Amanah & $\mathrm{F}$ \\
\hline Interviewer & Nofi Selfiyani & $\mathrm{F}$ & & & \\
\hline Interviewer & Aini Mubarokah & $\mathrm{F}$ & & & \\
\hline Team & Yogyakarta A & & Team & Yogyakarta B & \\
\hline Team Coordinator & Jejen Fauzan & M & Team Coordinator & Jejen Fauzan & $\mathrm{M}$ \\
\hline HH Supervisor & Muhammad Mukhlis & M & HH Supervisor & Agus Lesmana & $\mathrm{M}$ \\
\hline CAPI Supervisor & Endah Sriwiyani & $\mathrm{F}$ & CAPI Supervisor & Fitri Yuniati & $\mathrm{F}$ \\
\hline Interviewer & Wahib Ainurofiq & M & Interviewer & Sigid Suryanto & $\mathrm{M}$ \\
\hline Interviewer & Irma Wulandari & $\mathrm{F}$ & Interviewer & Meritaningrum Anggraeni & $\mathrm{F}$ \\
\hline Interviewer & Nofi Budi Widaryati & $\mathrm{F}$ & Interviewer & Muhammad Ridwan Firdaus & M \\
\hline Interviewer & Nurhardiyan Zainia Suharjo & $\mathrm{F}$ & Interviewer & Okti Anggarwati & $\mathrm{F}$ \\
\hline Interviewer & Winda Dwi Permatasari & $\mathrm{F}$ & Interviewer & Khulwatul Aeni & $\mathrm{F}$ \\
\hline Interviewer & Ilyafiq Maulithafuri Desita Sari & $\mathrm{F}$ & Interviewer & Siti Rodiyah & $\mathrm{F}$ \\
\hline Interviewer & Furqon Tri Mashuri & M & & & \\
\hline Team & East Java A & & Team & East Java B & \\
\hline Team Coordinator & Arief Gunawan & M & Team Coordinator & Arief Gunawan & $\mathrm{M}$ \\
\hline HH Supervisor & Agus Sh & M & HH Supervisor & M. Iksannudin & $\mathrm{M}$ \\
\hline CAPI Supervisor & Lilik Ummu Habibah & $\mathrm{F}$ & CAPI Supervisor & Lintang Widyaretna & $\mathrm{F}$ \\
\hline Interviewer & Hadi Suprayogi & M & Interviewer & Halim Nur Yahya & $\mathrm{M}$ \\
\hline Interviewer & Dewi Arfianty 'Azmi & $\mathrm{F}$ & Interviewer & Erry Nur Rahmawati, & $\mathrm{F}$ \\
\hline Interviewer & Krisma Jonartta & M & Interviewer & Muh. Syaifuddin & $\mathrm{M}$ \\
\hline Interviewer & Nur Laila & $\mathrm{F}$ & Interviewer & Fatin Zuraidah & $\mathrm{F}$ \\
\hline Interviewer & Davit Anwar Kamsay & M & Interviewer & Ali Musthofa & $\mathrm{M}$ \\
\hline Interviewer & Lina Mafula & $\mathrm{F}$ & Interviewer & Aqidatul Izza Mahmudah & $\mathrm{F}$ \\
\hline Team & East Java C & & Team & Bali & \\
\hline Team Coordinator & Arief Gunawan & M & Team Coordinator & Arief Gunawan & $\mathrm{M}$ \\
\hline HH Supervisor & Agus Setyawan & $M$ & HH Supervisor & Muhamad Nursamsu & $\mathrm{M}$ \\
\hline CAPI Supervisor & Elmi Kamilah & $\mathrm{F}$ & CAPI Supervisor & Nur Indah Setyawati & $\mathrm{F}$ \\
\hline Interviewer & Fauzi & M & Interviewer & Saharudin & $\mathrm{M}$ \\
\hline Interviewer & Tiara Kusuma Pariosi & $\mathrm{F}$ & Interviewer & Harning Nadia Wursattana & $\mathrm{F}$ \\
\hline Interviewer & Ach. Zaini & M & Interviewer & M. Lin Abdul Aziz & $\mathrm{M}$ \\
\hline Interviewer & Aulia Syelawati & $\mathrm{F}$ & Interviewer & Ni Luh Made Rusmayanti & $\mathrm{F}$ \\
\hline Interviewer & Mohammad Arys Muhlisin & M & Interviewer & Muhammad Ikhsan Nulzaen & $\mathrm{M}$ \\
\hline Interviewer & Amalia Rahma & $\mathrm{F}$ & Interviewer & Berlina Indrawati & $\mathrm{F}$ \\
\hline Interviewer & Fitrisari Setyorini & $\mathrm{F}$ & Interviewer & De Gaut Argadia Pradana & $\mathrm{M}$ \\
\hline Interviewer & Kholis Qodiyah & $\mathrm{F}$ & Interviewer & Via Keke Okta Pratama & $\mathrm{F}$ \\
\hline Team & West Nusa Tenggara & & Team & South Kalimantan & \\
\hline Team Coordinator & Endra Dwi Mulyanto & M & Team Coordinator & Endra Dwi Mulyanto & $\mathrm{M}$ \\
\hline HH Supervisor & Badri Maulana & $M$ & HH Supervisor & Amirul Arifin & $\mathrm{M}$ \\
\hline CAPI Supervisor & Dini Romantika & $\mathrm{F}$ & CAPI Supervisor & Farid Ma'ruf & $\mathrm{M}$ \\
\hline Interviewer & Moh Imam Ahmad & $M$ & Interviewer & Ahmad Afandi & $M$ \\
\hline Interviewer & Ridha Wahyuni & $\mathrm{F}$ & Interviewer & Siti Nurfaridah & $\mathrm{F}$ \\
\hline Interviewer & Satria Wangsa Dipura & $M$ & Interviewer & Hilman Febri Nanda & $\mathrm{M}$ \\
\hline
\end{tabular}




$\begin{array}{ll}\text { Interviewer } & \text { Aditya Desy Soraya } \\ \text { Interviewer } & \text { Juaini Pratama } \\ \text { Interviewer } & \text { Mayangsari } \\ \text { Interviewer } & \text { Januar Kurniawan } \\ \text { Interviewer } & \text { Hapzah }\end{array}$

$\begin{array}{cc}\text { F } & \text { Interviewer } \\ \text { M } & \text { Interviewer } \\ \text { F } & \text { Interviewer } \\ \text { M } & \\ \text { F } & \end{array}$

Dewi Ermawati

$\begin{array}{llc}\text { Team } & \text { South Sulawesi } & \\ \text { Team Coordinator } & \text { Endra Dwi Mulyanto } & \mathrm{M} \\ \text { HH Supervisor } & \text { Asmadi } & \mathrm{M} \\ \text { CAPI Supervisor } & \text { Eva Puri } & \mathrm{F} \\ \text { Interviewer } & \text { Hamdani Hamu } & \mathrm{M} \\ \text { Interviewer } & \text { Maftukhatus Syarifah } & \mathrm{F} \\ \text { Interviewer } & \text { Syaiful Rajamuddin } & \mathrm{M} \\ \text { Interviewer } & \text { Sarwendah } & \mathrm{F} \\ \text { Interviewer } & \text { Saktiawan Natas Jasmadi } & \mathrm{M} \\ \text { Interviewer } & \text { Purnamasari } & \mathrm{F} \\ \text { Interviewer } & \text { Arham Ichwardani S } & \mathrm{M} \\ \text { Interviewer } & \text { Herlina Pratiwi } & \mathrm{F}\end{array}$


Community and Facility Survey Teams

\begin{tabular}{|c|c|c|c|c|c|}
\hline Team & North Sumatera A & & Team & North Sumatera B & \\
\hline CAPI Supervisor & Pramudya Nugraha & $M$ & CAPI Supervisor & Ardiansyah Fajar Riyadi & M \\
\hline Interviewer & Dyan Miftachul & $\mathrm{F}$ & Interviewer & Sri Rezeki Hasanah & $\mathrm{F}$ \\
\hline Interviewer & Ratna putri setywati & $\mathrm{F}$ & Interviewer & Trisnoto & M \\
\hline Interviewer & Deni Riyanto & M & Interviewer & Binti Mahfudhoh & $\mathrm{F}$ \\
\hline Team & West Sumatera & & Team & South Sumatera & \\
\hline CAPI Supervisor & Flani Rancono & M & CAPI Supervisor & Rizky Wiraswasti Novitasari & $\mathrm{F}$ \\
\hline Interviewer & Dyah Ayu Anggun Siswati & $\mathrm{F}$ & Interviewer & Irdianty Novia Safutri & $\mathrm{F}$ \\
\hline Interviewer & Eko Teguh Wiyono & M & Interviewer & Tri Asinta Maharani & $\mathrm{F}$ \\
\hline Interviewer & Nur Anggrah Fatqiyatun & $\mathrm{F}$ & Interviewer & Adib & M \\
\hline Team & Lampung & & Team & DKI A & \\
\hline CAPI Supervisor & Danu Wijaya & M & CAPI Supervisor & Yunikasari Harbowo & $\mathrm{F}$ \\
\hline Interviewer & Nur Hidayatusholihah & $\mathrm{F}$ & Interviewer & Fakih Deni Sugiri & M \\
\hline Interviewer & Dina Utaminingsih & M & Interviewer & Kiki Chairani Saputri & $\mathrm{F}$ \\
\hline Interviewer & Tommy Setiawan & $\mathrm{F}$ & Interviewer & Fivi Hariastanti & $\mathrm{F}$ \\
\hline Team & DKI B & & Team & West Java A & \\
\hline CAPI Supervisor & Salman Fariz & M & CAPI Supervisor & Gilang Permata Sari & $\mathrm{F}$ \\
\hline Interviewer & Eka Rahmawati Kartika & $\mathrm{F}$ & Interviewer & Rachman Ramadhana & M \\
\hline Interviewer & Rizky Umami & $\mathrm{F}$ & Interviewer & Dwi krisna $\mathrm{P}$ & $\mathrm{F}$ \\
\hline Interviewer & Rilya Bagus Ariesta & M & Interviewer & Warsih & $\mathrm{F}$ \\
\hline Team & West Java B & & Team & West Java C & \\
\hline CAPI Supervisor & Dani Ramdani & M & CAPI Supervisor & Amalia Rahma & $\mathrm{F}$ \\
\hline Interviewer & Umi sahadah & $\mathrm{F}$ & Interviewer & Ibnu Nardono & M \\
\hline Interviewer & Chitra Dyan Pratama & $\mathrm{F}$ & Interviewer & Esti Wulandari & $\mathrm{F}$ \\
\hline Interviewer & SARIF HIDAYAT & M & Interviewer & Devina Yudianti & $\mathrm{F}$ \\
\hline
\end{tabular}




\begin{tabular}{llc} 
Team & West Java D & \\
\hline CAPI Supervisor & Ngatman, SH & M \\
Interviewer & Zaima Amalia & F \\
Interviewer & yati sunarti & F \\
Interviewer & Carissa Riskiananda & F \\
& \\
Team & Central Java B & \\
CAPI Supervisor & Nofi Selfiyani & F \\
Interviewer & ikshan nur fikri & M \\
Interviewer & Mayang Ratna Sari & F \\
Interviewer & Farizza Noor Amalia & F
\end{tabular}

Team
CAPI Supervisor
Interviewer
Interviewer
Interviewer

Central Java A

Dewi Ratnaningrum $\mathrm{F}$

Diva rahmawati $F$

Wahyu Trianasari $F$

Citrandy Pamungkas M

$\begin{array}{lll}\text { Team } & \text { Central Java C } & \\ \text { CAPI Supervisor } & \text { Sri Amanah } & \text { F } \\ \text { Interviewer } & \text { Iga Dirgahayuning } & \text { F } \\ \text { Interviewer } & \text { Nur Anifatul Aliyah } & \text { F } \\ \text { Interviewer } & \text { Fidyah Nurul Virlana } & \text { F }\end{array}$

\begin{tabular}{|c|c|c|c|c|c|}
\hline Team & Central Java B & & Team & Central Java C & \\
\hline CAPI Supervisor & Nofi Selfiyani & $\mathrm{F}$ & CAPI Supervisor & Sri Amanah & $\mathrm{F}$ \\
\hline Interviewer & ikshan nur fikri & $M$ & Interviewer & Iga Dirgahayuning & $\mathrm{F}$ \\
\hline Interviewer & Mayang Ratna Sari & $\mathrm{F}$ & Interviewer & Nur Anifatul Aliyah & $\mathrm{F}$ \\
\hline Interviewer & Farizza Noor Amalia & $\mathrm{F}$ & Interviewer & Fidyah Nurul Virlana & $\mathrm{F}$ \\
\hline Team & DI Yogyakarta A & & Team & DI Yogyakarta A & \\
\hline CAPI Supervisor & Laura Novianti & $\mathrm{F}$ & CAPI Supervisor & Septiyarini & $\mathrm{F}$ \\
\hline Interviewer & Sukiyanto & M & Interviewer & Halley Mashuri & M \\
\hline Interviewer & Erlin puji lestari & $\mathrm{F}$ & Interviewer & Affi Rusdaningrum & $\mathrm{F}$ \\
\hline Interviewer & Dwi Pujiastuti & $\mathrm{F}$ & Interviewer & Idiyanah Komsawati & $\mathrm{F}$ \\
\hline Team & East Java A & & Team & East Java B & \\
\hline CAPI Supervisor & Krisma Jonartta & M & CAPI Supervisor & Erry Nur Rahmawati & $\mathrm{F}$ \\
\hline Interviewer & Anisa rahmawati & $\mathrm{F}$ & Interviewer & Dinda yulian ardiani & $\mathrm{F}$ \\
\hline Interviewer & Weny Naulita Siregar & $\mathrm{F}$ & Interviewer & Dedi Wuryantoro & M \\
\hline Interviewer & Ria Bangkit N,A. & $\mathrm{F}$ & Interviewer & Sukmawati Rosidah & $\mathrm{F}$ \\
\hline Team & East Java C & & Team & Bali & \\
\hline CAPI Supervisor & Fauzi & M & CAPI Supervisor & De Gaut Argadia Pradana & M \\
\hline Interviewer & Anastasyia Eka Arista & $\mathrm{F}$ & Interviewer & Sri Rahmawati & $\mathrm{F}$ \\
\hline Interviewer & Endah Yuliana Dewi & $\mathrm{F}$ & Interviewer & Andri Setianingsih & $\mathrm{F}$ \\
\hline Interviewer & Hosni & M & Interviewer & Devi Agustina & $\mathrm{F}$ \\
\hline Team & West Nusa Tenggara & & Team & South Kalimantan & \\
\hline CAPI Supervisor & Januar Kurniawan & M & CAPI Supervisor & Purwanti & $\mathrm{F}$ \\
\hline Interviewer & Baiq Fitria Rahmiati & $\mathrm{F}$ & Interviewer & Andy Yudha Pratama & M \\
\hline Interviewer & Ni Ketut Fipit Ferawaty & $\mathrm{F}$ & Interviewer & Anggraini Tri Astuti & $\mathrm{F}$ \\
\hline Interviewer & Imam Hadi Kusuma & M & Interviewer & Okta Prastika Zakiyah & $\mathrm{F}$ \\
\hline Team & South Sulawesi & & & & \\
\hline CAPI Supervisor & Jasmaryadi & M & & & \\
\hline Interviewer & Dewi Sartika & M & & & \\
\hline Interviewer & Puspita Sari & $\mathrm{F}$ & & & \\
\hline
\end{tabular}


Table A.3

\section{Team Description}

\begin{tabular}{l|l|c|c}
\hline \multicolumn{1}{c|}{ Province } & \multicolumn{1}{c|}{$\begin{array}{c}\text { Team } \\
\text { Code(s) }\end{array}$} & $\begin{array}{c}\text { No. of HHS } \\
\text { Interviewers }\end{array}$ & No. of EAs \\
\hline Jakarta & F, G & 16 & 40 \\
West Java & H, I, J, K & 26 & 52 \\
East Java & Q, R, S & 20 & 30 \\
South Kalimantan & V & 6 & 13 \\
South Sulawesi & W & 8 & 16 \\
South Sumatra & D & 8 & 15 \\
West Nusa Tenggara & U & 8 & 16 \\
Central Java & L, M, N & 20 & 37 \\
Yogyakarta & O, P & 12 & 22 \\
Bali & T & 8 & 14 \\
North Sumatra & A, B & 14 & 26 \\
West Sumatra & C & 8 & 14 \\
Lampung & E & 6 & 11 \\
\hline
\end{tabular}




\section{Table A.4}

Main Office/Tracking Information Center

\begin{tabular}{|c|c|}
\hline Person & Position \\
\hline John Strauss & Principal Investigator \\
\hline Firman Witoelar & Co-Principal Investigator \\
\hline Bondan Sikoki & Co-Principal Investigator, Field Director \\
\hline Edy Purwanto & Field Coordinator for the Household Survey \\
\hline Nasirudin & Field Coordinator for the Community-Facility Survey \\
\hline lip Umar Rifai & Programming Coordinator for the Computer-Assisted Personal Interviewer (CAPI) \\
\hline Nur Arna Sucianti & CAPI programmer and HH Data Manager \\
\hline Amalia Rifana Widiastuti & CAPI programmer and CF Data Manager \\
\hline Lazimah & Data and tracking associate \\
\hline Dian Hestina Dwiyanti, S.Si & Data and tracking associate \\
\hline Rosalia Ari Astuti & Data and tracking associate \\
\hline Rini Kondesiana & Data and fascode-ing \\
\hline Ika Rini & Dried Blood Sample assistant \\
\hline Anindita Az Zahra Lutfiatunnisa' & Dried Blood Sample assistant \\
\hline
\end{tabular}


Table A.5

\begin{tabular}{ll}
\hline & Household Post-Fieldwork Staff \\
\hline Lazimah & Faroh Dina \\
Dian Hesti Dwiyanti & Endah Sriwiyani \\
Rosalia Ari Astuti & Irma Wulandari \\
Kusmaintan Widya Lestari & Eva Puri \\
\hline
\end{tabular}

Table A.6

\begin{tabular}{ll}
\hline & COMFAS Post-Fieldwork Staff \\
\hline Santi Wulandari & Tri Rahayu \\
Bening Kisworini & Purwanti \\
Syarifah Vebrina Tri Susanti & Salman Fariz \\
Rini Kondesiana & Yunikasari Harbowo \\
Mariani & Rizky Wiraswati Novitasari \\
Hendy Pusphita P & Septiyarini \\
Ngatman & Sri Amanah \\
Ardiansyah Fajar Riyadi & Nugroho \\
Angky Bayu Putranto & \\
\hline
\end{tabular}

